
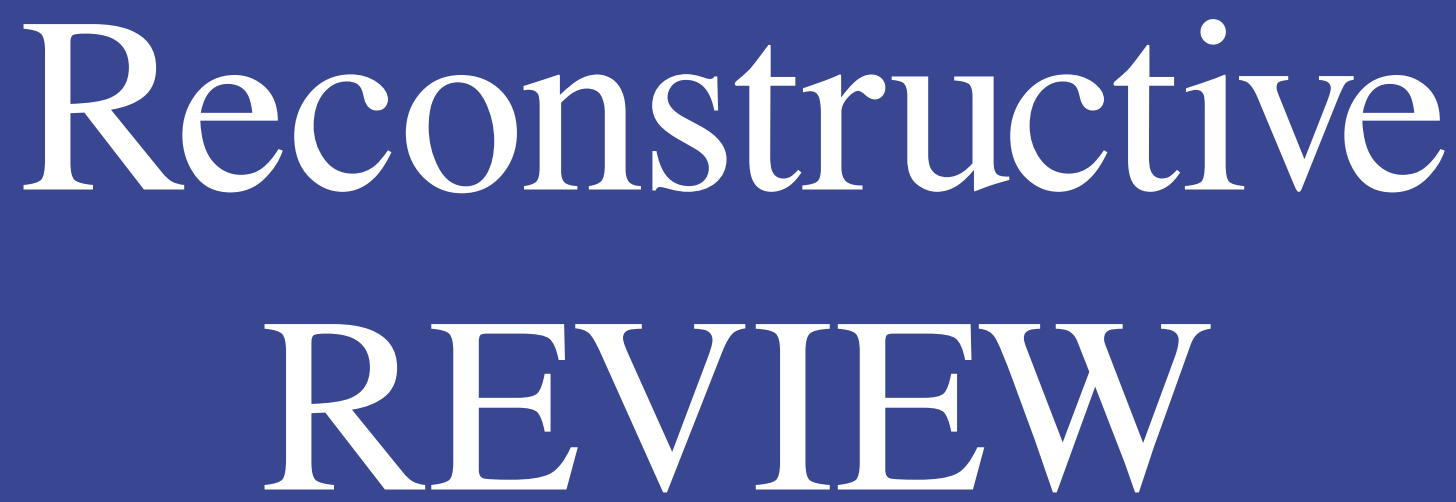

An Open Access Journal

OFFICIAL JOURNAL OF THE

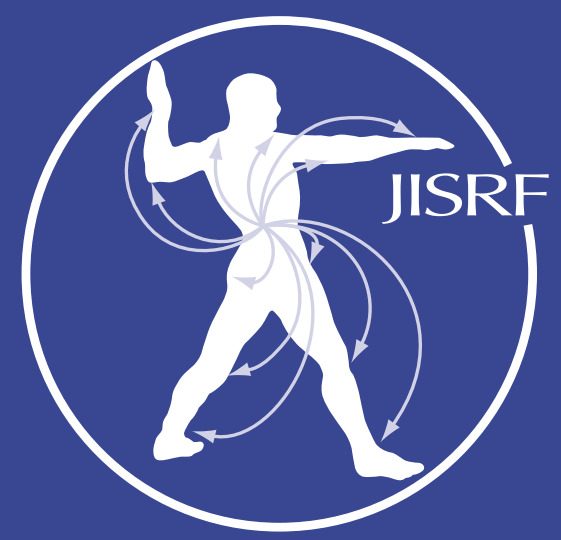

Joint Implant Surgery and Research Foundation

Strategic Alliance with

$I C \mathrm{R} \mid \begin{aligned} & \text { International Congress } \\ & \text { for Joint Reconstruction }\end{aligned}$ 


\section{Reconstructive REVIEW}

OFFICIAL JOURNAL OF THE

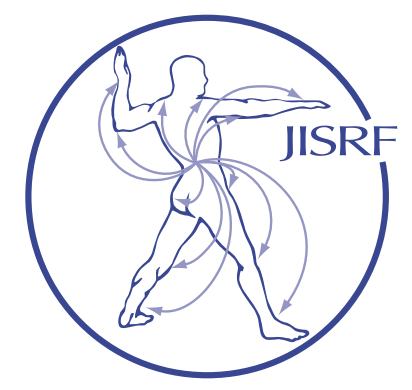

Joint Implant Surgery and Research Foundation

Strategic Alliance with

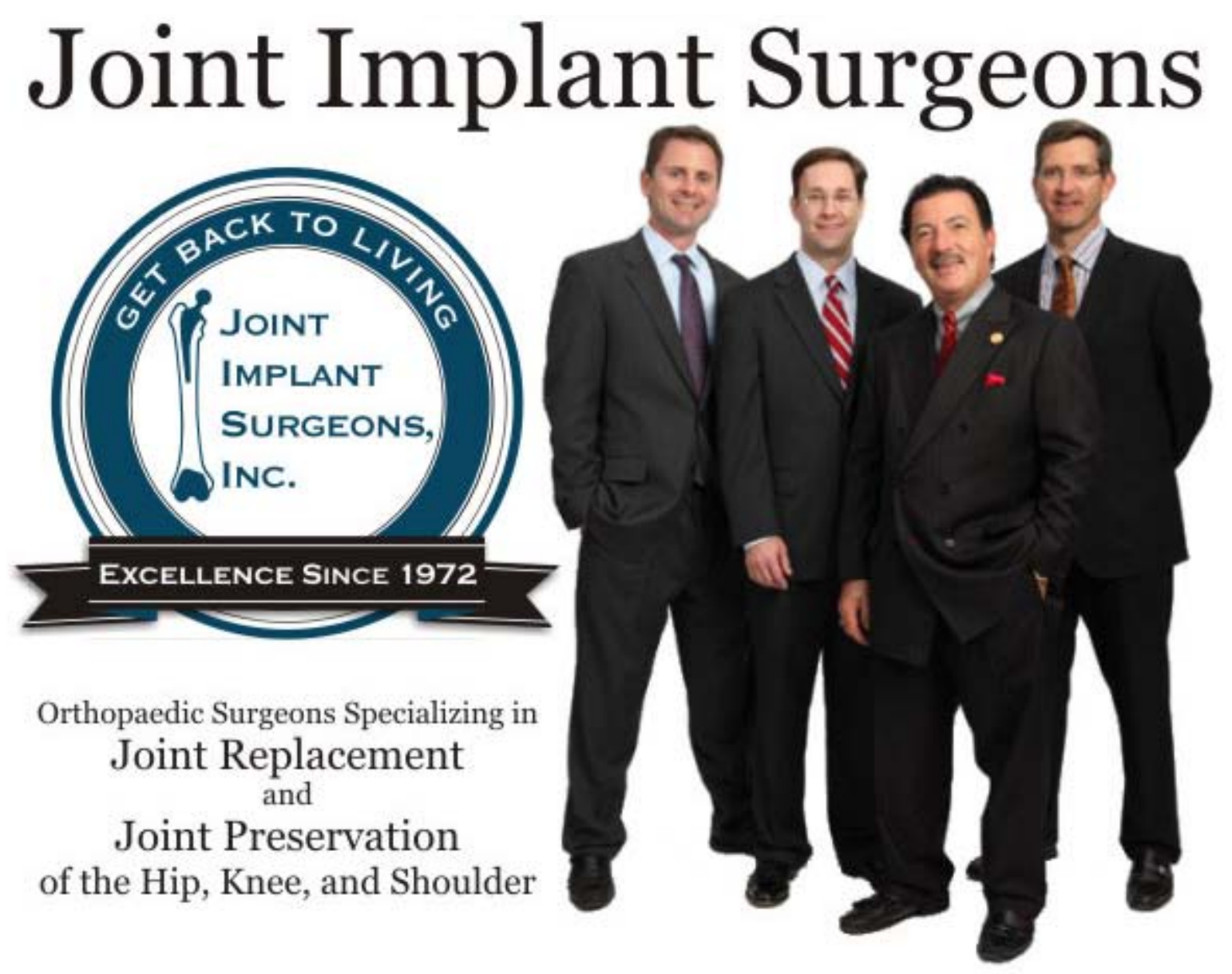




\section{Strategic Alliance}

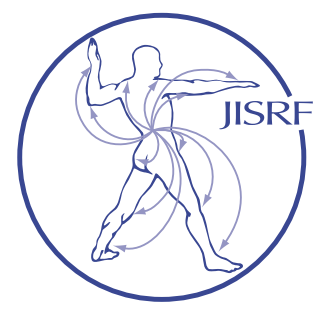

\section{Joint Implant Surgery \& Research Foundation}

is Pleased to Gontinue a Strategic Alliance with the

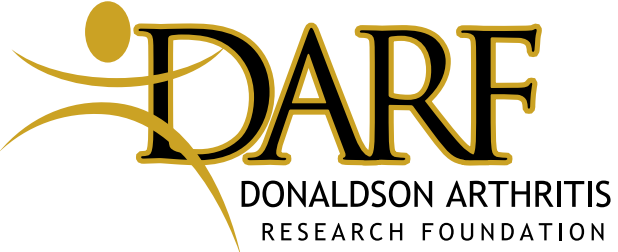

Donaldson Arthritis Research Foundation

DARF, founded in 2005 by Dr. Thomas K. Donaldson, has a focus on outcome studies and basic science with major emphasis on implant retrievals. His ongoing collaboration with Ian Clarke, $\mathrm{PhD}$ provides a synergy between the laboratory and clinical surgical science. Both men are Board Members of JISRF and have a significant working relationship with its Executive Director Timothy McTighe Dr. HS (hc).

JISRF, founded in 1971, has had significant experience with continuing medical education, product development, and clinical surgical evaluation of total joint implant devices.

The long term relationships JISRF has with total joint surgeons world wide and the experience of its Co-Directors and research evaluation equipment of the DARF Retrieval Center make for a strong long-term relationship.

Together both groups will provide unprecedented analysis of your Retrievals.

$$
\text { www.jisrf.org - www.darfcenter.org }
$$

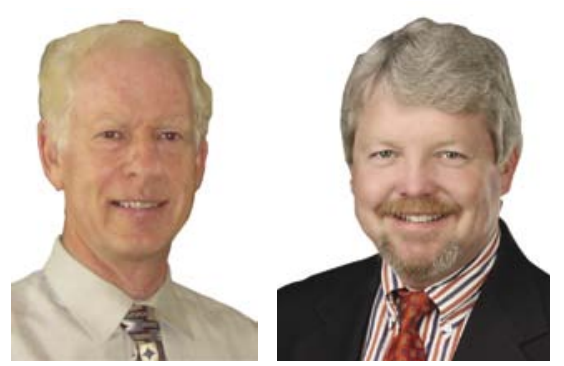

Ian Clarke, PhD \& Thomas K. Donaldson, MD

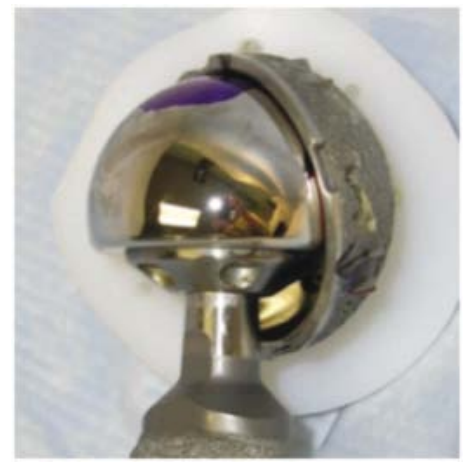

Metal on metal retrieval 


\section{Reconstructive Review}

A Journal Published by the Joint Implant Surgery \& Research Foundation

\section{Editor-in-Chief}

Timothy McTighe, Dr. HS (hc)

Executive Director, JISRF

Chagrin Falls, OH, USA

tmct@jisrf.org

\section{Associate Editor-in-Chief USA}

Keith R. Berend, MD

Joint Implant Surgeons

New Albany, OH, USA

\section{Associate Editor-in-Chief UK}

Evert J. Smith, MD

Associate Editor-in-Chief

Pacific Rim

Rami M Sorial, FRACS FAOrthA

\section{Editor Emeritus}

M.A.R. Freeman, MD, FRCS

London, UK

(Deceased, 1931-2017)

\section{Managing Editor}

David Faroo

Chagrin Falls, OH, USA

dfaroo@jisrf.org

\section{Associate Editor for Scientific Quality}

Linda Walton, MLS, AHIP

University of Iowa

\section{USA Editorial Board}

Daniel C. Allison, MD

Keith R. Berend, MD

John Bowsher

Harbinder S. Chadha, MD

Terry Clyburn, MD

Douglas Dennis, MD

Thomas K. Donaldson, MD

Chris Drinkwater, MD

Ron Hillock, MD

Eric Hirsch, MD

Riyaz Jinnah, MD

Kristaps J. Keggi, MD
$\underline{\text { John M. Keggi, MD }}$
$\underline{\text { Robert "Ted" Kennon, MD }}$
$\underline{\text { Louis Keppler, MD }}$
$\underline{\text { Stefan Kreuzer, MD }}$
Richard Kyle, MD
Audley Mackel, MD
David Mauerhan, MD
Michael B. Mayor, MD
Joseph McCarthy, MD
Ed McPherson, MD

David Langton, MD

Jeremy Latham. MA MCh FRCS

Lewis Samuels, MD

Jasmeet Saren, MD

Suresh Siva, MD, FRCS

Evert Smith, Bsc, MBBCh, FRCS

Rami M Sorial, MD

Robert M. Streicher, $\mathrm{PhD}$ $\underline{\text { Jon Minter, DO }}$

Russell Nevins, MD

Lee Rubin, MD

Frank Schmidt, MD

H. Del Schutte, MD

W. Norman Scott, MD

David Stulberg. MD

Sam Sydney, MD

Thomas Tkach, MD

Bradley Walter, MD
Prof. Emer. Panayot Tanchev, MD

Allen Turnbull, MD

Adrian van der Rijt, MD

Peter Walker, MD

Duncan Whitwell, MD

David Wood, MD

Ian Woodgate, MD

Christian Kothny, MD

Lafayette Lage, MD 


\section{JISRF Board Members}

Charles O. Bechtol, MD

(Founder 1971-1998)

Louise Bechtol, R.N.

(Founding member)

Keith Berend, MD

Declan Brazil, PhD

Hugh U. Cameron, MB, ChB

Jack Diamond, Esq.

Dr. John M. Harrison AM

John Keggi, MD

Louis Keppler, MD

Edward James McPherson, MD

Timothy McTighe, Dr. HS (hc)

\section{Lifetime Achievement Honorees}

1991 Charles O. Bechtol, MD

1992 Charles O. Townley, MD

1993 Irwin S. Leinbach, MD

1994 Bruce D. Shepherd, MB

1995 James E. Bateman, MD

1996 Roderick H. Turner, MD

1997 William R. Murray, MD

2003 Thomas H. Mallory, MD

2007 Ian Clarke, PhD

2010 Kristaps J. Keggie, MD

2014 John H. Harrison, PM, MD
Clinical/Surgical Research Advisors:

David Campbell, MD

Michael Christie, MD

Terry Clyburn, MD

KristapsJ. Keggi, MD

Robert Kennon, MD

Evert Smith, MD

Adrian van der Rijt, MD

\section{Reviewers}

The goal of JISRF and Reconstructive Review is to provide peer-reviewed, open-access orthopaedic articles focusing on total joint arthroplasty. To achieve this goal we rely on those individuals who are willing to take on the responsibility, and privilege, to review articles written by their peers. The following is Reconstructive Review's current list of reviewers.

$\begin{array}{llll}\text { Charles Alexander } & \text { C. Anderson Engh } & \text { David Mauerhan } & \text { Raj Sinha } \\ \text { Daniel Allison } & \text { Mark Froimson } & \text { Michael Mayor } & \text { Evert Smith } \\ \text { Hani Alnakhli } & \text { Jerry Gorski } & \text { Joseph McCarthy } & \text { Rami Sorial } \\ \text { Christopher Anderson } & \text { Kenneth Greene } & \text { Lorcan McGonagle } & \text { Panayot Tanchev } \\ \text { Asaad Asaad } & \text { William Griffin } & \text { Harry McKellop } & \text { Panayot Tanchev, Jr. } \\ \text { Keith Berend } & \text { Ronald Hillock } & \text { Edward McPherson } & \text { Richard Tarr } \\ \text { Declan Brazil } & \text { Kirby Hitt } & \text { Timothy McTighe } & \text { Jeffery Taylor } \\ \text { Warwick Bruce } & \text { John Ireland } & \text { Jon Minter } & \text { Robert Thornberry } \\ \text { Hugh Cameron } & \text { Robert Jamieson } & \text { Russell Nevins } & \text { Allen Turnbull } \\ \text { David Campbell } & \text { Riyaz Jinnah } & \text { Steven Nishiyama } & \text { Anthony Unger } \\ \text { Edward Cheal } & \text { Maurice Jove } & \text { Philip Nobel } & \text { Adrian van der Rijt } \\ \text { Michael Christie } & \text { Stephen Kayiaros } & \text { Mary O’Connor } & \text { Bradley Walter } \\ \text { Ian Clarke } & \text { John Keggi } & \text { Julio Palacio } & \text { William Walter } \\ \text { Terry Clyburn } & \text { Kristaps Keggi } & \text { Christopher Peters } & \text { Bill Walter } \\ \text { Simon Coffey } & \text { Robert Kennon } & \text { Derek Pupello } & \text { Andrew Wassef } \\ \text { Richard Cook } & \text { Louis Keppler } & \text { Lee Rubin } & \text { Duncan Whitwell } \\ \text { Paul Della Torre } & \text { Stefan Kreuzer } & \text { Mark Sacaris } & \text { Sumesh Zingde } \\ \text { Paul DiCesare } & \text { Lafayette Lage } & \text { Lewis Samuels } & \\ \text { Matt Dipane } & \text { Jeremy Latham } & \text { Kent Samuelson } & \\ \text { Thomas Donaldson } & \text { Audley Mackel } & \text { Frank Schmidt } & \\ \text { Scott Dunitz } & \text { Michael Manley } & \text { W. Norman Scott } & \\ & & & \end{array}$




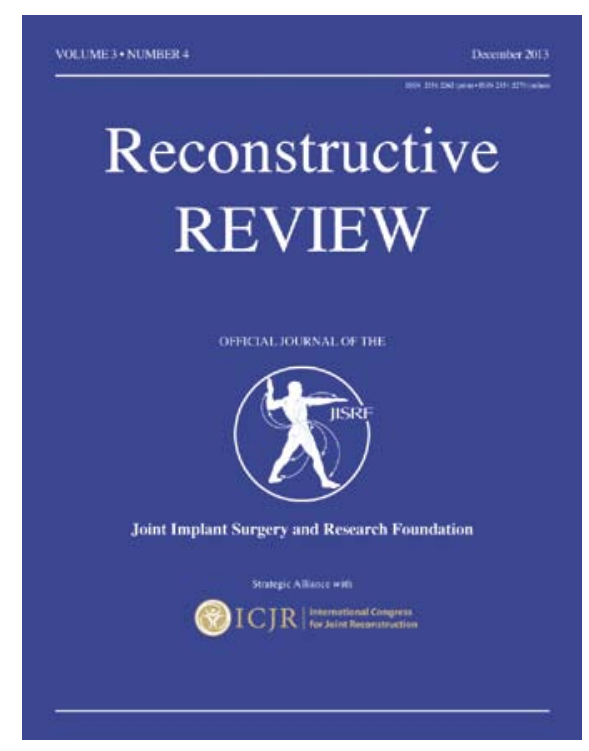

The Reconstructive Review (ISSN 2331-2262 print, ISSN 2331-2270 online) will be published yearly by the Joint Implant Surgery \& Research Foundation, 46 Chagrin Plaza \#117, Chagrin Falls, Ohio 44023.

\section{Editorial Correspondence}

Please direct any requests for inclusion, editorial comments or questions to Timothy McTighe, Dr. HS (hc), Executive Director, JISRF, 46 Chagrin Plaza \#117, Chagrin Falls, Ohio 44023, tmct@jisrf.org.

\section{Correspondence}

Direct any questions regarding the submission process, or requests for reprints to David Faroo, Director of Communications, JISRF, 46 Chagrin Plaza \#117, Chagrin Falls, Ohio 44023, dfaroo@jisrf.org.

There is no subscription charge for receipt of this publication. This is done as a service keeping with the overall mission of JISRF.

For information on how to submit articles to the Reconstructive Review please review the following or visit https://www.reconstructivereview.org.

\section{Submit Articles to the Reconstructive Review}

Please visit ReconstructiveReview.org to submit an article for review and publication in the Reconstructive Review. All material to be considered for publication should be submitted via this online submission system.

Before submitting an article to Reconstructive Review, please follow the instructions below.

\section{ARTICLE TYPES}

Reconstructive Review accepts the following categories of articles:

- Original Articles

- Basic Science

- Case Reports

- Clinical/Surgical

- Commentary

- Controversial Issues (i.e. modularity, tapers, MoM)

- Healthcare Policy/Economics

- Reviews

- Letters to the Editor

- Surveys

The emphasis for these subjects is to address real life orthopaedics in a timely fashion and to encourage the participation from a broad range of professionals in the orthopaedic health care field.

We will strive to be responsible and reactive to the needs expressed to our editors and all members of JISRF. We anticipate our format will evolve as we move forward and gain more experience with this activity. Your opinion is a critical step to our motivation and overall success, please do not hesitate to communicate with us.

\section{INSTRUCTIONS FOR SUBMITTING ARTICLES}

Please read the following information carefully to ensure that the review and publication of your paper is as efficient and quick as possible. The editorial team reserves the right to return manuscripts that have not been submitted in accordance with these instructions.

\section{File Formats}

- All articles must be submitted as Word files (.doc/. docx) with lines of text numbered. PDF's are not acceptable for submission.

- Figures, images, and photographs should be high quality .JPG images (at least 150 dpi, 300 dpi if possible). All illustrations and line art should be at least 1200 dpi.

\section{Article Preparation}

Articles submitted will need to be divided into separate files including cover page and manuscript. Figures, images, and photographs should be submitted separately.

- Cover Page - includes article title, lists all authors that have contributed to the submission and provides all authors information including their title, full name, their association with the paper, their full postal address and email. Please list all authors in the order that you want them to appear.

- Manuscript - EXCLUDES ALL AUTHOR INFORMATION. The manuscript is used in creating the file for peer review - a double blind process. Your sub- 
mission should follow this structure:

- Title

- Structured Abstract (Introduction, Materials \&

Methods, Results, Discussion, and Conclusion)

- Introduction

- Materials \& Methods

- Results

- Discussion

- Conclusion

- References (for styles please refer to the website http://www.nlm.nih.gov/bsd/uniform requirements.html)

- Figures, Images and Photographs - Please do not embed figures, images, and photographs in the main manuscript. They should be uploaded as individual files.

Once you have prepared your manuscript according to the information provided above, please go to our website ReconstructiveReview.org and click on the Register link. Once you have registered you will click on the Submit New Manuscript link. Detailed instructions on how to submit your manuscript can be found at ReconstructiveReview.org.

\section{INFORMED CONSENT}

Any manuscript dealing with human subjects must include a statement that proper disclosure was given and patient consent was received.

\section{COPYRIGHT AGREEMENT}

Authors retain copyright and grant the journal right of first publication with the work. Reconstructive Review follows the Creative Commons Attribution-NonCommercial CC BY-NC. This license allows anyone to download works, build upon the material, and share them with others for non-commercial purposes as long as they credit the senior author, Reconstructive Review, and the Joint Implant Surgery \& Research Foundation (JISRF). An example credit would be: "Courtesy of (senior author's name), Reconstructive Review, JISRF, Chagrin Falls, Ohio". While works can be downloaded and shared they cannot be used commercially.

\section{DISCLOSURE STATEMENT}

As part of the online submission process, corresponding authors are required to confirm whether they or their co-authors have any disclosures to declare, and to provide details of these. If the Corresponding author is unable to confirm this information on behalf of all co-authors, the authors in question will then be required to submit a completed Disclosure Statement form to the Editorial Office (editors@reconstructivereview.org). It is the Corresponding author's responsibility to ensure that all authors adhere to this policy.

There are three statements to choose from on the Disclosure Statement form, they are:

1 No benefits or funds were received in direct or indirect support of this article.

2 Benefits or funds were received in support of this article either directly or indirectly.

3 Either family, institution I am associated with, or I have received benefits or funds either directly or indirectly regarding this article. (Examples include: Royalties, Consulting Fees, Stock Options, Equity, Institutional Funds)

\section{Reconstructive Review Production Specifications}

The Reconstructive Review is currently constructed using InDesign running on a Mac. The document is published on the web, available for download as a PDF, and printed in limited quantities.

- Trim Size: 8.5" x 11"

- Live Area: 7.25" x 9.25"

- No Bleeds

Ad Specification

- Full color or black and white - available sizes:

- Full Page, 7.25" x 9.25"

- Half Page Horizontal, 7.25" x 4.25"

- Half Page Vertical, 3.25" x 9.25"

Any questions regarding these specifications should be directed to media@jisrf.org.

\section{General Statement}

The ideas, opinions and statements expressed in the Reconstructive Review do not necessarily reflect those of the publisher and or editor of this publication. Publication of advertisement does not indicate an endorsement of product or service by the publisher or editor of JISRF. The publisher and editor assume no responsibility for any injury or damage resulting out of any publication of material within the Reconstructive Review. The reader is advised to review and regard with balance any information published within this publication with regard to any medical claim, surgical technique, product features or indications and contraindications. It is the responsibility of the professional treating medical physician to review any and all information before undertaking any change of treatment for their patients. 


\section{(2) Sigmaturere}

Design

Derolop

Pwotity

Mannetwere

Centortatern

Signature Orthopaedics is a design, development and manufacturing company for orthopaedic implants and instruments.

The head office located in Sydney Australia, with offices in Europe and North America.

We have years of experience in taking concepts right through design and development and into certification, whether it be the FDA, BSI or the TGA.

We are routinely supplying parts for the Hip, Knee, foot and ankle, spine, shoulder, both to the locally and international markets. With the added capability of making custom implants for specific cases, using the latest software to guarantee the perfect fit.

We are happy to design and develop both instruments and prosthesis for your needs, or we can supply one of our many FDA approved solutions as an OEM vendor.

Our product, your box!
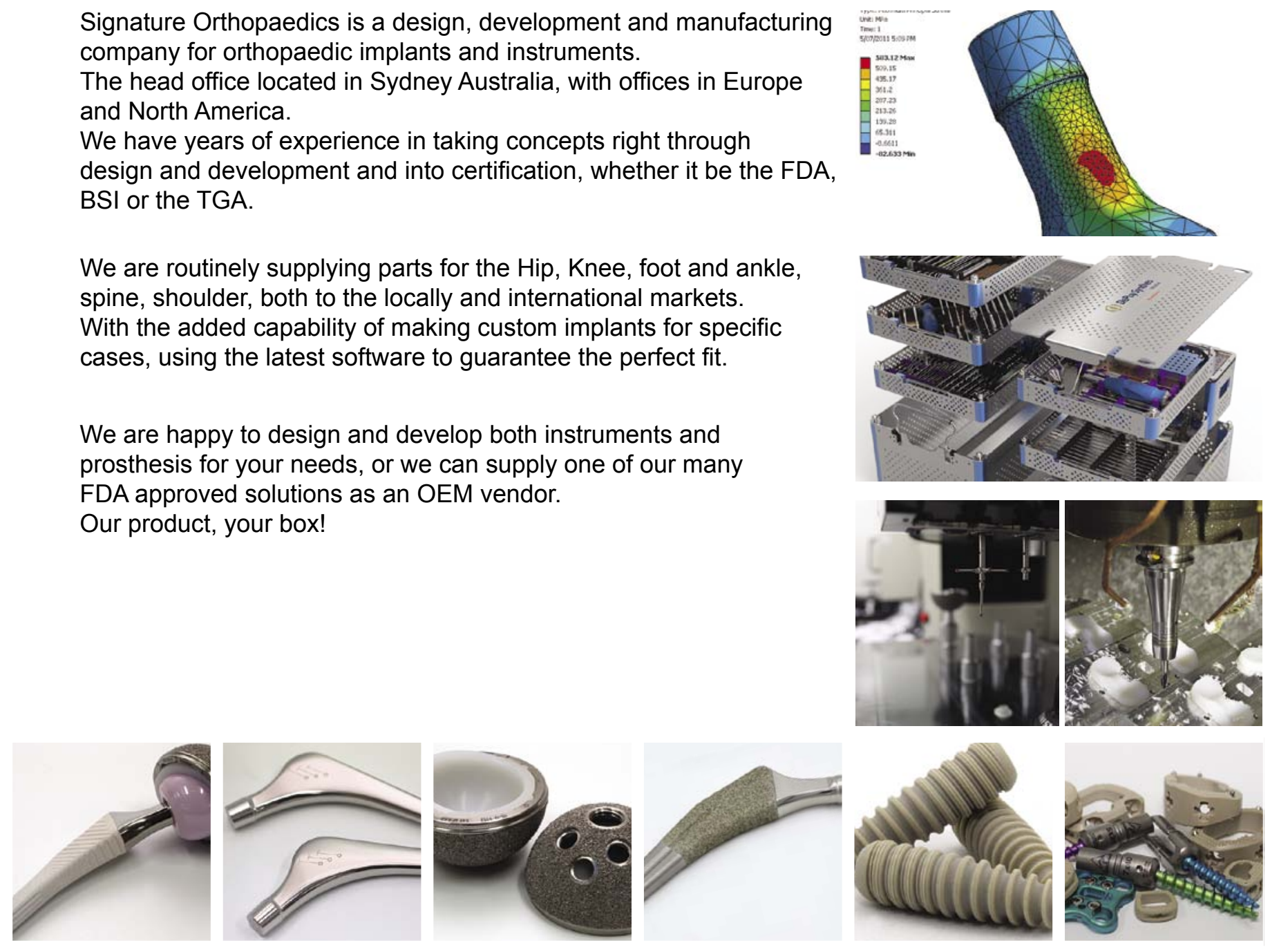

Call os email to discuss which solution is right for you! 


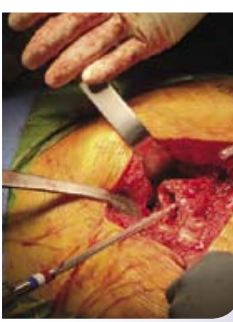

Flexible Ball Nose Reamer Designed for safe and effective use in removing pedestal formation in the femoral and tibial canals
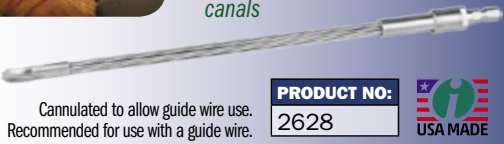

Cannulated to allow guide wire
Recommended for use with a guide wie.

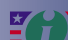
$\pm$ USA MADE

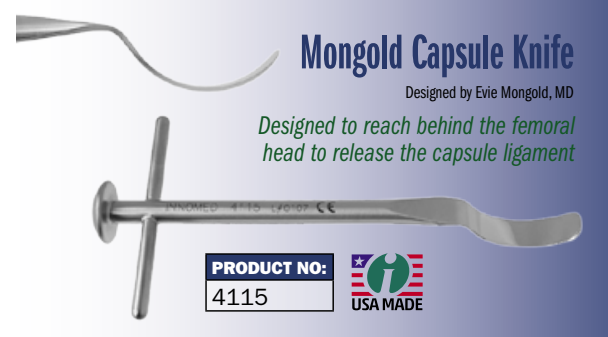

\section{Angied Capsule Scissors}

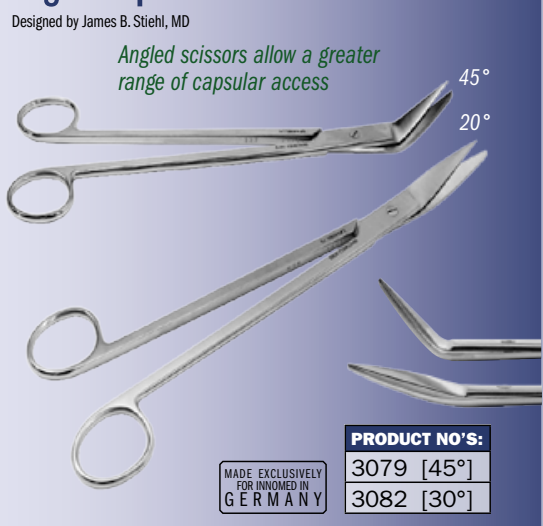

Lombardi

Taper Cleaner

Designed by Adolph V. Lombardi Jr., M

Designed to help clean a

hip stem taper of corrosive

byproducts prior to placement

of the new femoral head

\section{PRODUCT NO'S:}

8034 Short Taper $11.3 / 12.2 \mathrm{~mm}$

8034-01 Long Taper $11.4 / 13.4 \mathrm{~mm}$

$8035-01 \quad 11 / 13 \mathrm{~mm}$

8035-02 $12 / 14 \mathrm{~mm}$

8035-03 14/16 mm

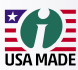

\section{Large Bone Curettes}

Designed with a 5/16" (8 $\mathrm{mm}$ ) diameter shaft allowing better visualization into the medullary canal

\section{PRODUCT NO'S:}

5160 [Set of 1 each including Case] Available individually:

5160-01 [Angled Small - $10 \times 18 \mathrm{~mm}$ ] 5160-02 [Straight Small - $10 \times 18 \mathrm{~mm}$ ] 5160-03 [Angled Medium - $10 \times 24 \mathrm{~mm}$ ] 5160-04 [Angled Large - $24 \times 24 \mathrm{~mm}$ ] 5160-05 [Straight Medium - $10 \times 24$ mm]

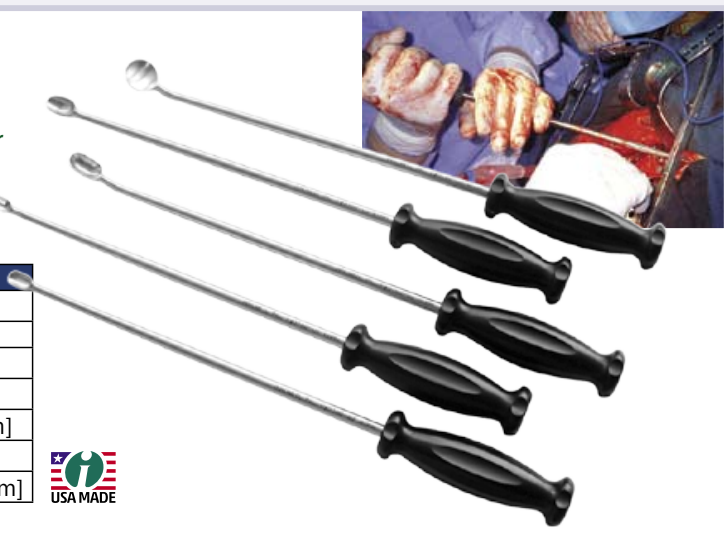

Namba Hip Slide Designed br probers. Nanaba, Mo

Safely glides femoral heads into the acetabulum - essential for ceramic heads
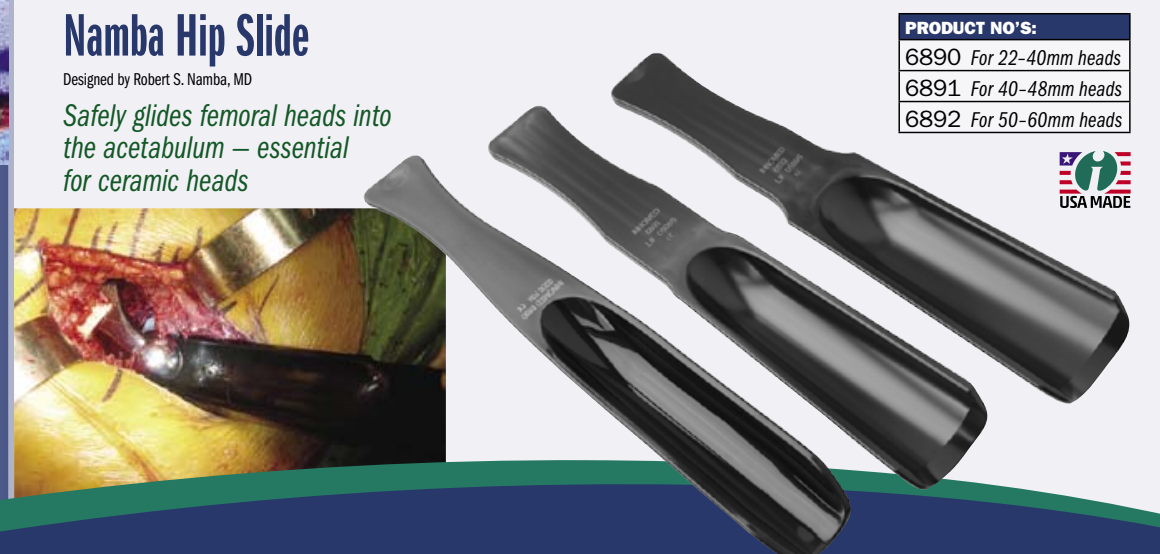

6890 For $22-40 \mathrm{~mm}$ heads 6891 For $40-48 \mathrm{~mm}$ heads

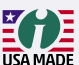

Mazzara Pistol Grip Extra Long Rongeur

Designed by James T. Mazzara, MD

PRODUCT NO:

1768-02 [8 x 16 mm Jaw]

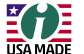
and slippage, and allows for better visualization

Extra Long Ronguer

1771-01 [5 × $16 \mathrm{~mm}$ Jaw] \begin{tabular}{l} 
MADEFPRNONOEDIN \\
GER M AN Y \\
\hline
\end{tabular}

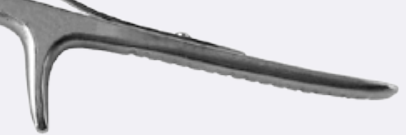

ISO 13485:2016

\section{FREE TRIAL ON MOST INSTRUMENTS}
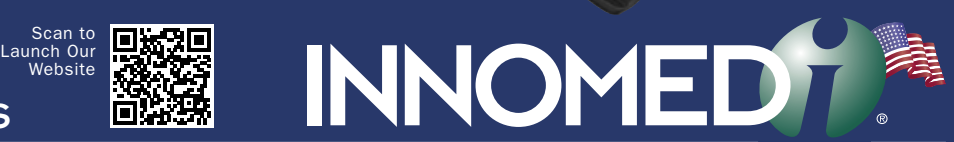

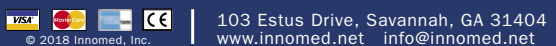

912.236 .0000 Phone
912.236 .7766 Fax

Innomed-Europe Tel. +41417406774
Fax +41417406771

1.800.548.2362 


\section{ONTENTS}

\section{Reconstructive Review}

Volume 9.1, 2019

\section{CLINICAL/SURGICAL}

13 Does Implant Design Affect Hospital Metrics and Patient Outcomes? TKA Utilizing a "Fast-Track" Protocol

Buch RG, Schroeder L, Buch R, Eberle R

17 Restoration of Femoral Condylar Anatomy for Achieving Optimum Functional Expectations: Continuation of an Earlier Study At 5-Year Minimum Follow-Up Durbhakula S, Durbhakula V, Durbhakula N

\section{ORIGINAL ARTICLE}

23 Techniques of Insertion and Early Clinical Impressions with a Short Curved Tissue Sparing Implant for Total Hip Arthroplasty (The French Experience) Venet G, Tesson A, Le Cour Grandmaison F, Fraquet N, Brazil D, McTighe T

31 Can We Improve Screening Costs in Asymptomatic Metal on Metal Total Hip Arthroplasties?

Martin JR, Otero JE, Springer BD, Griffin WL

43 Long-Term Screening is Necessary in Patients with Metal on Metal Total Hip Arthroplasty

Martin JR, Odum S, Griffin WL

49 Risk Factors for Blood Transfusion After Primary Total Hip Arthroplasty Kesler K, Brown T, Martin JR, Springer BD, Otero JE

\section{COMMENTARY}

55 What is Considered a Conflict of Interest or What to Disclose in Lectures and Publications?

McTighe T 


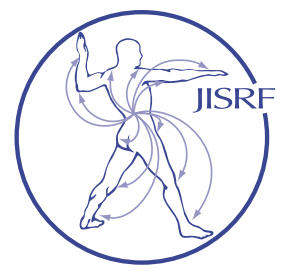

\title{
Does Implant Design Affect Hospital Metrics and Patient Outcomes? TKA Utilizing a "Fast-Track" Protocol
}

\author{
Buch $R G^{1}$, Schroeder $L^{2}$, Buch $R^{1}$, Eberle $R^{1}$
}

\section{Abstract}

Background: "Fast-Track" protocols have been introduced in TKA with the intention to increase health care savings while maintaining or improving patient outcomes. The influence of the implant design in a "Fast-Track" setting has not been described yet. The primary goal of this study was to compare a customized implant with standard off-the-shelf (OTS) devices when utilizing a "Fast-Track" protocol

Methods: Sixty-two (62) patients were prospectively enrolled at a single center and implanted with either a customized or a standard off-the-shelf implant resulting in thirty (30) patients being treated with an OTS design and thirty-two (32) with the customized design. The same institutional fast-track protocol was utilized on all patients and included pre-, intra-, and postoperative medical treatment. We assessed total length of stay (LOS), discharge destination and range of motion at 6-8 weeks post-op and at an average of 16 months post-op follow-up to compare the OTS implant with the customized device. Implant survivorship was assessed at a minimum of 25 months post-op.

Results: Using the fast track protocol we were able to decrease overall LOS to 2.1 days versus 3.6 days prior to introduction of the protocol. The use of the customized implant further reduced LOS significantly to 1.6 days. Significantly higher number of patients who got implanted with the customized device (66\%) were discharged within 24 hours than in the OTS group (30\%). Patients treated with the customized implant were found to be discharged home more often than patients treated with the OTS implants (97\% vs. $80 \%)$ and achieved higher range of motion both at 6-8 weeks $\left(114^{\circ}\right.$ vs. $\left.101^{\circ}\right)$ and at an average of 16 months $\left(122^{\circ}\right.$ vs. $\left.114^{\circ}\right)$ than patients who got treated with the OTS device. At an average follow-up of 28 months, there was 1 implant revision in the customized group (due to tibial fracture resulting from patient fall). For the OTS group there was 1 implant revision (late infection) and 1 poly swap (due to instability).

Discussion: Based on our analysis we observed a positive influence of the customized device on patient outcomes and hospital metrics and we therefore conclude that the implant choice is an important factor for TKA in a "fast-track" setting.

\section{Background}

In the current health care environment there is an increased focus on health care savings while maintaining or improving patient outcomes. This has become an important factor for patients undergoing total knee arthroplasty (TKA) with practicing physicians constantly aiming to increase the efficiency and cost effectiveness of the proce-

Keywords: Fast Track; customized; total knee arthroplasty Level of Evidence: AAOS Therapeutic Level II 
dure. One methodology to decrease patient's length of stay (LOS) is to incorporate a fast track protocol and thereby reducing per patient burden on the hospital. "Fast-track" has been defined as a hospitalization which provides best possible evidence-based treatment, using fewer clinical resources within a hospital stay while maintaining high patient satisfaction and few complications [1]. Success criteria have been described as reduction of perioperative morbidity, optimized pain management, shorter convalescence, a reduction in postoperative length of stay and a rapid functional recovery due to early mobilization [1- $\underline{3}]$.

Previous studies examining clinical outcomes following a fast track protocol have shown that changing patient care has its benefits and drawbacks. They have investigated various factors such as the type of anesthesia, postoperative rehabilitation and optimized pain relief that can influence faster discharge while maintaining optimum patient care [4-6]. Preoperative anemia in fast-track TKA however has been seen to be associated with an increased risk of patients receiving transfusion during admission, increased risk of readmission within 90 days from the procedure and increased risk of LOS of more than 5 days [7].

To our knowledge, the effect of an implant design on overcoming these challenges has not been examined. Customized implants, designed to provide optimal fit by replicating patient individual knee geometry, and particularly, restoration of the patient's femoral condylar anatomy, have been introduced to the market with the goal to achieve better patient outcome, faster recovery and mobilization postsurgery and therefore reducing the time of hospitalization.

Hence the purpose of our study was to compare standard off-the-shelf implants with a customized TKA design in a well-defined "Fast-Track" setting to determine, if implant design has any significant influence on hospital metrics or patient outcomes.

\section{Methods}

In this single-center case series sixty-two (62) patients were prospectively enrolled and were implanted with one of two implant systems. All surgeries were performed by the same surgeon. All patients consented for their data to be used for research purposes. Patients were given the option to choose between the customized and a standard offthe-shelf (OTS) implant based on the preference for timing of the surgery. Patients who preferred their procedure to be on the next possible date were treated with the OTS implant and patients who were willing to wait 6 weeks, the timespan needed for the implant manufacturing process, with the customized design.
This resulted in thirty (30) patients being treated with an OTS (53\% female) (Columbus ${ }^{\circledR}$ Total Knee System, B Braun Melsungen AG, Hessen, Germany; Vanguard ${ }^{\circledR}$ Knee System, Zimmer Biomet, Warsaw, Indiana) and thirty-two (32) with the customized implant (41\% female) (iTotal ${ }^{\circledR} \mathrm{G} 2$, Cruciate Retaining TKA, ConforMIS, Inc., Billerica, MA). Regardless of component brand, all patients in both groups received a cruciate retaining TKA level of constraint. Patient demographics in terms of age at the time of surgery (57.2yrs OTS and 57.3yrs Customized; $\mathrm{p}=0.969)$, BMI (31.0 OTS and 33.4 Customized; $\mathrm{p}=0.116$ ) and 17 tracked comorbid conditions (e.g. Diabetes, coronary artery disease, hypertension etc.) were collected preoperatively to ensure patients of both groups were comparable. No statically significant difference could be seen in the observation (Tables 1 and 2). During hospitalization the same institutional fast track protocol was utilized on all patients included in this study. As such it involved preoperative medical treatment with Hibiclens ${ }^{\circledR}$ (Mölnlycke, Norcross, Georgia, USA) daily for three days and Bactro-

Table 1. Patient demographics

\begin{tabular}{|c|c|c|c|}
\hline & OTS & Customized & p-value \\
\hline Number of Patients & 30 & 32 & \\
\hline Gender (\% Female) & $53 \%$ & $41 \%$ & 0.45 \\
\hline Body Mass Index (BMI) & $31.0(22-38)$ & $33.4(24-53)$ & 0.116 \\
\hline Age at Surgery (Years) & $57.2(34-67)$ & $57.3(42-72)$ & 0.969 \\
\hline
\end{tabular}

Table 2.Patients comorbidities. Seventeen comorbidities were tracked pre-operatively but no significant differences were seen between the two groups

\begin{tabular}{|c|c|c|c|}
\hline & OTS & Customized & p-value \\
\hline Diabetic & 5 & 6 & $>0.05$ \\
\hline CAD & 0 & 2 & $>0.05$ \\
\hline HTN & 13 & 16 & $>0.05$ \\
\hline RA & 2 & 2 & $>0.05$ \\
\hline Smoker & 5 & 6 & $>0.05$ \\
\hline Contracture & $2<100$ & $3<100$ & $>0.05$ \\
\hline
\end{tabular}

Table 3. Medication flow chart of the fast-track protocol

\begin{tabular}{|c|c|c|}
\hline $\begin{array}{c}\text { One Week Before } \\
\text { Surgery }\end{array}$ & At Surgery & Hospital / Home \\
\hline Celebrex 200Mg & Marcaine & \\
\hline 5 Minutes Before & Celebrex 200Mg & \\
\hline Cymbalta 60Mg & $\begin{array}{c}\text { Exparel 20Cc W/ } \\
\text { 100CC of Saline }\end{array}$ & Norco 10/325 Prn \\
\hline Norco T Prn & Spinal & Morphine/Dilaudid \\
\hline & Lovenox & Cymbalta 60Mg \\
\hline & & Aspirin 325 \\
\hline
\end{tabular}


ban ${ }^{\circledR}$ nasal ointment (GlaxoSmithKlein, Brentford, London, UK) starting 48 hours prior surgery to remove potentially pathogenic bacteria from the nasopharyngeal region as well as patients ceasing all anticoagulants 5 days prior to the procedure. All study participants underwent an educational review consisting of a preparation course, a CD and a pamphlet to inform about the operational flow, possible complications and evaluating and setting patient's expectations. A standard set of medications (Table 3) was given to all subjects participating in this study pre-, at and post-surgery. Post-operatively all patients were mobilized within 3 hours and were treated with CPM or Active Ice ${ }^{\circledR} 3.0$ (Polar Products, Inc., Stow, OH, USA) if needed. As for criteria of discharge, patients had to be able to walk over 100 feet, get out of bed independently and needed to have at least $60^{\circ}$ of flexion. Both, discharge criteria and the time of discharge was determined by physical therapist and hospitalist, independent of the surgeon.

During the data collection we assessed patient's time of discharge, the total length of stay in the hospital (LOS) as well as their discharge destination. Patient's range of motion (ROM) and the need for walking aids were examined at their 6-8 week post-op visit and at an average of 16 months post-op. All adverse events including manipulation under anesthesia (MUA) and revisions were followed up to a minimum of 25 months post-op (average 28 months).

Statistical analysis was performed in Minitab 17.1 (MiniTab Inc, PA-USA). All data was included for the analysis. Continuous variables were tested for normality prior to statistical comparisons. Variables with a normal distribution were compared using 2 tailed t-test assuming unequal variances. Non-normal variables were tested using Mann-Whitney test. Categorical variables were compared between the customized and OTS outcomes using frequency counts. Significance was determined using a Fisher Exact Test. A p value of 0.05 was used to determine a significant difference between the customized group and OTS group outcomes.

\section{Results}

Overall, when utilizing the "Fast Track" protocol, LOS was decreased to 2.1 days versus 3.6 days, which was the average LOS after TKA for patients in our institution that did not undergo the fast track protocol.

The data analysis revealed that the average length of stay using standard OTS implant designs was found to be 2.7 days (range, 1-6 days) and 1.6 days (range, 1-6 days) when the customized TKA got implanted. This difference was found to be of statistical significance $(p=0.004)$. Al-

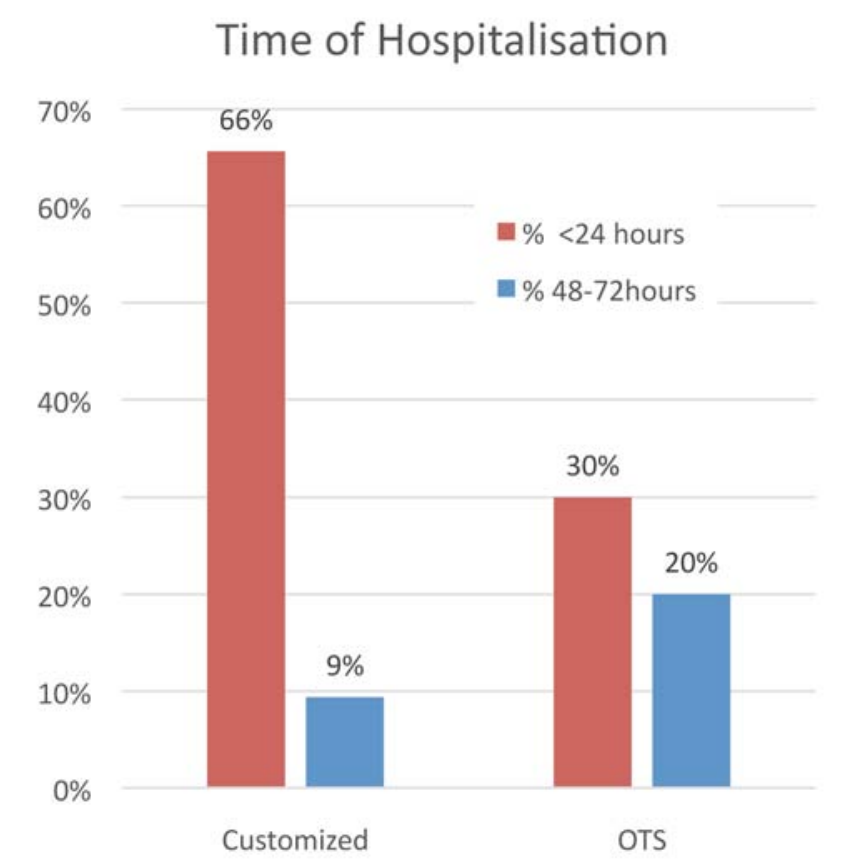

Figure 1. Comparison of patient's time of hospitalisation between the customized and the OTS implants

though the LOS range was seen to be the same, there was one patient in the customized group who was hospitalized for 6 days compared to 6 patients who received the OTS TKA.

We observed that significantly more patients treated with the customized implant were discharged from the

\section{Discharge Destination}

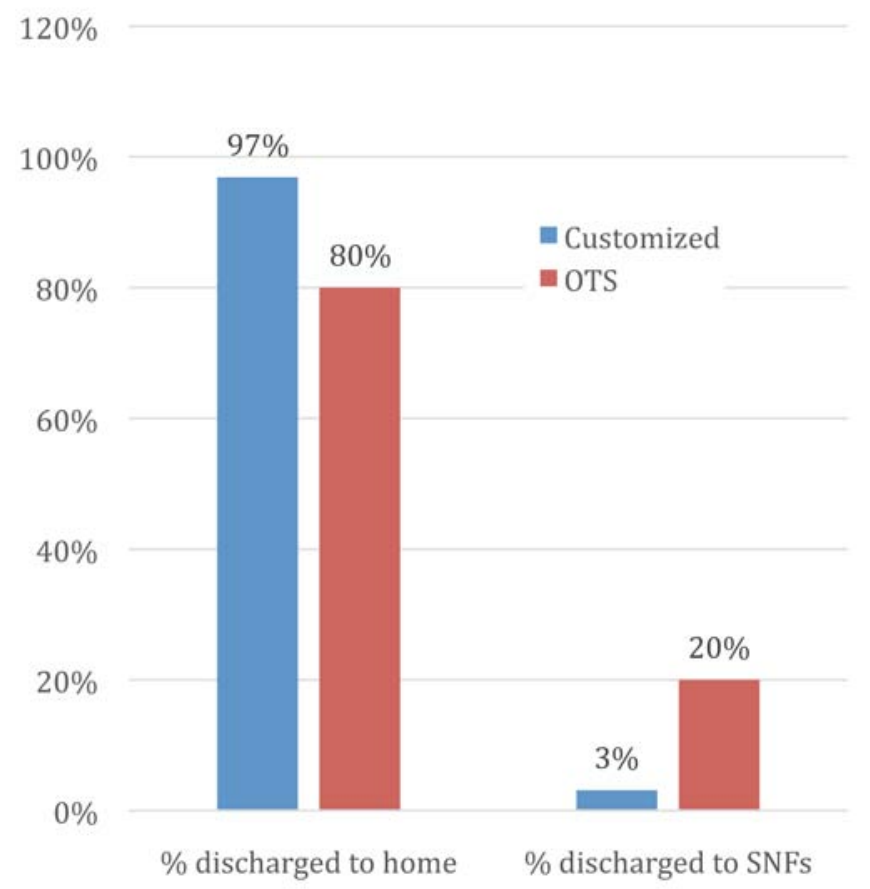

Figure 2. Destination of discharge after the time of hospitalisation 
hospital within 24 hours post-surgery (66\%) compared to patients from the OTS TKA group (30\%) (Figure 1) $(\mathrm{p}=0.006)$. When assessing patients discharge destination a significantly higher proportion of patients discharged home was seen in the customized group (97\%) compared to the OTS group (80\%) (Figure 2) $(\mathrm{p}=0.05)$.

At the 6-8 week follow-up time point significantly less patients with a customized implant needed a walking aid (13\%) compared to patients with an off-the-shelf implant $(60 \%)(\mathrm{p}=0.02)$. During that time period we found a difference in range of motion between both groups with patients who got an OTS TKA implanted $\left(101^{\circ}\right)$ experiencing $13 \%$ less ROM on average than patients with the patient specific implant $\left(114^{\circ}\right)$ (Figure 3).

\section{Range of Motion}

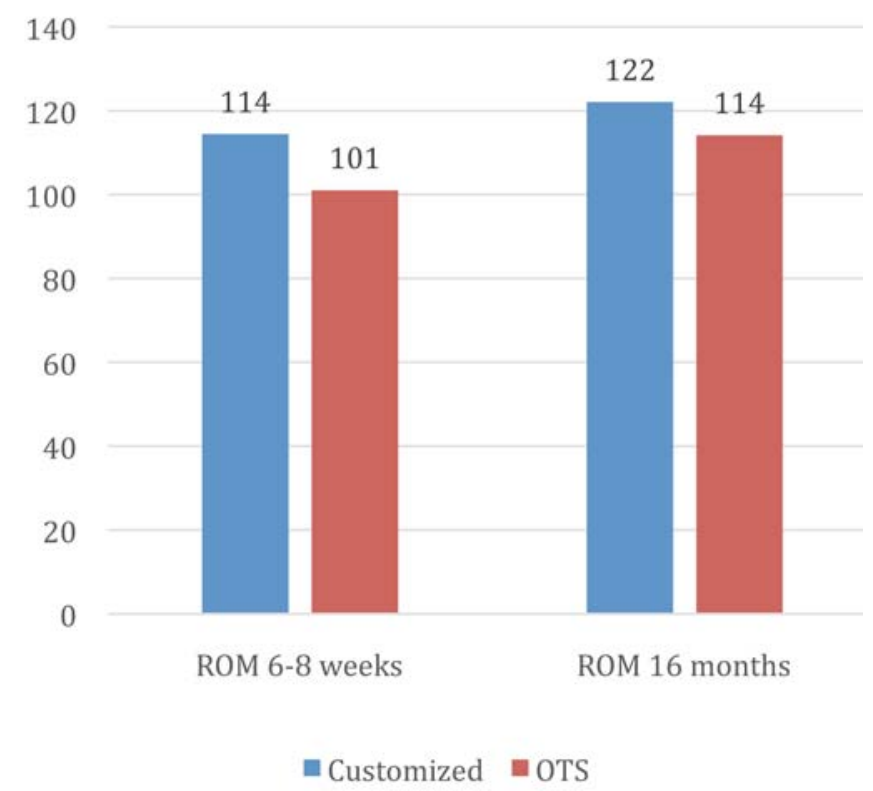

Figure 3. Patient's range of motion post-surgery

Range of motion at an average of 16-month follow-up continued to be significantly higher among patients with the customized TKA $\left(122^{\circ}\right.$ vs. $\left.114^{\circ} \mathrm{p}<0.001\right)$. Additionally, a significantly higher proportion of patients with the customized TKA than patients with the standard TKA were found to have a ROM of $\geq 120^{\circ}$ at the final time of followup (84\% vs. $45 \%$; $\mathrm{p}=0.003)$. None of the patient with the customized implant showed a ROM of $<100^{\circ}$ compared to $13 \%$ of patients with the OTS implant at the time of the final follow-up (Table 4). This was shown to be of statistical

Table 4. Patient's ROM at an average of 16 months.

\begin{tabular}{|c|c|c|c|}
\hline & OTS & Customized & P-value \\
\hline $\mathrm{ROM} \geq 120$ degrees (\%) & $45 \%$ & $84 \%$ & 0.003 \\
\hline $\mathrm{ROM}<100$ degrees (\%) & $14 \%$ & $0 \%$ & 0.046 \\
\hline
\end{tabular}

significance $(\mathrm{p}=0.046)$.

For adverse event reporting the average follow-up of the cohort was 28 months. Post-operatively there were two manipulations under anesthesia in the customized group and one among the OTS patients $(\mathrm{p}=0.99)$. There were no returns or re-admissions to hospital in a 60-day period. One patient in the customized group underwent a revision procedure at 30 months post op due to a fractured tibia resulting from a fall that loosened the tibial baseplate. In the OTS group there was 1 patient who developed a late infection at 2.5 years and had to be revised. In addition, one patient in the OTS group underwent a poly swap procedure to correct instability.

\section{Discussion}

Fast-track surgery has been implemented to improve surgical management by improving perioperative care and decreasing postoperative complications and therefore shorten the time of full recovery and reduce the need for hospitalization and convalescence. The "Fast-Track"-program has been introduced by Kehlet et al and been developed and applied to clinical practice over the last 15 years $[\underline{8}, \underline{9}]$. With the purpose of enhancing the cost-effectiveness and general efficiency of health care, multiple factors during patient's time of hospitalization and their impact on patient's recovery have been analyzed. Optimized pain management, transfusion strategy, rehabilitation and physiotherapy, patient's information, fluid management and anaesthetic technique has led to a LOS of 1-2 days after TKA and better patient post-operative outcomes $[\underline{4}, \underline{6}, \underline{10}, \underline{11}]$

To our knowledge the potential influence of the implant design on peri- and post-operative outcomes after TKA in a fast-track setting has not yet been described. We believe this is the first study to compare the effect of the knee implant design on length of stay and hospital metrics in a defined fast-track program. Our study was not without limitations which have to be taken into consideration when interpreting the results. This study was carried out prospectively with patients selecting the implant design. Including blind randomization of the patient / component matching may have eliminated potential selection bias between the two study groups. Therefore we had little influence on the composition of the study cohorts which might have led to inequalities between the study groups. However, since patient demographics and comorbid conditions were similar and no statistically significant difference was detected between the two groups we consider our result to be valid. With a total of 62 patients participated in this study our patient cohort was relatively small. Nevertheless, the dif- 
ferences seen between the groups were large enough to be of significance and we believe they would be similar for a larger study population. We suggest that further research with a larger study population should be undertaken in the future. For this study all TKAs were performed by a single surgeon who is experienced with all devices used. Experience and a high expertise in performing TKA has been shown to result in better outcomes and additional studies at different sites should be conducted to verify if the implant design does have an impact on a faster discharge. Lastly, fast track surgery can be implemented in multiple ways with the same guidelines but different protocols. Our results only reflect the fast-track protocol we utilized in this study. As there is no single definition of the "fast track protocol" in literature we propound that our protocol should be used in future research in order to validate our findings.

Overall, we observed a reduction in length of stay of 0.4 days after implementing the fast track protocol (3.1 days to 2.7 days). However, when using the customized implant, the average length of stay was reduced by a further 1.1 days. Culler et al compared LOS after TKA of patients treated with a customized implant and patients treated with an OTS design and noticed a tendency of reduced LOS in the customized group. Additionally, they found that a significantly greater proportion of patients in the customized study arm were being discharged from their TKA hospitalization in $<3$ days ( $<72$ hours from admission to discharge) than in the OTS arm [12]. We can therefore agree with and support their findings that patients treated with the customized implant experience shorter LOS than patients with the OTS design.

In a study to evaluate whether there is a significant difference in surgical time, intraoperative blood loss, postoperative range of motion and length of stay between customized and OTS TKA Schwarzkopf et al observed a decreased range of motion with customized compared to off-the-shelf implants [13]. When assessing postoperative ROM, we had different findings. Patients with the customized implant design showed significantly better results both, at 6-8 weeks after surgery and at an average of 16 months post-op, than patients treated with the OTS implant. As having more than $60^{\circ}$ of flexion was a discharge criterion in our study we believe that providing better results in ROM early after surgery could be one reason for higher ROM of customized patients.

The number of patients being discharged to a rehab facility (SNFs) was significantly higher in the OTS study group than among the customized patients. Additionally, more patients in the customized group went home after their time of hospitalization than patients in the OTS group. Reasons for a discharge to rehab care facilities have been examined in previous research and found to be correlated to patient's demographics and characteristics e.g. comorbid conditions [14-16]. As we observed no significant difference in those metrics between our study arms, we assume that the difference in the implant plays a crucial role in patient's post-surgical recovery and therefore in their discharge destination.

In the light of the Comprehensive Care for Joint Replacement (CJR) program, bundled payments will be paid for TKA procedures based on multiple variables in order to improve healthcare costs and treatment efficiency. Previously published studies have revealed great cost variations for different discharge settings and potential savings due to shortened length of stay [17-19]. Utilizing discharge costs analysis as published by Ramos et al we observed a potential average cost reduction when using the customized implant for less patients being discharge to inpatient rehab facilities of $\$ 1,100$ per patient. Furthermore, our results would potentially save hospitals $\$ 1,100$ per patients on average from a shortened average length of stay of 1.1 days (LOS of 2.7 days in OTS group and 1.6 days in the customized group). In summary, based on our findings healthcare costs could be potentially cut by approximately $\$ 2200$ by using the customized compared to OTS implants.

We believe that the customized implant has a positive influence on patient outcomes in a "Fast Track" setting and surgeons and hospitals should consider implant choice as an important factor in fast-track TKA surgery.

\section{References}

1. Rodriguez-Merchan, E. Carlos. "Pros and cons of fast-track total knee arthroplasty.” International Journal of Orthopaedics 2.3 (2015): 270-279.

2. Husted, Henrik, Gitte Holm, and Steffen Jacobsen. "Predictors of length of stay and patient satisfaction after hip and knee replacement surgery: fast-track experience in 712 patients." Acta orthopaedica 79.2 (2008): 168-173.

3. Holm, Bente, et al. "Loss of knee-extension strength is related to knee swelling after total knee arthroplasty." Archives of physical medicine and rehabilitation 91.11 (2010): 1770-1776.

4. Kehlet, Henrik, and Douglas W. Wilmore. "Evidence-based surgical care and the evolution of fast-track surgery." Annals of surgery 248.2 (2008): 189-198.

5. Kehlet, Henrik, and Jørgen B. Dahl. "Anaesthesia, surgery, and challenges in postoperative recovery." The Lancet 362.9399 (2003): 1921-1928.

6. Wu, Christopher L., et al. "Correlation of postoperative pain to quality of recovery in the immediate postoperative period." Regional anesthesia and pain medicine 30.6 (2005): 516-522.

7. Jans, Øivind, et al. "Role of preoperative anemia for risk of transfusion and postoperative morbidity in fast-track hip and knee arthroplasty." Transfusion 54.3 (2014): 717-726.

8. Wilmore, Douglas W., and Henrik Kehlet. "Recent advances: Management of patients in fast track surgery.” BMJ: British Medical Journal 322.7284 (2001): 473.

9. Kehlet, Henrik, and Emmanuel Thienpont. "Fast-track knee arthroplasty-status and future challenges." The Knee 20 (2013): S29-S33.

10. Kehlet, Henrik, and Kjeld Søballe. "Fast-track hip and knee replacement-what are the issues?." Acta orthopaedica 81.3 (2010): 271-272.

11. White, Paul F., et al. "The role of the anesthesiologist in fast-track surgery: from multimodal analgesia to perioperative medical care." Anesthesia \& Analgesia 104.6 (2007): 1380-1396. 
12. Culler, Steven D., Greg M. Martin, and Alyssa Swearingen. "Comparison of adverse events rates and hospital cost between customized individually made implants and standard off-the-shelf implants for total knee arthroplasty." Arthroplasty Today (2017).

13. Schwarzkopf, Ran, et al. "Surgical and functional outcomes in patients undergoing total knee replacement with patient-specific implants compared with "off-the-shelf" implants." Orthopaedic journal of sports medicine 3.7 (2015): 2325967115590379.

14. Bozic, Kevin J., et al. "Predictors of discharge to an inpatient extended care facility after total hip or knee arthroplasty." The Journal of arthroplasty 21.6 (2006): 151-156.

15. Munin, Michael C., et al. "Predicting discharge outcome after elective hip and knee arthroplasty." American journal of physical medicine \& rehabilitation 74.4 (1995): 294-301.

16. Pablo, Paola de, et al. "Determinants of discharge destination following elective total hip replacement." Arthritis Care \& Research 51.6 (2004): 1009-1017.

17. Ramos, Nicholas L., et al. "Correlation between physician specific discharge costs, LOS, and 30-day readmission rates: an analysis of 1,831 cases." The Journal of arthroplasty 29.9 (2014): 1717-1722.

18. Barad, Steven J., Stephen M. Howell, and Joyce Tom. "Is a shortened length of stay and increased rate of discharge to home associated with a low readmission rate and cost-effectiveness after primary total knee arthroplasty?." Arthroplasty Today (2015).

19. Healy, William L., et al. "Impact of cost reduction programs on short-term patient outcome and hospital cost of total knee arthroplasty." JBJS 84.3 (2002): 348-353.

\section{SUBMISSION HISTORY}

Submitted: April 12, 2018

Reviewed: May 5, 2018

Revised: March 1, 2018

Accepted: March 8, 2019

Published: March 31, 2019

\section{AUTHOR AFFILIATIONS}

1 Richard Buch, MD; Rylie Buch; Robert Eberle Dallas Limb Restoration Center, Dallas, TX-USA

2 Lennart Schroeder

Department of Orthopaedic Surgery, Orthopädische Klinik König-Ludwig-Haus, Julius-Maximilians-University Würzburg, Würzburg, Germany

(Direct inquires to Lennart Schroeder, lennartschroeder@gmx.de)

\section{AUTHOR DISCLOSURES}

The authors declare that there are no disclosures regarding the publication of this paper.

\section{COPYRIGHT \& OPEN ACCESS}

(C) 2019 Buch, Schroeder, Buch, Eberle. All rights reserved.

Authors retain copyright and grant the journal right of first publication with the work. Reconstructive Review is an open access publication and follows the Creative Commons Attribution-NonCommercial CC BY-NC. This license allows anyone to download works, build upon the material, and share them with others for non-commercial purposes as long as they open 2 access credit the senior author, Reconstructive Review, and the Joint Implant Surgery \& Research Foundation (JISRF). An example credit would be: "Courtesy of (senior author's name), Reconstructive Review, JISRF, Chagrin Falls, Ohio".

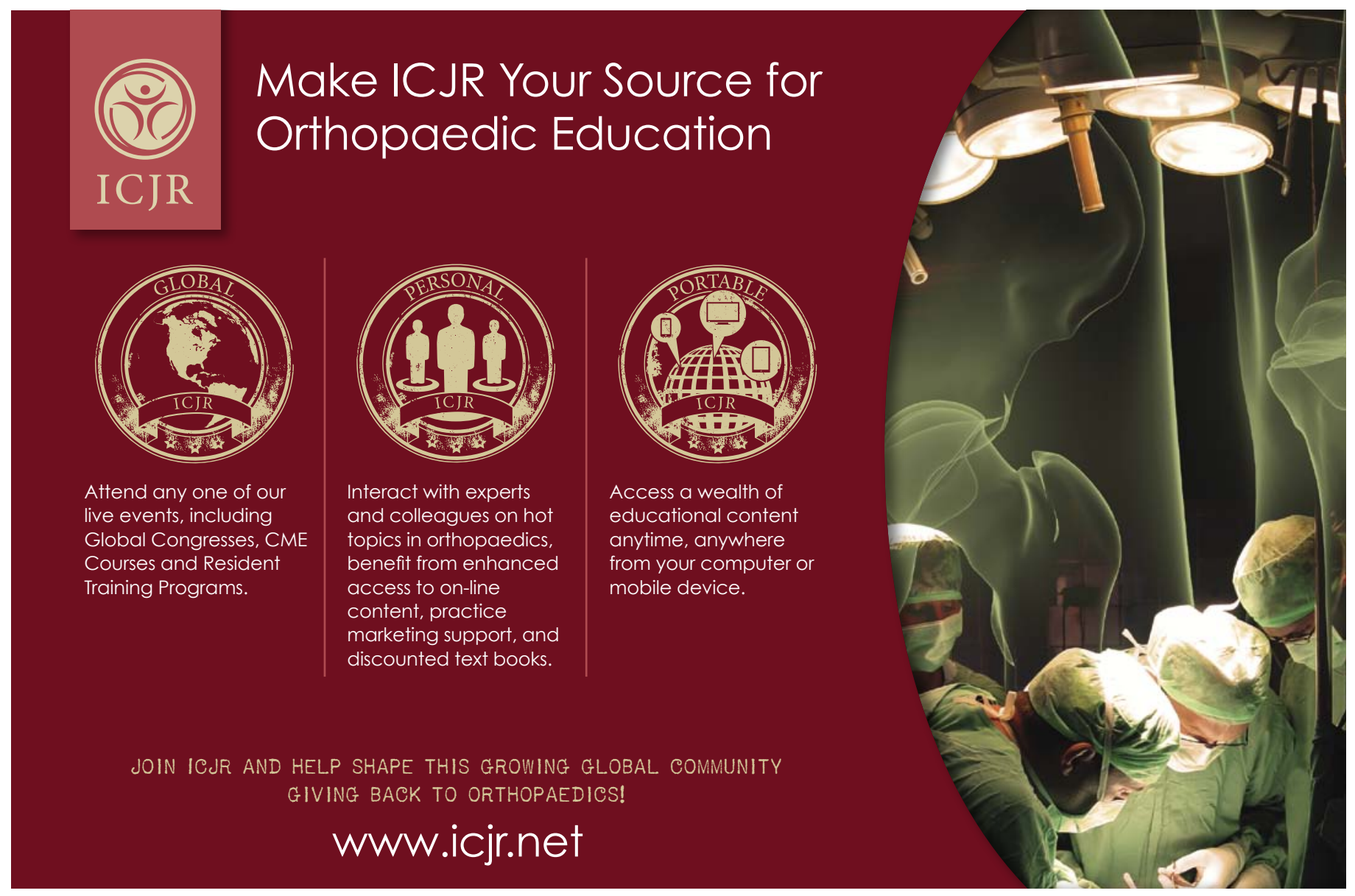




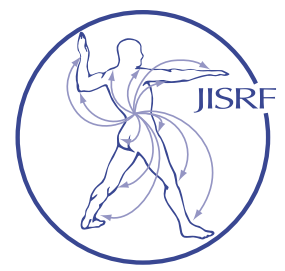

\section{Restoration of Femoral Condylar Anatomy for Achieving Optimum Functional Expectations: Continuation of an Earlier Study At 5-Year Minimum Follow-Up}

Durbhakula $S^{1}$, Durbhakula $V^{1}$, Durbhakula $N^{1}$

\section{Abstract}

Background: Studying and reporting the continuous, prospective outcomes of a post-surgical orthopaedic population without loss to follow-up at various standard landmarks over time is rarely achieved in total knee arthroplasty (TKA) literature. Small case series populations reported at an early follow-up time is common, and usually not beyond any initial publication for further reporting. The purpose of this study was to advance the knowledge base of the performance of Freedom Knee system through the continuous monitoring of a previously reported early series TKA patient population.

Methods: A prospective, continuous series of 176 primary posterior stabilized (PS) TKAs were performed in 172 patients by a single surgeon. Femoral component size distribution was assessed and all patients were followed for a minimum of five-years post-operatively. Total Hospital for Special Surgery (HSS) scores and range of motion (ROM) was assessed for the entire cohort and by gender.

Results: There were no patients lost to follow-up. Two patients required early post-operative incision and drainage for superficial wound infection of the indicated knees. One patient required tibial component and polyethylene insert revision following a motor vehicle accident resulting in a proximal tibial fracture and component loosening. There was no radiographic evidence of component failure. As expected, femoral component size frequency use was skewed by gender with the larger sizes in males. There were no pre- or post-operative clinical or functional differences by gender and at the recent follow-up (avg. 6.9 years). In addition, there was an average significant increase in change of HSS score $(\mathrm{p}<0.001)$ and ROM $(\mathrm{P}<0.001)$ when compared to pre-operative baseline but no significant difference in HSS or ROM between the two and five-year outcome results.

Conclusions: The design characteristic for component sizing and functional expectations were re-confirmed in the reported Western population cohort series, and observed optimum safety, performance and efficacy through five-years. Further continued study efforts of this primary TKA system is warranted across multiple surgeons and all ethnic cultures.

\section{Background}

Studying and reporting the continuous, prospective outcomes of a post-surgical orthopaedic population without loss to follow-up at various standard landmarks over time is rarely achieved in total knee arthroplasty (TKA) literature. $[1,2]$ Small case series populations reported at an

Keywords: total knee; condylar anatomy

Level of Evidence: AAOS Therapeutic Level III 
early follow-up time is common, and usually not beyond any initial publication for further reporting. [3, 4 ] Equally common is reporting the "average time to follow-up" across a large range of time post-operatively. $[4,5]$ There exists a number of well known reasons for discontinuing review of an initial population including lack of interest due to removal of the original component offering, changes in component design, new competitive product offerings, change in surgeon / corporate alliance, and surgical practice growth reducing the ability to track all patients.

Of the few long-term continuous reports, the publication series on the cemented Total Condylar prosthesis (Johnson \& Johnson, New Brunswick, NJ; Howmedica, Rutherford, NJ) spans 20 years, $[\underline{1}, \underline{6}-\underline{8}]$ and the Press-Fit Condylar (DePuy Orthopaedics, Warsaw, IN) has been reported through 25 years. [9] The authors have followed the long-term results of their respective original populations through various post-operative landmarks that yielded multiple intermediate publications. [10-14] In all, these study series have revealed successful "performance and reliability of a surgical procedure", the long-term durability of the prosthetic composite and has set benchmarks by which other component series are studied and understanding on the longevity and outcome of these devices and patient population.

The design concept and early results of 176 MAXX Freedom Total Knee ${ }^{\circledR}$ system TKA patients, with a minimum follow-up at 2-years, have been previously published. [15] In an effort to advance the knowledge of the prospective results of the Freedom TKA system, the original patient population identified in the previously published study was monitored through their 5-year followup landmark. The purpose of this study was to advance the knowledge base of the performance of Freedom Knee system through the continuous monitoring of a previously reported early series TKA patient population.

\section{Materials and Methods}

As was previous reported at the two-year post-operative follow-up, between November 2010 and December 2013, the senior author performed 176 consecutive primary TKAs in 172 patients, without selection, utilizing the posterior stabilized (PS) Freedom Total Knee ${ }^{\circledR}$ system (MAXX Orthopedics, Inc., Norristown, Pennsylvania) (Figure 1). [15] The Freedom Total Knee system is manufactured from cast cobalt chromium (ASTM F-75 CoCrMo), and the articular bearing surfaces use ram-extruded UHMWPE (GUR 1020). The Freedom Total Knee system was also designed with the intent to address bone conser-
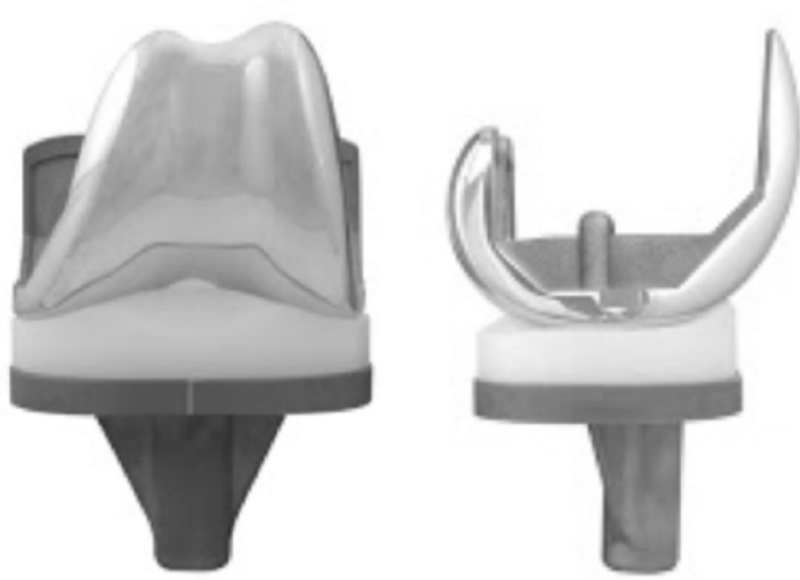

Figure 1. Anterior-Postetior and Lateral views of the Posterior Stabilized (PS) Freedom Total Knee ${ }^{\circledR}$ system (MAXX Orthopedics, Inc., Norristown, Pennsylvania).

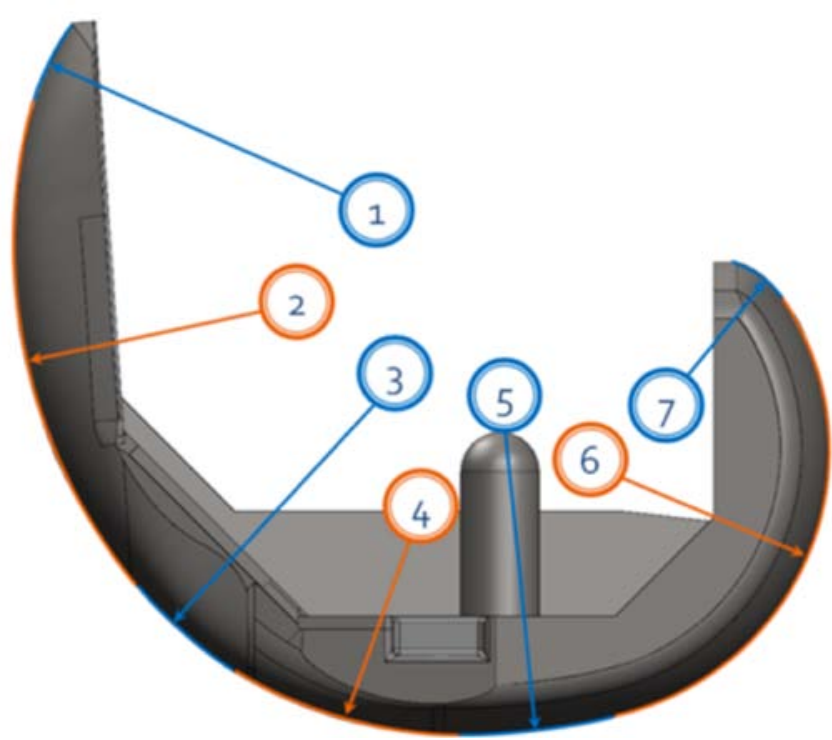

Figure 2. Multi-radius design of the Freedom Knee in which seven tangential radii were incorporated to accommodate changes in rollback across the available surface through the transition from walking through deep flexion. Radii 1, 2 and 3 manage patellofemoral contact, and radii 4, 5, 6 and 7 control femoral rollback and flexion.

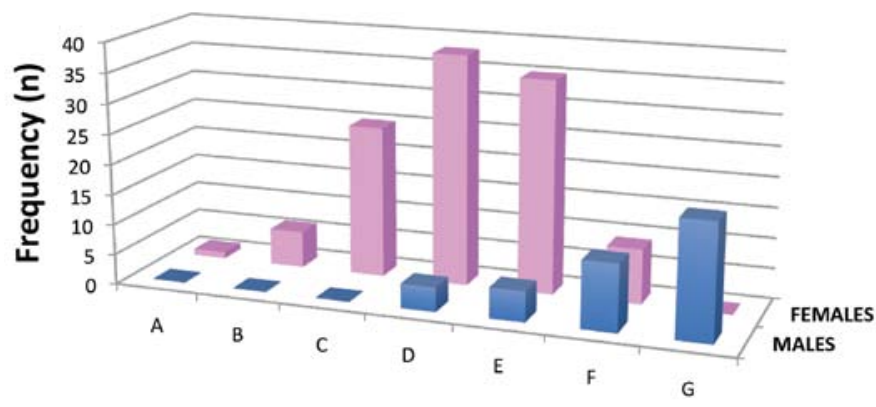

Femoral Component Size

Figure 3. Distribution of component size by gender. 
vation while permitting optimal high-flexion motion up to 155 degrees, dependent on the patient's anatomy and cultural activities of daily living, such as frequent and prolonged squatting and kneeling. To achieve high-flexion, the femoral component was engineered utilizing a multiradius design in which seven tangential radii were incorporated to accommodate changes in rollback across the available surface through the transition from walking through deep flexion (Figure 2). In addition, development of femoral component sizing was optimized to include the anthropomorphic dimensions of Western and Pan-Asian patient populations.

Of the 172 patients studied, there were 129 females (75.0\%) and 43 males (25.0\%) with an average patient age at surgery of $69.7 \pm 7.6$ years (range: 52.3 years to 98.6 years). The average age of the female patient (69.3 years) when compared to the male patients (70.7 years) was not significantly different $(\mathrm{p}=0.311)$. (Table 1$)$ In this continuous series, four female patients underwent bilateral TKA under the same anesthesia. In this set of patients, the pre-operative diagnosis was predominately degenerative joint disease (DJD) in 170 knees $(96.6 \%)$ and rheumatoid arthritis (RA) in 6 knees (3.4\%). The surgical side was evenly distributed across all patients with 86 left $(48.9 \%)$ and 90 right $(51.1 \%)$ knees (Table 1). In all cases the deep-vein thrombosis (DVT) prophylaxis was Lovenox ${ }^{\circledR}$ (SanofiAventis, Bridgewater, NJ).

\section{Results}

All 172 originally studied patients had a post-operative minimum follow-up of 5-years with an average time to follow-up of $6.5 \pm 0.9$ years (range: 5.0 years to 8.1 years). Overall, the pre-operative Hospital for Special Surgery (HSS) score was $49.2 \pm 5.7$ (range: 40.0 to 65.0 ), which significantly improved to a 2-year follow-up average of 88.4 \pm 3.6 (range: 80.0 to 95.0$)(\mathrm{p}<0.001)$ and remained statistically identical a 5-year follow-up average of $88.8 \pm 3.4$ (range: 80.0 to 95.0$)(\mathrm{p}<0.001$ Table 2$)$. As observed with the HSS at 2-years minimum follow-up, there was no statistical difference in pre-operative $(\mathrm{p}=0.208), 2$-years postoperative $(\mathrm{p}=0.939), 5$-years post-operative $(\mathrm{p}=0.366)$ or any difference between 2 - and 5-years $(\mathrm{p}=0.505)$ by gender for HSS.

Functionally, the pre-operative range of motion (ROM) was $113.8 \pm 6.1$ degrees (range: 95 degrees to 125 degrees), which significantly improved at the 2-year mini-
Table 1. Patient Demographics - there was no statistical difference in patient age at $p=0.311$. Also, there were 172 patients with 176 TKAs (4 bilateral cases).

\begin{tabular}{|l|l|l|l|}
\hline & $\mathbf{n}$ & Males & Females \\
\hline Total Patients & $172(100 \%)$ & $43(25.0 \%)$ & $129(75.0 \%)$ \\
\hline Average Age & $69.7 \pm 7.9$ years & $70.7 \pm 7.3$ years & $69.3 \pm 7.7$ years \\
\hline Side & $\mathrm{R}=86(48.9 \%)$ & $\mathrm{R}=21(51.2 \%)$ & $\mathrm{R}=86(48.1 \%)$ \\
$\mathrm{L}=90(51.1 \%)$ & $\mathrm{L}=22(48.8 \%)$ & $\mathrm{L}=67(48.1 \%)$ \\
\hline $\begin{array}{l}\text { Pre- } \\
\text { Operative } \\
\text { Diagnoses }\end{array}$ & & & \\
\hline DJD & $170(96.6 \%)$ & $43(100.0 \%)$ & $123(95.0 \%)$ \\
\hline RA & $6(3.4 \%)$ & $0(0.0 \%)$ & $6(5.0 \%)$ \\
\hline
\end{tabular}

Table 2. Independent of gender, changes in HSS and ROM from pre- to either postoperative follow-up landmarks were statistically significant $(p<0.001)$. There was pre-operative or post-operative HSS or ROM.

\begin{tabular}{|l|l|l|l|}
\hline & Total Population & Males & Females \\
\hline Avg Follow-Up & $6.5 \pm 0.9$ years & $6.3 \pm 1.1$ years & $6.7 \pm 0.9$ years \\
\hline HSS Score & & & \\
\hline Pre-Operative & $49.2 \pm 5.7$ & $48.3 \pm 5.6$ & $49.5 \pm 5.7$ \\
\hline 2-Years Follow-Up & $88.4 \pm 3.6^{*}$ & $88.4 \pm 4.2^{*}$ & $88.4 \pm 3.4^{*}$ \\
\hline 5-Years Follow-Up & $88.8 \pm 3.4^{*} \#$ & $89.2 \pm 2.9^{* \#}$ & $88.6 \pm 3.5^{* \#}$ \\
\hline Range of Motion & & & \\
\hline Pre-Operative & $113.8 \pm 6.1$ & $114.3 \pm 6.0$ & $113.7 \pm 6.2$ \\
\hline 2-Years Follow-Up & $128.5 \pm 4.1^{*}$ & $128.3 \pm 3.8^{*}$ & $128.5 \pm 4.3^{*}$ \\
\hline 5-Years Follow-Up & $128.7 \pm 4.1^{* \#}$ & $128.6 \pm 3.7^{* \#}$ & $128.7 \pm 4.3^{* \#}$ \\
\hline
\end{tabular}

* Statistically significant difference from baseline at $\mathrm{p}<0.001$

\# No statistical difference between 2-year and 5-year follow-up results

mum follow-up ROM of $128.5 \pm 4.3$ degrees (range: 110 degrees to 140 degrees) to an average 5-year post-operative ROM of $128.7 \pm 4.1$ degrees (range: 115 degrees to 140 degrees). The change in ROM was statistically significant at $\mathrm{p}<0.001$. There was no statistical difference in pre-operative $(\mathrm{p}=0.566)$, two-years $(\mathrm{p}=0.702)$ or five-years $(\mathrm{p}=0.913)$ in ROM by gender. All pre- and post-operative HSS and ROM data is summarized in Table 2. There was no radiographic evidence of aseptic component loosening or osteolysis (Figures 4A-4C).

As was previously reported, two patients $(1.1 \%)$ required subsequent incision and drainage surgery for superficial wound infections. Following these procedures both patients went on to successful clinical and functional outcomes through two and five-years post-operatively. No other patient had any subsequent infection through fiveyears. However, at 4.5-years post-index TKA, one female patient $(<1 \%)$ with a previously well-functioning, Free- 


\section{FIGURES $4 A-C$}
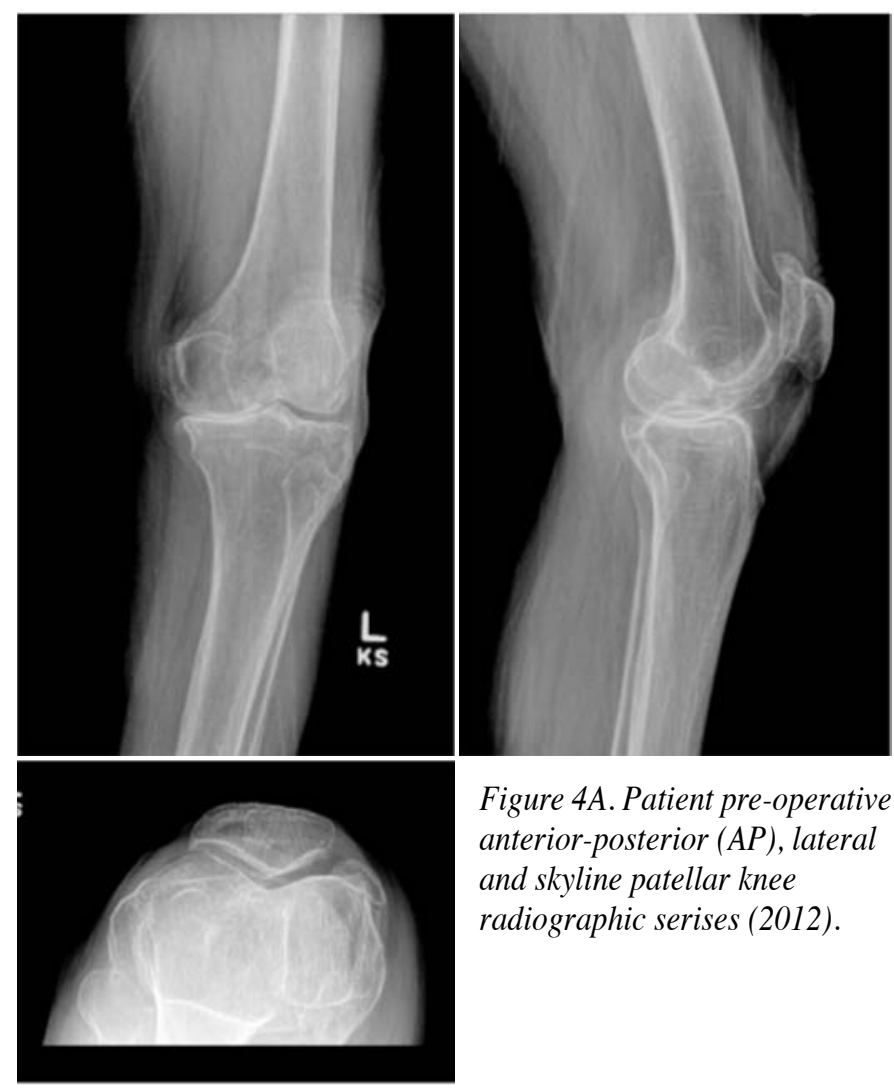

Figure 4A. Patient pre-operative anterior-posterior $(A P)$, lateral and skyline patellar knee radiographic serises (2012).
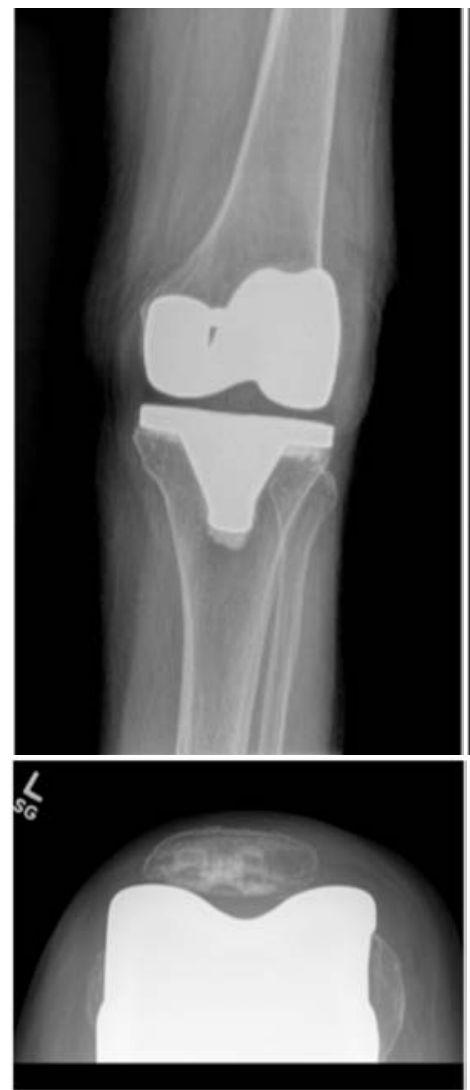

Figure 4B. 2-year minimum follow-up series (2015) after primary TKA with the MAXX Freedom Knee System.
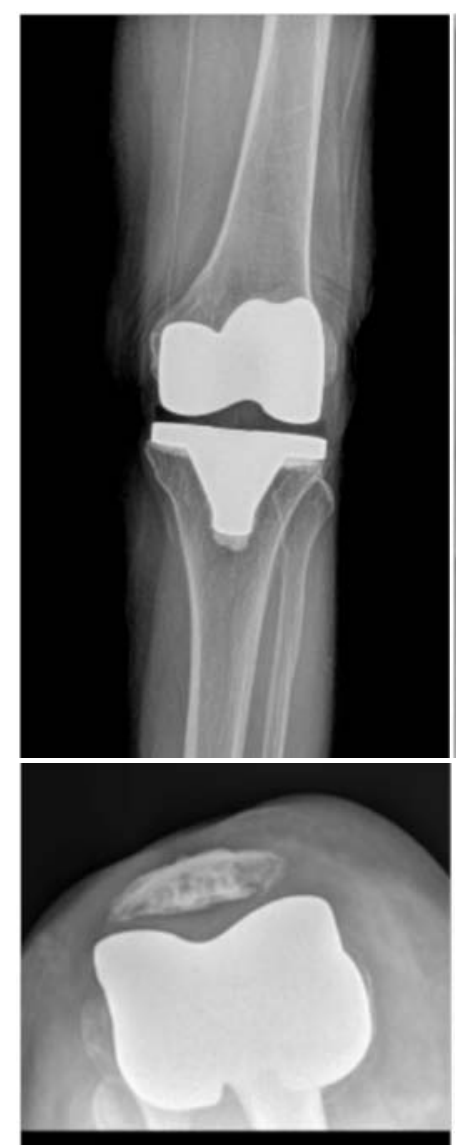

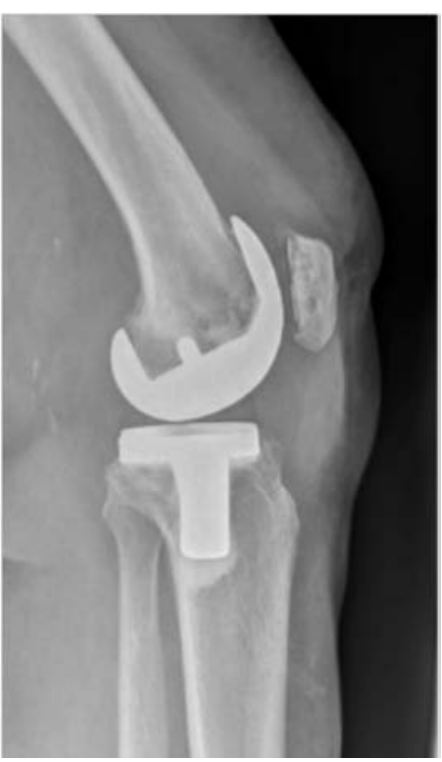

Figure 4C. 5-year minimum AP radiographic follow-up (2018) after primary TKA with the MAXX Freedom Knee System. dom Total Knee system prosthesis was involved in a motor-vehicle accident (MVA) that resulted in chronic pain and decrease of function involving the left proximal tibia. There was radiographic evidence of a proximal tibial stress fracture and tibial component loosening which were confirmed at the time of tibial component revision. Only the index tibial component and polyethylene insert were removed and a cemented MAXX Freedom ${ }^{\circledR}$ Knee Revision tibial baseplate (MAXX Orthopedics, Inc., Plymouth Meeting, Pennsylvania) with an extended tibial stem and PS polyethylene tibial insert were implanted without the use of any other adjunctive fixation hardware. The patient recovered without issue and at the most recent follow-up is well functioning without pain or ambulatory deficit.

\section{Discussion}

We report on the minimum five-year follow-up of a single surgeon, non-randomized, consecutive case series of patients that received the Freedom Total Knee system for primary TKA. This is the second prospective follow-up report of the original population previously published. [15] The results of this current follow-up show reveal continued optimum TKA performance without patient lost to followup, related complications, component failure or deterioration of the prosthetic composite. 
Continuous monitoring of total joint arthroplasty devices is of paramount importance including review of new technologies, materials and material combinations, and clinical relevance. Within the current healthcare budgetary climate and increasing healthcare costs, hospital systems are requiring increasing levels of device claims proof prior to approval and use. Currently, while the United States Food and Drug Administration (FDA) is the primary regulator of public health safety involving drugs and devices, there is no centralized technology assessment organization for technology and device monitoring. Therefore, various societies and associations have developed multiple voluntary registries that are beginning to yield published observations. [16-18] Unlike the existing international joint arthroplasty registries that are mandatory for all cases performed, voluntary participation in US domestic registries introduces a bias in the devices referenced and data collected. Prospective continuous case series studies can be used to generate information to use for publication, presentation or various hospital Value Added Technology (VAT) committees. The strategic use of large continuous patient study series may yield information that is meaningful for assessing component performance over time. Serial publications of the Total Condylar knee replacement revealed early issues with femoral component sizing, instrumentation and evolving design considerations from the original single pegged cemented patella. $[\underline{2}, \underline{10}, \underline{11}, \underline{13}]$ These items are of common knowledge today yet were not known upon the early design releases until tried and monitored. Intermediate studies have shown results for component design, patient morphology and surgical technique with and without navigation. $[\underline{6}, \underline{14}, \underline{19}-\underline{22}]$ Our results have shown favorable restoration of femoral condylar anatomy and restoration of continuous normal knee function through two and five-years in the same study population.

From our patient monitoring efforts with this study we had one patient that required revision of the tibial component following an MVA 4.5 years post-operatively. At the time of revision surgery, use of the MAXX Freedom Knee Revision tibial component was used which allowed for retention of the well-fixed and functioning index primary femoral component. The MAXX Freedom Knee Revision tibial component is engineered to be bone conserving and allows for the use of the available MAXX modular polyethylene inserts independent of femoral component constraint. This avoided the risks that are associated with prolonged surgery that would have most likely occurred with any attempt to remove the well-fixed femoral component and reimplantation of an entire revision TKA system. In addition, the multiple straight or offset stem options are available dependent on the patient's available tibial anato- my. In this specific case, a stem was required to bypass the proximal tibial fracture. There were no other patients presenting with clinical or radiographic evidence of adverse events or component failure.

As was identified in the earlier publication, this single surgeon, non-randomized consecutive case series had an imbalance of patients by gender (females $n=129$, males $n=43$ ). [15] However, other than femoral component size usage, the measured clinical outcomes were not statistically different when comparing by gender. In this population Lovenox ${ }^{\circledR}$ (Sanofi-Aventis, Bridgewater, NJ, USA) was used in all patients as their DVT prophylaxis, which has been changed to aspirin due to current results in the literature. Also, the patients included were of a Western ancestry population, so no comparative assessments to Middle-Eastern or Pan-Asian populations were available. However, efforts are being made to capture a similar study data across various ancestral populations for comparative review with the currently presented study group.

In conclusion, the reported study of patients receiving the Freedom Total Knee system for primary TKA support the design considerations for anthropomorphic considerations while achieving an increased degree of ROM while minimizing bone resection. The study included a large cohort $(n=172)$ of continuous non-selected series of patients without loss to follow-up for any reason through 5-years. In a cooperative effort between the author and the company, every effort will be made to continue study of this study population through the next follow-up landmark. From these results we believe that continued use and study is warranted to confirm achieving similar results across surgeons and to further study multiple ancestral populations.

\section{Acknowledgment}

The authors wish to thank Robert Eberle for his assistance with the preparation of this manuscript.

\section{References}

1. Rodriguez, J.A., H. Bhende, and C.S. Ranawat, Total condylar knee replacement: a 20-year followup study. Clin Orthop Relat Res, 2001(388): p. 10-7.

2. Rasquinha, V.J., et al., The press-fit condylar modular total knee system with a posterior cruciate-substituting design. A concise follow-up of a previous report. J Bone Joint Surg Am, 2006. 88(5): p. 1006-10.

3. Lonner, J.H., et al., Total knee arthroplasty in patients 40 years of age and younger with osteoarthritis. Clin Orthop Relat Res, 2000(380): p. 85-90.

4. Chon, J.G., A.V. Lombardi, Jr., and K.R. Berend, Hybrid stem fixation in revision total knee arthroplasty (TKA). Surg Technol Int, 2004. 12: p. 214-20.

5. Levitsky, K.A., et al., Total knee arthroplasty without patellar resurfacing. Clinical outcomes and long-term follow-up evaluation. Clin Orthop Relat Res, 1993(286): p. 116-21.

6. Insall, J., et al., Total condylar knee replacment: preliminary report. Clin Orthop Relat Res, 1976(120): p. 149-54.

7. Ranawat, C.S. and O. Boachie-Adjei, Survivorship analysis and results of total condylar knee arthroplasty. Eight- to 11-year follow-up period. Clin Orthop Relat Res, 1988(226): p. 6-13. 
8. Ranawat, C.S., et al., Long-term results of the total condylar knee arthroplasty. A 15-year survivorship study. Clin Orthop Relat Res, 1993(286): p. 94-102.

9. Patil, S., et al., How do knee implants perform past the second decade? Nineteento 25-year followup of the Press-fit Condylar design TKA. Clin Orthop Relat Res, 2015. 473(1): p. 135-40.

10. Walker, P.S., C. Ranawat, and J. Insall, Fixation of the tibial components of condylar replacement knee prostheses. J Biomech, 1976. 9(4): p. 269-75.

11. Ranawat, C.S., H.A. Rose, and W.J. Bryan, Replacement of the patello-femoral joint with the total condylar knee arthroplasty. Int Orthop, 1984. 8(1): p. 61-5.

12. Ranawat, C.S., H.A. Rose, and D.S. Rich, Total condylar knee arthroplasty for valgus and combined valgus-flexion deformity of the knee. Instr Course Lect, 1984. 33: p. 412-6.

13. Ranawat, C.S., The patellofemoral joint in total condylar knee arthroplasty. Pros and cons based on five- to ten-year follow-up observations. Clin Orthop Relat Res, 1986(205): p. 93-9.

14. Ranawat, C.S., W.F. Flynn, Jr., and R.G. Deshmukh, Impact of modern technique on long-term results of total condylar knee arthroplasty. Clin Orthop Relat Res, 1994(309): p. 131-5.

15. Durbhakula, S.R., L., Restoration of femoral condylar anatomy for achieving optimum functional expectations: Component design and early results. Reconstructive Review, 2016. 6(September): p. 5.

16. Ayers, D.C., et al., Using joint registry data from FORCE-TJR to improve the accuracy of risk-adjustment prediction models for thirty-day readmission after total hip replacement and total knee replacement. J Bone Joint Surg Am, 2015. 97(8): p. 668-71.

17. Etkin, C.D. and B.D. Springer, The American Joint Replacement Registry-the first 5 years. Arthroplast Today, 2017.3(2): p. 67-69.

18. Heckmann, N., et al., Early Results From the American Joint Replacement Registry: A Comparison With Other National Registries. J Arthroplasty, 2019.

19. Vaidya, S.V., et al., Anthropometric measurements to design total knee prostheses for the Indian population. J Arthroplasty, 2000. 15(1): p. 79-85.

20. Uehara, K., et al., Anthropometry of the proximal tibia to design a total knee prosthesis for the Japanese population. J Arthroplasty, 2002. 17(8): p. 1028-32.

21. Rosenstein, A.D., et al., Gender differences in the distal femur dimensions and variation patterns in relation to TKA component sizing. Orthopedics, 2008. 31(7): p. 652 .

22. Matsumoto, T., et al., Differing prosthetic alignment and femoral component sizing between 2 computer-assisted CT-free navigation systems in TKA. Orthopedics, 2011.34(12): p. e860-5
SUBMISSION HISTORY

Submitted: March 11, 2019

Reviewed: March 16, 2019

Accepted: March 16, 2019

Published: March 31, 2019

\section{AUTHOR AFFILIATIONS}

1 Sridhar Durbhakula, M.D., Vinay S. Durbhakula, Navin S. Durbhakula Washington Joint Institute at OrthoBethesda, The Camalier Building, 10215 Fernwood Road; Suite 502, Bethesda, MD 20817

(Direct inquires to Sridhar Durbhakula, sdurbhak@gmail.com)

\section{AUTHOR DISCLOSURES}

Sridhar Durbhakula declairs either family, institution I am associated with, or I have received benefits or funds either directly or indirectly regarding this article. All other authors declare that there are no disclosures regarding the publication of this paper.

\section{COPYRIGHT \& OPEN ACCESS}

(c) 2019 Durbhakula S, Durbhakula V, Durbhakula N. All rights reserved. Authors retain copyright and grant the journal right of first publication with the work. Reconstructive Review is an open access publication and follows the Creative Commons Attribution-NonCommercial CC BY-NC. This license allows anyone to download works, build upon the material, and share them with others for non-commercial purposes as long as they credit the senior author, Reconstructive Review, and the Joint Implant Surgery \& Research Foundation (JISRF). An example credit would be: "Courtesy of (senior author's name), Reconstructive Review, JISRF, Chagrin Falls, Ohio". 

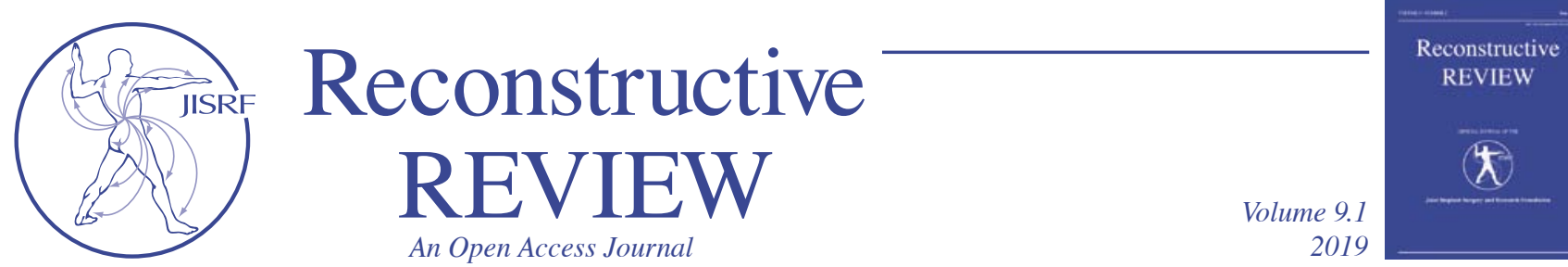

Check for updates

\section{Techniques of Insertion and Early Clinical Impressions with a Short Curved Tissue Sparing Implant for Total Hip Arthroplasty (The French Experience)}

Venet $G^{1}$, Tesson $A^{1}$, Le Cour Grandmaison $F^{1}$, Fraquet $N^{1}$, Brazil $D^{2}$, McTighe $T^{3}$

\section{Abstract}

Background: Total hip arthroplasty (THA) is one of the most effective orthopedic procedures, providing consistently high success rates across all population segments as measured by pain relief, improved function, and patient satisfaction. However clinical outcomes have been less favorable in young active patients, that lead to the re-development of metal on metal hip resurfacing (HR), with the most successful being the Birmingham Hip Replacement (BHR) introduced in 1997. Evolving complications due to increased metal ion debris has lead to a great reduction of use for all metal on metal (MOM) HR designs, leading many surgeons and patients to look for an alternative surgical selection. This search has focused on the development and use of short stems for THA. One such style of short stems is curved neck preserving designs. This paper will review our French experience with one of those designs.

Materials and Methods: This is a retrospective review of four surgeons series of a short curved tissue sparing cementless femoral implant (TSI ${ }^{\mathrm{TM}}$ Hip Stem, Signature Orthopaedics) for THA. The femoral component was used with two different cementless acetabular styles (Mathys RM Pressfit, and Zimmer Biomet Allofit ${ }^{\circledR}$ ). Results on the cups will not be revived in this paper. $150 \mathrm{TSI}^{\mathrm{TM}}$ Stems by four surgeons at the same institution utilizing the posterior surgical approach since September 2016. 40\% women, average age 66 years with extremes of 27 to 78 years. 10 cases of dysplastic hips, 6 cases of aseptic osteonecrosis, 1 fracture, 1 rheumatoid coxitis, and the rest primary coxathosis, with 7 patients operated on both hips at the same time. $23.3 \%$ have been Dorr type A canal shape.

Results: There has been no aseptic loosing, three femoral components have been explanted due to postoperative infection. There was one intra-operative femoral distal fracture in a Dorr type A bone profile during stem insertion. One posterior dislocation; there has been two patients with thigh pain with pathological bone scan, and one with low back pain and no leg length discrepancies greater than plus or minus $5 \mathrm{~mm}$.

Conclusion: This short curved tissue sparing implant has demonstrated excellent initial short-term results, with excellent implant stability, excellent medial calcar bone remodeling with one dislocated stem, two thigh pain and one patient with low back pain. One distal intra-operative fracture in a Dorr type A bone. This has now been addressed with the use of distal sizing gauges and the use of flexible reamers to open the distal canal prior to stem insertion. Removal of the infected stems demonstrated implant stability

Keywords: Tissue Sparing Implant; short curved neck preserving stem; total hip arthroplasty; bone remodeling Level of Evidence: AAOS Therapeutic Level II 
with early bone attachment in the proximal porous surface. The high neck resection allows for ease of revision and conversion implanting a new primary conventional length cementless stem design.

There is a short but definitive learning curve in fitting the implant to the femoral neck versus the standard metaphyseal and diaphyseal conventional style stems.

\section{Background}

Total hip arthroplasty (THA) is one of the most effective orthopedic procedures, providing consistently high success rates across all population segments as measured by pain relief, improved function, and patient satisfaction. [1] However, clinical outcomes have been less favorable in young active patients, $[\underline{2}, \underline{3}]$ which lead to the re-development of metal on metal hip resurfacing (HR), with the most successful being the Birmingham Hip Replacement (BHR) introduced in 1997. [4] Evolving complications due to increased metal ion debris has lead to a great reduction of use for all metal on metal (MOM) HR designs, leaving many surgeons and patients to look for an alternative surgical selection. [푸으, $\underline{7}]$

In the past ten years short stems and in particularly neck preserving stem designs have received a significant level of interest at continuing medical education (CME) meetings as a result of the decline of HR. $[\underline{8}, \underline{9}, \underline{10}]$

\section{Material and Methods}

This is a retrospective review of four surgeons series of a short curved tissue sparing cementless femoral implant (TSI $^{\text {TM }}$ Hip Stem, Signature Orthopaedics) for THA. The femoral component was used with two different cementless acetabular styles (Mathys RM Pressfit, and Zimmer Biomet Allofit $\left.{ }^{\circledR}\right)$. Results on the cups will not be revived in this paper.

$150 \mathrm{TSI}^{\mathrm{TM}}$ Stems by four surgeons at the same institution utilizing the posterior surgical approach since September $2016.40 \%$ women, average age 66 years with extremes of 27 to 78 years. 10 cases of dysplastic hips, 6 cases of aseptic osteonecrosis, 1 fracture, 1 rheumatoid coxitis, and the rest primary coxathosis, with 7 patients operated on both hips at the same time. $23.3 \%$ have been Dorr type A canal shape. Figure 1.

The TSI ${ }^{\mathrm{TM}}$ stem (Tissue Sparing Implant) is a short, anatomically curved stem designed to retain most of the patient's femoral neck. The implant sits in the patient's femoral neck, and curves anatomically down into the patient's
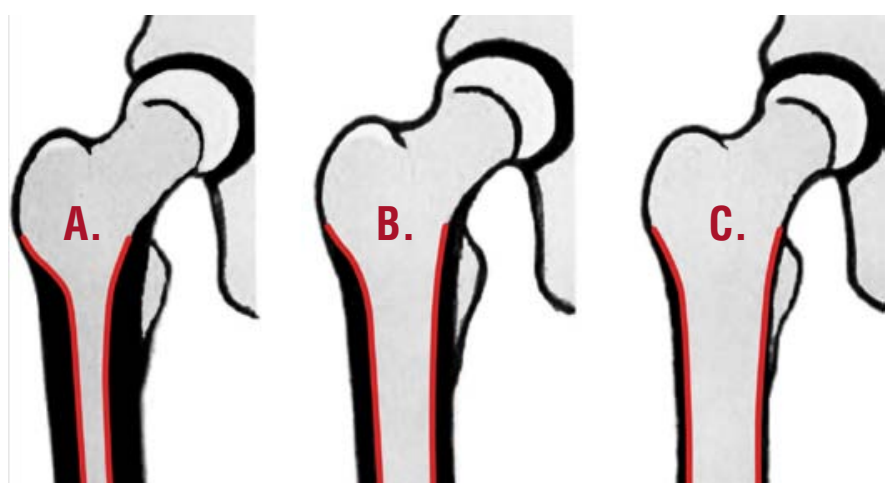

Figure 1. Illustration Dorr bone classification. Type A, narrow canal, $B$ normal canal, and $C$ wide canal.

proximal femoral canal, to maintain anatomical compressive loading of the retained bone. The stem is manufactured from Ti6Al4V alloy and is proximally coated with titanium plasma spray plus hydroxyapatite (HA) to promote bone attachment. The stem is distally polished and has a sagittal plane cutout to reduce distal hoop tension which has been shown to induce thigh pain [11]. Additionally, the stem has a gentle conical flare at the resection line to reduce subsidence and maintain compressive loads to the medial calcar. A lateral $\mathrm{T}$ back design enhances torsional stability reducing chances of aseptic loosening (Figures $2 \& 3$ ).

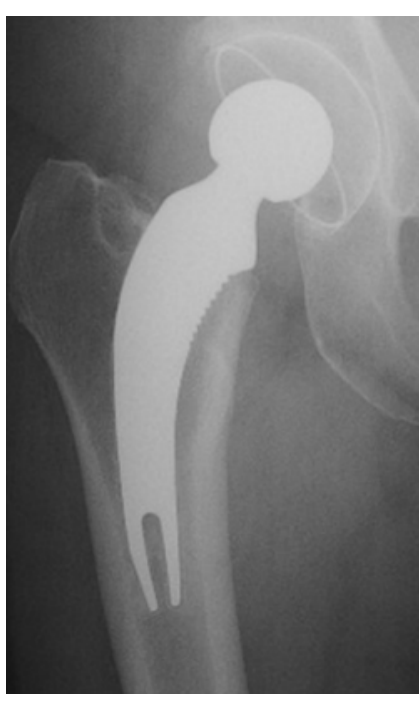

Figure 2. Post-op A/P view of TSI ${ }^{\text {TM }}$ stem and Mathys RM Pressfit Cup.

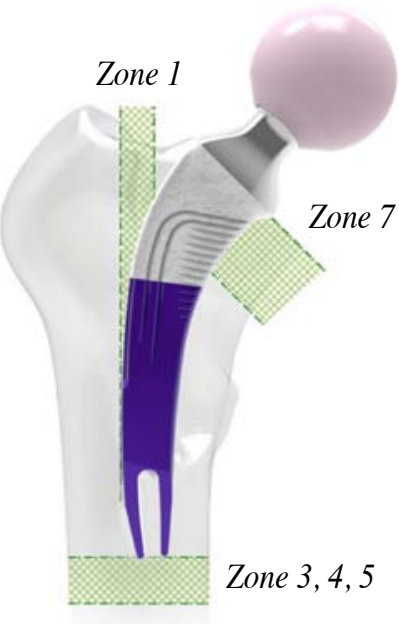

Figure 3. TSI Stem Illustration showing bone preservation in Gruen zones 1, 3, 4,5 \& 7
The simple yet novel short curved stem design reduces the need to go lateral into the trochanteric bed where you can increase damage to the musculature and cancellous bone resulting in increased blood loss. Six degrees of femoral neck anteversion is built into the TSI stem with one medial stem curve. Stem length and medial curve allow for more tissue preserving techniques for both soft and 
hard tissue without sacrificing implant stability. The internal proximal conical flair provides for a unique structure to enhance proximal compressive load transfer to the medial calcar resulting in less medial calcar resorption .

Technique Femoral Preparation. The first step is preoperative planning utilizing either plain radiographic templates or dedicated software. Both femoral neck resection and resection angle can be predetermined to ensure proper restoration of joint mechanics and stem position.

Preoperative templating is crucial to select the appropriate implant size and optimal neck shaft angle. Prosthetic templates show the implant in a true $\mathrm{A} / \mathrm{P}$ projection (approximately 20 degrees of internal rotation) while radiographs of arthritic hips may or may not represent a true A/P of the proximal femur and diaphysis because of positioning error and/or limited range of motion. If the hip is externally rotated, a position commonly seen in osteoarthrosis, the femoral neck appears shorter and more vertical $[\underline{11}, \underline{12}]$ (Figure 4).

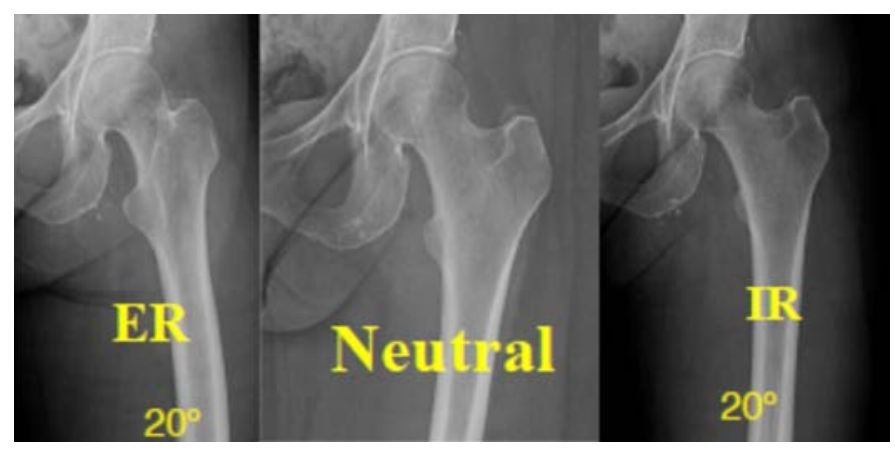

Figure 4. Radiographic views demonstrating external rotation of $20^{\circ}$, neutral and $20^{\circ}$ of internal rotation.

Lack of proper offset leads to soft tissue laxity as well as increased risk of impingement and dislocation.Templating is challenging even under the most optimal x-ray conditions since the surgeon is using two-dimensional $\mathrm{x}$-rays to assess a three-dimensional femoral head and neck. In the osteoarthritic patient the femoral head position tends to be in external rotation. Traditional radiographs taken with the foot perpendicular to the cassette underestimate offset due to the position of the femoral head with respect to the image beam. Studies have demonstrated as much as $7 \mathrm{~mm}$ can be underestimated in femoral offset in preoperative templating, especially in patients whose arthritis fixes the femur in external rotation $[\underline{11}, \underline{12}, \underline{13}]$ (Figures 5, 6).

The patient is in a decubitus lateral position with bottom and pubic support. The incision (about $8-10 \mathrm{~cm}$ ) is located on the greater trochanter's posterior part, centered at the top. The acetabular and external rotators approach is done just next to the greater trochanter and the intra-trochanteric line while dissecting the internal and external obturator muscle and the gastrocnemius muscles. Flexing the

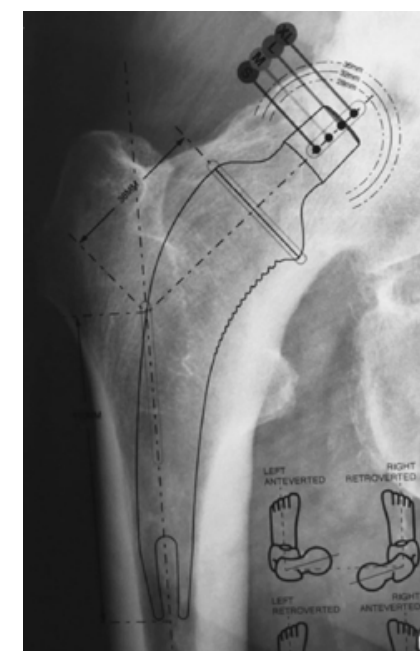

Figure 5. A/P X-ray template with femur in $20^{\circ}$ of external rotation.

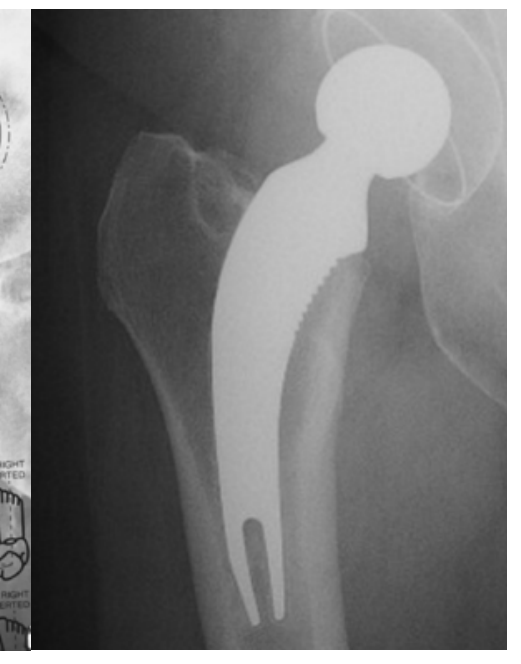

Figure 6. A/P Post-operative view with femur in $20^{\circ}$ of internal rotation.

hip and the knee, associated with an internal hip adduction rotation allows hip dislocation. The piroformis, and and the quadratus femoris muscle are preserved.

Using the postero-lateral approach to the hip, the superior one-half of the short external rotators are released from the posterior greater trochanter down to the base of the femoral neck. The capsule is preserved with transverse incisions made at the acetabular rim and the base of the femoral neck. A longitudinal capsular incision is made in between. This creates anterior and posterior capsular flaps that can be repaired at closure. Once the hip is dislocated, the femoral neck is resected 5 to $10 \mathrm{~mm}$ below the subcapital junction with a fine-toothed saw (Figure 7 ). The neck cut is based upon preoperative and intra-operative templating to restore head center of rotation. The neck sparing stem design and instrumentation is based upon following the native medial curvature of the proximal femoral neck (Figure 8).

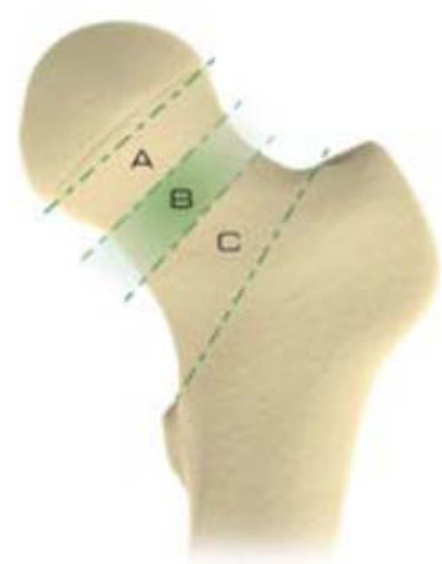

Figure 7. Illustration showing neck resection zones. Zone $B$ being $510 \mathrm{~mm}$ as recommendation.

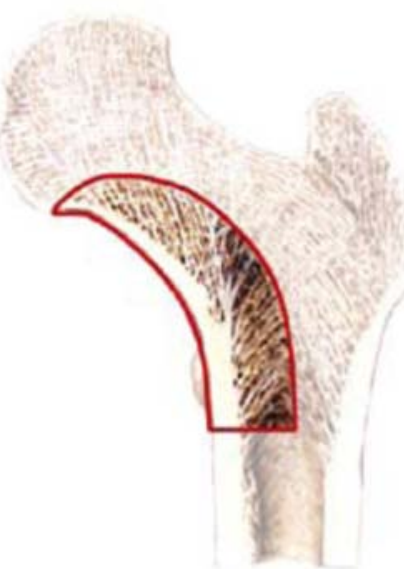

Figure 8. Illustration showing medial femoral curve. (Courtesy JISRF Archives) 
Neck resection angle is important in achieving optimal stem placement and proper biomechanical loading of compressive forces on the medial calcar. The use of a resection guide or trial stem as a cutting template is helpful ensuring the proper angle and level of neck resection (Figure 9). If the neck resection is too vertical the stem can be in valgus, if resection is too horizontal the stem can end up in varus.

Opening the femoral canal can be accomplished by a number of ways dependent on surgeon's preference. A curved curette, a curved metal sucker, a trocar drill or our preference is the curved canal finder supplied in the set of instruments (Figure 10).

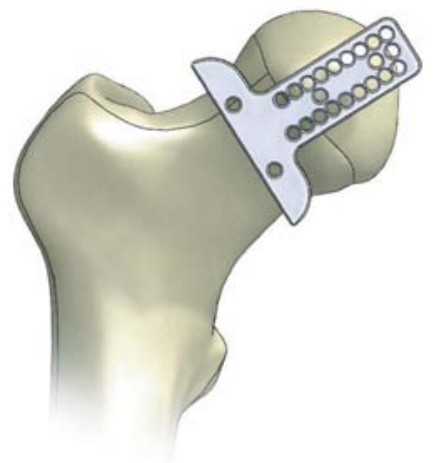

Figure 9. Align the resection guide with the femoral neck and determine the amount of femoral neck to be resected. Pin the guide into position and resect the head.

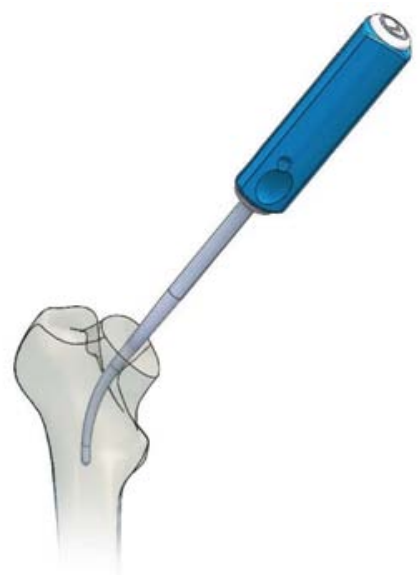

Figure 10. The curved canal finder aids in locating and following the femoral canal.

The femoral canal is then rasped with gentle force starting with the starter rasp with progression in sequence to the desired size fitting and filling the femoral neck. A canal sounder can be used to explore the distal size of the femur, and aid in determination of final stem sizing (Figures $11,12)$.

A trial reduction can be performed with the rasp in place by using the appropriate trial neck and head or by the use of the trial stem with a modular neck and head (Figures $13,14,15)$.

Trial stem can be extracted and the final definitive stem inserted with gentle force. Over impaction can result in fracturing the femoral neck (Figures 16, 17).

Trial heads can be used on the final definitive stem to determine proper leg length and joint stability (Figures 18, 19).

Note: Neck-sparing stems are at increased risk for mechanical impingement, especially with retained osteophytes attached to the femoral neck. Head neck assessing for boney impingement tested at end flexion with internal rotation as well as at end extension with external rotation.

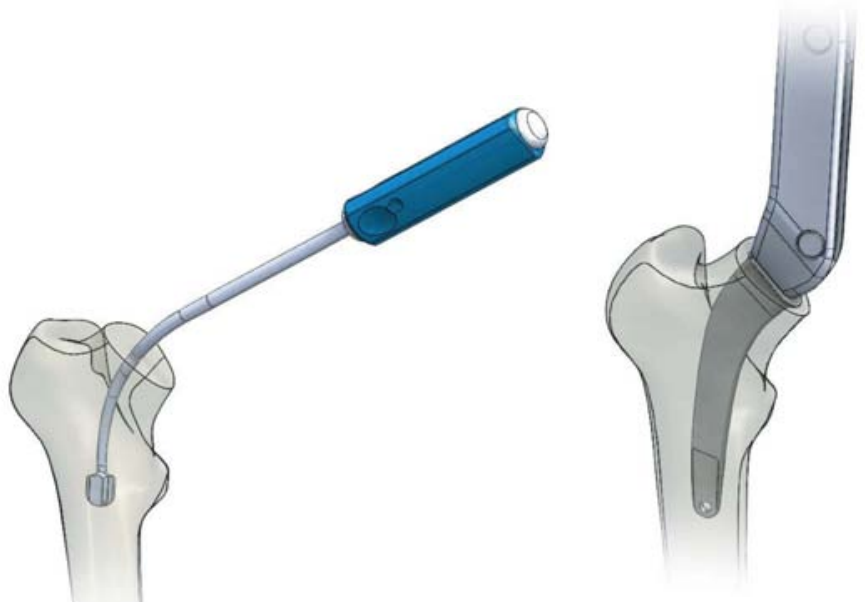

Figure 12. Rasps are

Figure 11. Illustration of completely seated when the top of the surface of the rasp canal sizing gauge. is flush with the resection line.

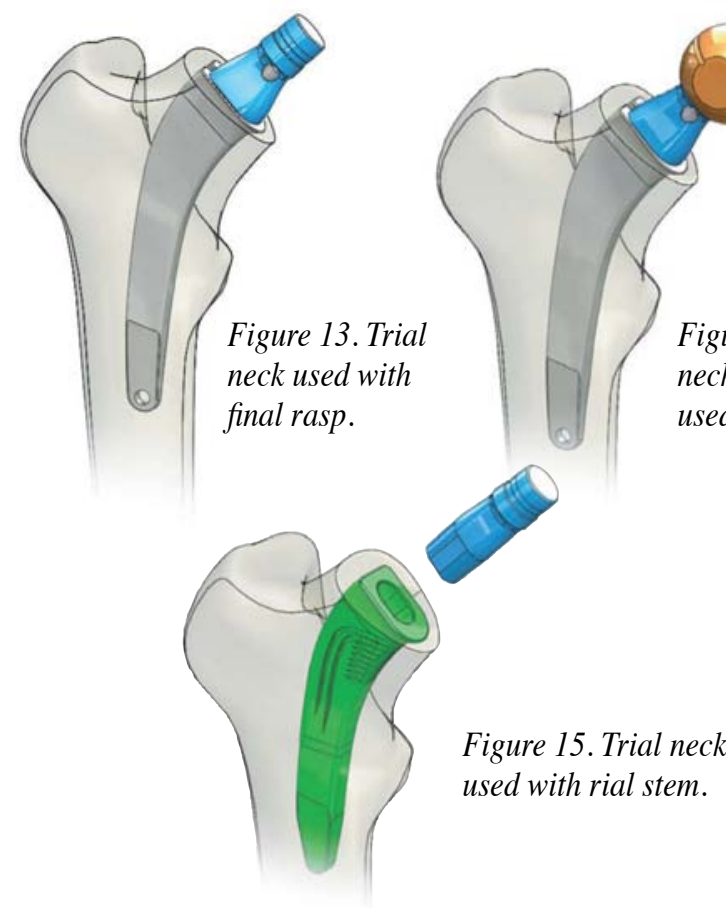

All impinging osteophytes and excess bone must be removed to maximize hip range without impingement and levering [14]. The use of head sizes of $32 \mathrm{~mm}$ or greater is recommended. Acetabuli that require a $28 \mathrm{~mm}$ head or smaller may be better treated with a dual mobility style cup design. 


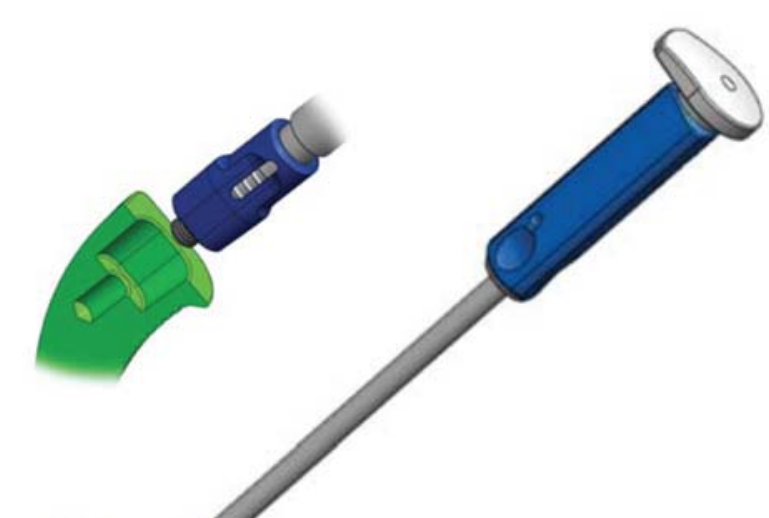

Figure 16. Trial extractor threads into the trial stem.
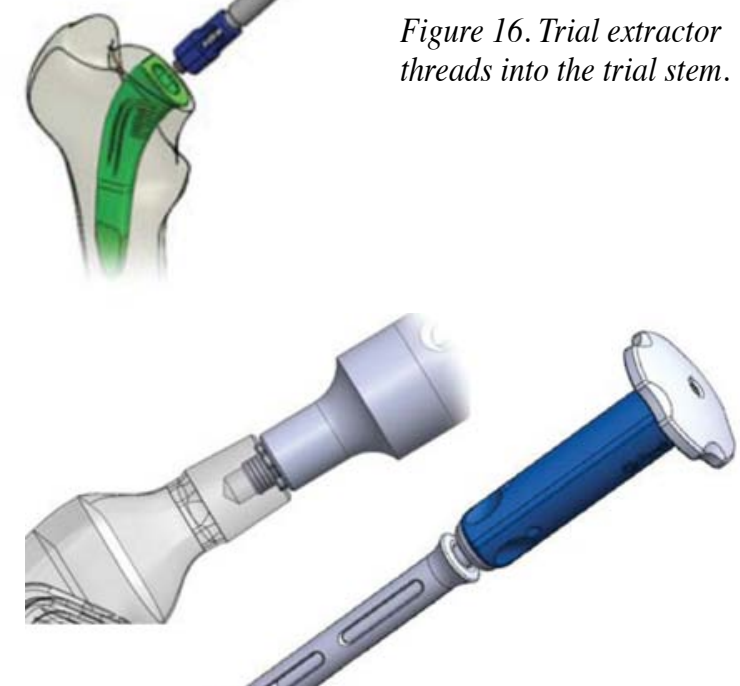

Figure 17. Stem inserter threads into the final implant.

Figure 18. Final head size is impacted onto the implanted stem.

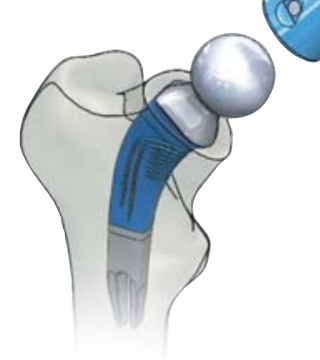

\section{Results}

There have been three femoral components explanted due to postoperative infection (Figure 20). There was one intra-operative femoral distal fracture in a Dorr type A

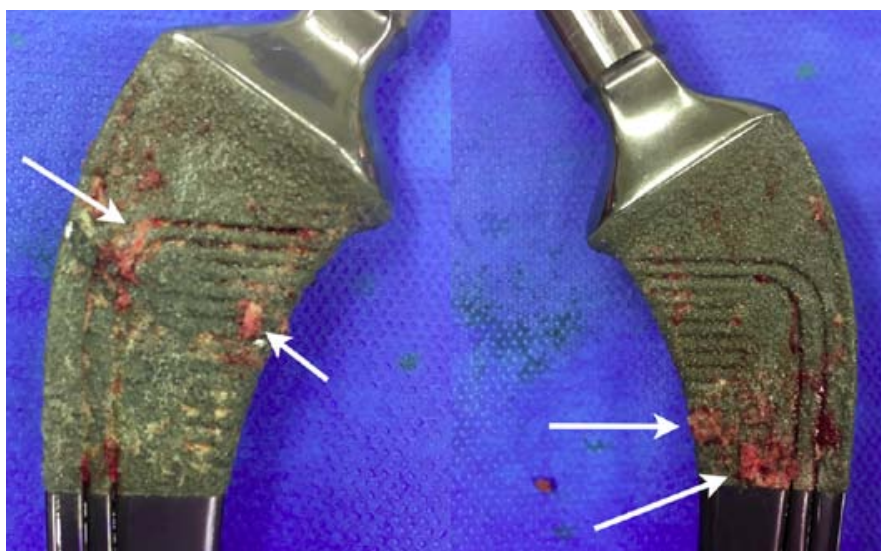

Figure 20. This stem was removed for infection at one month postoperatively was very stable with the beginning of good bone fixation through out the proximal porous coating.

bone profile during stem insertion. There one posterior dislocation; there has been two patients with thigh pain and one associated with low back pain. One patient with purely mechanical pain was very intense initially but diminished with time (1 year post-op). Now she has little discomfort and little functional limitation. At the distal lateral portion of the stem there is a lateral cortical hypertrophy without a real pedestal. This can happen if the distal lateral portion of the stem engages or wedges into the isthmus of the femoral canal. Pain reduces as the distal bone stiffens around the implant. For this reason we aim for a neutral stem position within the canal (Figures 21, 22, 23). Note the medial conical flair is slightly proud of the resection line so there is diminished proximal load transfer as seen with some mild medial bone remodeling. No leg length discrepancies greater than plus or minus $5 \mathrm{~mm}$. [14,15]

When the proximal conical flair is engaged with the medial calcar as seen in Figures 23, 24, and 25 the calcar is loaded in compressive forces and we see positive bone maintenance over the years. This is similar in radiographic results as seen and reported by van der Rijt at the European Hip Society and in 2012 Figure 26 with a similar neck sparing stem with a proximal conical flair. [16] 


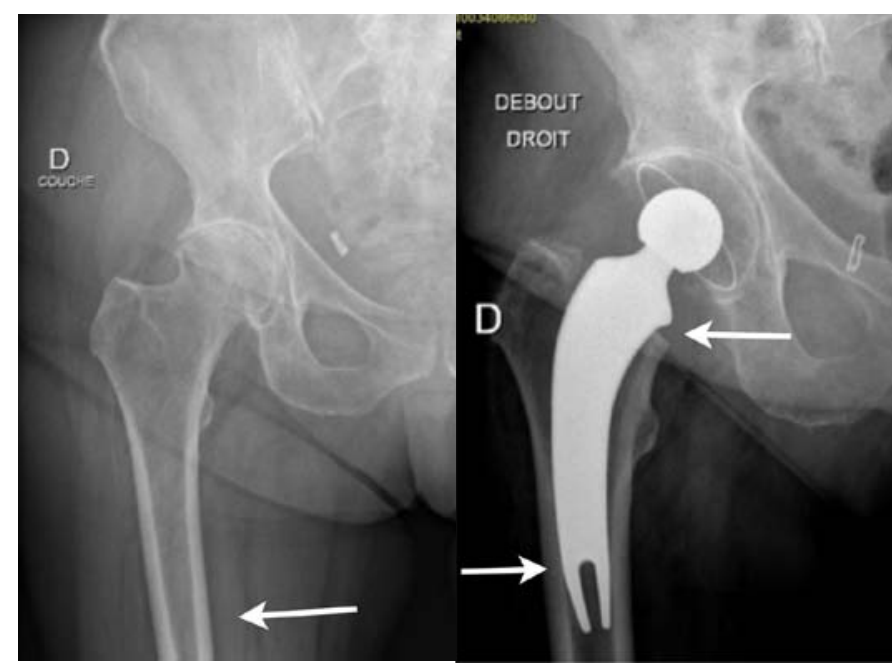

Figure 21. Patient A.

Preoperative showing a tight distal canal.
Figure 22. Patient A. Post-op demonstrating a tight distal canal fit and a slight gap at the medial conical flair.

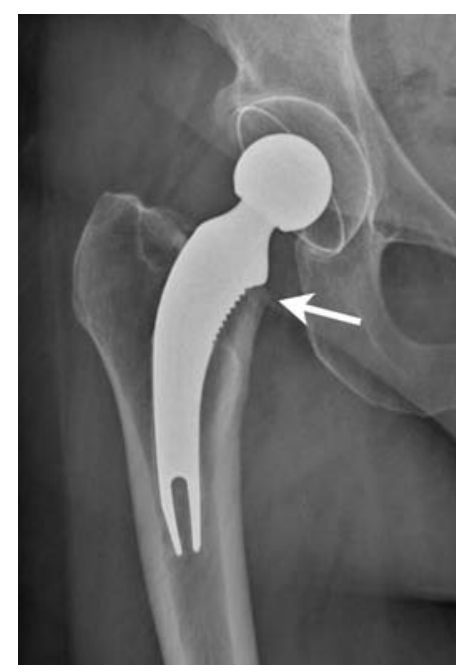

Figure 25. Patient B. December 2019.

Demonstrating good maintenance of medial calcar at 3 years postoperatively.

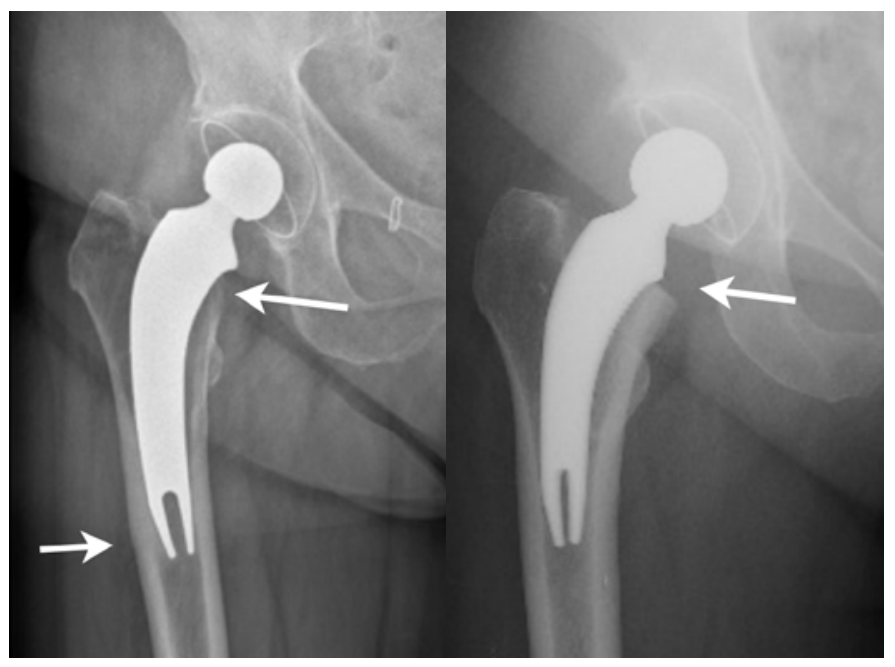

Figure 23. Patient A. One year post-op demonstrating medial calcar rounding and distal

Figure 24. Patient B. Post-op Oct. 2016. Conical Flair engaged with medial calcar.

lateral hypertrophy

\section{Conclusion}

This short curved tissue sparing implant has demonstrated excellent initial short-term results, with excellent implant stability, excellent medial calcar bone remodeling with one dislocated stem, no aseptic loosening two thigh pain one patient associated with low back pain, one female patient that experienced anterolateral thigh pain at six months post-operatively with diminished pain at one year and one distal intra-operative fracture in a Dorr type A bone. This has now been addressed with the use of distal sizing gauges and the use of flexible reamers to open the distal canal prior to stem insertion. Removal of the infected stems demonstrated implant stability with early bone

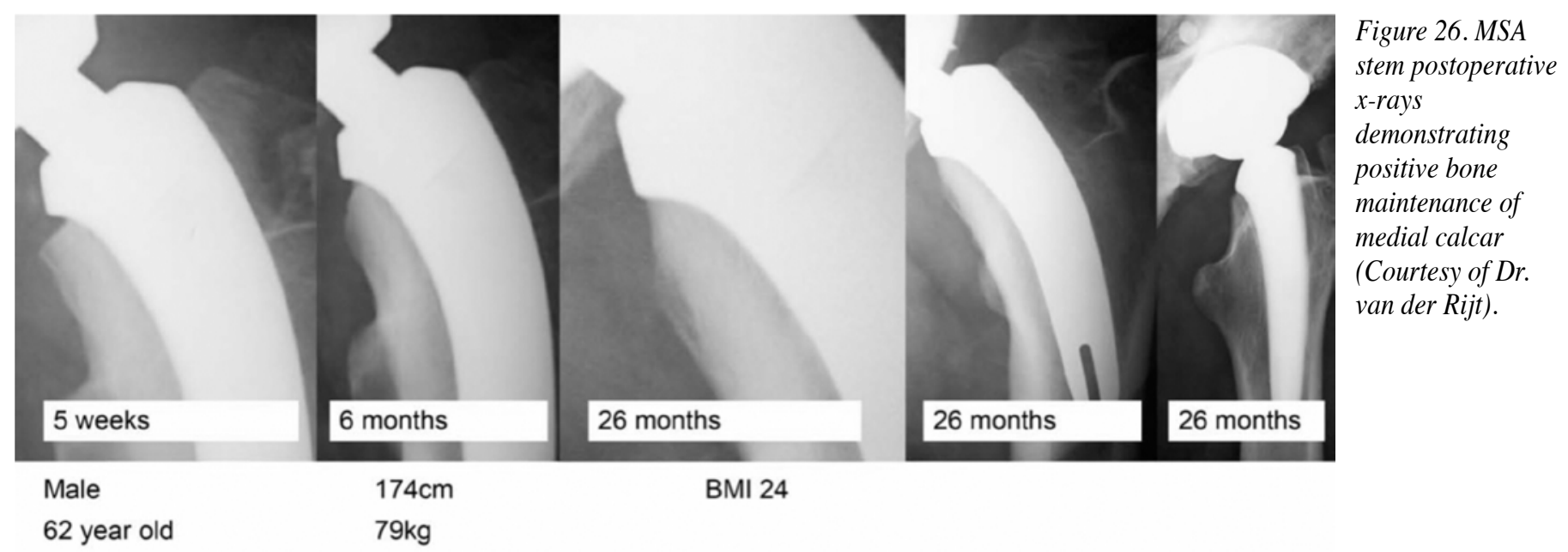


attachment in the proximal porous surface. The high neck resection allows for ease of revision and conversion implanting a new primary conventional length cementless stem design.

There is a short but definitive learning curve in fitting the implant to the femoral neck as compared to implantation of a conventional style cementless stem. The neck resection is a critical part of maintaining positive medial calcar bone remodeling. Overall the authors are optimistic and continuing advocating the use of this neck preserving style stem.

\section{References}

1. Engh CA Jr, Culpepper WJ, Engh CA. Long-term results of use of the anatomic medullary locking prosthesis in total hip arthroplasty. J Bone Joint Surg Am. 1997;79:177-184

2. Polkowski GG, Callaghan JJ, Mont MA, Closhisy JC. Total Hip arthroplasty in the very young patient. J Am Acad Orthop Surg. 2012 Aug;20(8):487-97. doi: 10.5435/JAAOS-20-08-487.

3. Girard J, Glorion C, Bonnomet F, et al. Risk factors for revision of hip arthroplasties in patients younger than 30 years. Clin Orthop Relat Res. 2011;469(4):11411147

4. Barrack R,. The Case for Hip Resurfacing: A Bigger Picture. Current Concepts in Joint Replacement Meeting. December 2010.

5. Amstutz HC. Hip Resurfacing: A 40-year Perspective. HSS J. 2012 Oct;8(3):27582. doi: 10.1007/s11420-012-9293-9. Epub 2012 Sep 14.

6. Wong JM, Liu YL, de Steiger R. What is the Rerevision Rate After Revising Hip Resurfacing Arthroplasty? Analysis From the AOANJRR. Clin Orthop Relat Res. 2015 Nov;473(11):3458-64. doi: 10.1007/s11999-015-4215-z.

7. Clarke I, Lazennec J. Margin-of-safety Algorithm Used with EOS Imaging to Interpret MHRA Warning for 46-48mm MOM Arthroplasty. https://doi. org/10.15438/rr.5.3.115

8. McTighe T, Woodgate I, Turnbull A, et al. A New Approach to Neck-Sparing THA Stem. March 2008 DOI: 10.13140/RG.2.1.1799.5367, Conference: AAOS At: San Francisco Volume: Poster Exhibit 32

9. McTighe T, Brazil D, Keggi JM, Keppler L, McPherson EJ. "Short-stem Designs for Total Hip Arthroplasty: Neck Stabilized Femoral Components" In book: The Adult Hip "Hip Arthroplasty Surgery" Third Edition, Chapter 64, Publisher: Wolters Kluwer, Editors: John J. Callaghan, Aaron G. Rosenberg, Harry E. Rubash, John C. Clohisy, Paul E. Beaule, Craig J. Della Valle, pp.823-849

10. McTighe T, Stulberg SD, Keppler L, Keggi J, et al. Total Hip Stem Classification System. https://doi.org/10.15438/rr.v4i2.70

11. Schutte D, Conrad J, Romero N, McTighe T. http://www.jisrf.org/pdfs/predictingtotal-hip-arthroplasty.pdf ICJR Poster 59 April 27-29, 2012 Coronado, CA

12. Lindgren JU, Rysavy J. Restoration of femoral offset during hip replacement. A radiographic cadaver study. Acta Orthop Scand. 1992;63(4):407-410.https://www. ncbi.nlm.nih.gov/pubmed/1529690
13. Sakai, T, Sugano, N, Ohzono K, Nishii T, Haraguchi K, Yoshikawa H. Femoral anteversion, femoral offset, and abductor lever arm after total hip arthroplasty using a modular femoral neck system. J Orthop Sci. 2002;7(1):62-7. DOI: 10.1007/ $\underline{\mathrm{s} 007760200010}$

14. McPherson E, Vaughn B, Keppler L, Brazil D, McTighe T. The Incidence of Dislocation Utilizing a Neck Sparing Stem in Primary THA in Community Based Practices with the Posterior Approach. https://doi.org/10.15438/rr.5.2.106

15. McTighe T, Brazil D, Keggi J, Keppler L, McPherson E. Short-stem Designs for Total Hip Arthroplasty: Neck Stabilized Femoral Components. https://www.researchgate.net/publication/301689235 Short-stem Designs for Total Hip Arthroplasty Neck Stabilized Femoral Components

16. Van der Rijt A, Van der Rijt R, Solaiman R. Early experience with MSA $^{\mathrm{TM}}$ neck sparing stem via anterolateral approach. Oral Paper at European Hip Society 10th Congress; September 2012; Milano, Italy.

\section{SUBMISSION HISTORY}

Submitted: January 2, 2019

Reviewed: March 24, 2019

Accepted: March 26, 2019

Published: March 31, 2019

\section{AUTHOR AFFILIATIONS}

1 Guillaume Venet, MD; Antoine Tesson, MD; Francois Le Cour Grandmaison, MD; Nicolas Fraquet, MD

Service de Chirurgie Orthopédique et Traumatologique, CHD VENDEE, 85925 La Roche Sur Yon Cedex, FR

2 Declan Brazil, PhD

Signature Orthopaedics, 7 Sirius Rd Lane Cove West NSW 2066 AU

3 Timothy McTighe, Dr HS (hc) Joint Implant Surgery \& Research Foundation, 46 Chagrin Shopping Plaza, \#117, Chagrin Falls, OH 44022 US

(Direct inquires to Guillaume Venet, guillaume.venet@chd-vendee.fr)

\section{AUTHOR DISCLOSURES}

Guillaume Venet, Declan Brazil and Timothy McTighe declare Either family, institution I am associated with, or I have received benefits or funds either directly or indirectly regarding this article.

Drs. Tesson, Le Cour Grandmaison and Fraquet declare that there are no disclosures regarding the publication of this paper.

\section{COPYRIGHT \& OPEN ACCESS}

(C) 2019 Venet, Tesson, Le Cour Grandmaison, Fraquet, Brazil, McTighe. All rights reserved.

Authors retain copyright and grant the journal right of first publication with the work. Reconstructive Review is an open access publication and follows the Creative Commons Attribution-NonCommercial CC BY-NC. This license allows anyone to download works, build upon the material, and share them with others for non-commercial purposes as long as they credit the senior author, Reconstructive Review, and the Joint Implant Surgery \& Research Foundation (JISRF). An example credit would be: "Courtesy of (senior author's name), Reconstructive Review, JISRF, Chagrin Falls, Ohio". 


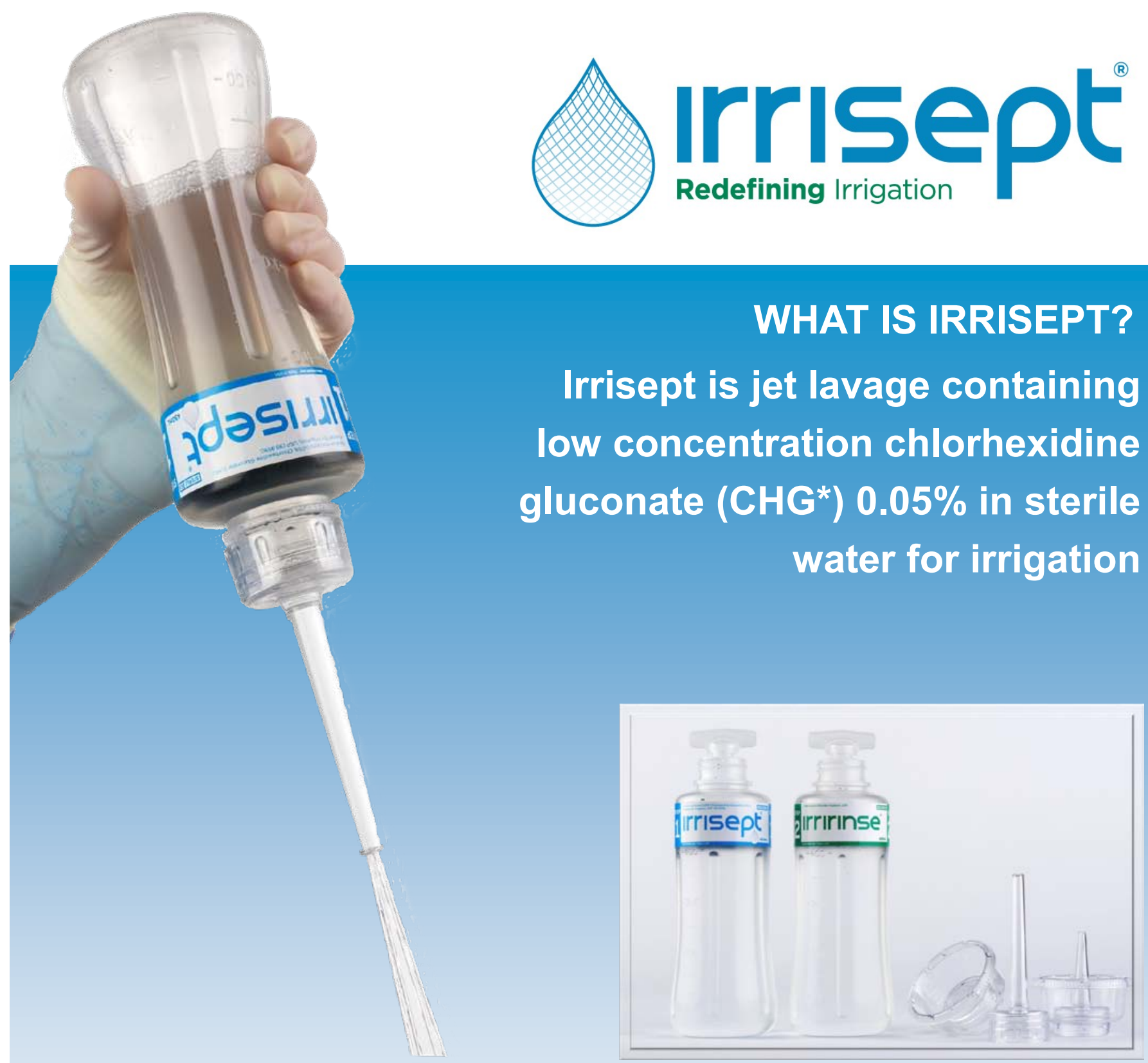

Irrisept is sterile packaged, contents include:

\section{HOW IRRISEPT WORKS}

Irrisept's bottle design allows users to control the pressure of the solution through manual bottle compression.

The mechanical action of Irrisept helps remove bacteria, particulate and debris in wounds without harming underlying tissues. 


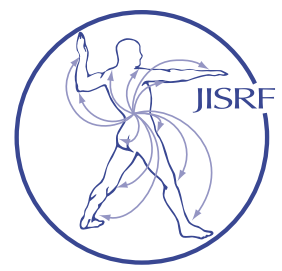

\section{Can We Improve Screening Costs in Asymptomatic Metal on Metal Total Hip Arthroplasties?}

Martin $J R^{1}$, Otero $J E^{2}$, Springer $B D^{1}$, Griffin $W L^{1}$

\section{Abstract}

Background: Metal on Metal (MoM) total hip arthroplasty (THA) has been largely abandoned in the United States secondary to high failure rates. Many of the failures are attributed to adverse local tissue reactions (ALTR). Therefore, patients that have a MoM THA are routinely screened by checking serum metal ion levels every two years, as was recommended by the FDA. However, there is limited data on the costs of current screening protocols.

Materials and Methods: 318 consecutive patients who underwent a MoM THA at a single institution were retrospectively enrolled. The average follow-up was 8.2 years. Clinical data, metal ion levels, revision and reoperation rates were prospectively collected. The costs of clinical screening for this patient population was calculated and compared to the cost of an annual screening protocol.

Results: 12 patients had either an elevated $\mathrm{Co}$ or $\mathrm{Cr}$ level ( $>4.5 \mathrm{ppb})$. Eight patients were revised secondary to ALTR. The total cost of screening during the study was $\$ 612,250$. Additionally, if annual screening had been performed, total screening costs would be approximately $\$ 1,719,200$.

Discussion: Eight patients in the following study were revised secondary to ALTR with a total cost of screening of $\$ 612,500$. These costs are substantially less than the cost of annual screening $(\$ 1,719,200)$. Due to the considerable costs of screening asymptomatic MoM THA patients, we recommend both optimizing the frequency of screen- ing and evaluating the specific risk of the implant being screened.

\section{Background}

Metal on metal (MoM) total hip arthroplasty (THA) has largely been abandoned as a bearing surface as numerous studies have demonstrated adverse local tissue reactions secondary to the implant bearing [1-4]. The exact number of patients implanted with a MoM THA has been estimated to be over $1,000,000$. It is believed that there remain hundreds of thousands of asymptomatic patients with these implants that still require follow-up. There is currently no consensus on how to screen this patient population to avoid complications associated with adverse local tissue reaction $[\underline{5}, 6]$. Some international screening protocols require annual follow-up with serum or whole blood cobalt and chromium metal ion levels. "Elevated" levels (which may range from 4.5 to $7.5 \mathrm{ppb}$ ) commonly require cross sectional imaging including a Metal Artifact Reduction Sequence Magnetic Resonance Imaging (MARS MRI) or an ultrasound [-ㅁ] .

Metal ion values have not demonstrated a clear relation-

Keywords: metal on metal; total hip replacements; screening protocols; cost savings

Level of Evidence: AAOS Therapeutic Level IV 
ship in the diagnosis of adverse local tissue reaction [10]. The actual metal ion value that is considered "elevated" varies, and may not directly correlate with adverse local tissue reaction $[11,12]$. Additionally, the timing for obtaining metal ion levels and the time interval between screenings is not uniform. In the United Kingdom, the Medicines and Healthcare products Regulatory Agency (MHRA) currently recommends annual screening for all patients with a MoM THA with a femoral head $36 \mathrm{~mm}$ or larger [13]. However, Kiran et. al. noted that metal ion levels remained stable after seven years and had no significant elevation. Therefore, they suggested that annual screening may not be necessary [12]. Additionally, there is a paucity of data available on the costs of screening this patient population.

Beginning in 2010, we adopted a protocol of monitoring metal ion levels every two years in asymptomatic MoM THA patients. Prior to this, routine screening was not utilized for asymptomatic patients. Revision THA secondary to adverse local tissue reaction has been minimal at our institution; therefore, there remains a substantial cost for screening this asymptomatic patient population. Consequently, the following study was designed to determine the costs of our current surveillance program on asymptomatic MoM THA patients and to compare these with the potential costs of annual screening. Additionally, we sought to determine the cost per patient to identify a single case of an adverse local tissue reaction.

\section{Materials and Methods}

After obtaining institutional review board approval, the following study was performed retrospectively. 318 consecutive patients underwent primary THA. All THAs were performed by the senior author, a fellowship trained arthroplasty surgeon, through a posterior approach. A Pinnacle (DePuy; Warsaw, IN) acetabular component with an Ultamet metal liner was utilized in each case. $98 \%$ of cases were performed with the S-ROM stem (DePuy; Warsaw, IN) and 2\% were performed with an AML stem (DePuy; Warsaw, IN).

\section{Patient Demographics}

The patient cohort included 318 patients with $457 \mathrm{MoM}$ THAs identified. The average age at the time of surgery was 55 years (20-78 years). The average time in situ was 8.2 yrs. The median femoral head size was $36 \mathrm{~mm}$ and the median cup angle was 40 degrees.

\section{Screening Protocol}

Routine monitoring for patients with asymptomatic
MoM THA included a physical examination, AP pelvis and lateral radiograph of the involved hip, and cobalt and chromium metal ion levels. However, there was not a standardized time between physical examination/screens. Starting in 2010, patients were routinely screened every two years. The screening period coincided with the widespread availability of cobalt and chromium metal ion labs. Prior to this time, only a few centers had the ability to measure serum/ whole blood metal ion levels. Sidaginamale et. al. [15] previously noted that a Co level of $4.5 \mathrm{ppb}$ was highly sensitive and specific for the detection of abnormal wear of a MoM THA. While other cutoff values have been evaluated, we chose $4.5 \mathrm{ppb}$ as a more sensitive screening level. Therefore, any metal ion level over $4.5 \mathrm{ppb}$ was considered elevated by the senior author and the patient was then scheduled to undergo a MARS MRI. Fluid collections suggestive of adverse local tissue reaction in the setting of elevated metal ions were considered to be diagnostic for a failed metal on metal total hip arthroplasty and were subsequently revised. Therefore, we calculated the costs of screening based on 1) actual follow-up, 2) desired followup (every 2-years), 3) annual follow-up, and 4) every fouryears with the assumption that the same number of ALTR were identified in each screening protocol. A multivariate analysis was performed on our patient population to determine if any patient demographics were associated with an increased risk of ALTR.

\section{Costs of Screening}

Costs of screening metal ion levels are not uniform and have changed throughout the duration of the study. The costs as of 2014 were approximately $\$ 300$, but have decreased to around $\$ 124$ as of 2018 for one laboratory. It should be noted that screening evaluations will likely continue to become more cost-effective with decreasing lab costs. However, in order to simplify the calculations, the costs of each screening modality are approximated. The table below demonstrates the approximate costs for each exam/test (Table 1).

Table 1

\begin{tabular}{|l|l|}
\hline Exam/Test & Cost of Exam (dollars) \\
\hline Clinical Exam/X-rays & 350 \\
\hline Metal Ion Levels & 300 \\
\hline MARS MRI & 2000 \\
\hline
\end{tabular}

Patients were followed with serial clinical examination, $\mathrm{x}$-rays, and metal ion levels. If an elevated metal ion level was identified, the patient underwent a MARS MRI. All patients that had a positive MRI (large fluid collections, soft tissue masses, etc.) and a clinical examination 
concerning for mechanical symptoms or increasing pain underwent revision for ALTR. The total costs of routine screening as well as MRI evaluation for those with elevated metal ion levels were calculated for this patient population. Additionally, the theoretical screening costs were then calculated utilizing both planned screening as well as annual serial screening protocols. It was assumed that the same number of elevated metal ion levels would be identified as well as the same number of ALTR.

\section{Results}

We identified 18 elevated cobalt and or chromium levels in 12 patients of the 318 (3.8\%). The median cobalt and chromium level on lab draw one was $1.3 \mathrm{ppb}$ and $1.1 \mathrm{ppb}$ and on lab draw 2 was $1.4 \mathrm{ppb}$ and $1.3 \mathrm{ppb}$, respectively. Of the 12 patients that underwent MARS MRI for elevated metal ion levels, eight patients $(2.5 \%)$ had confirmed cases of ALTR and were subsequently revised. Of these eight patients, two had groin pain concerning for an ALTR, one patient had radiating low back pain, and the other five patients were minimally symptomatic. The only risk factor associated with ALTR was the time in situ ( $\mathrm{p}=0.0008)$. Age, gender, cup abduction angle, and femoral head size were not statistically associated with an increased risk of ALTR.

\section{Total Cost of Current Screening}

The costs for the clinical evaluations and $\mathrm{x}$-rays for this cohort was $\$ 316,750$. The cost of screening patients with metal ion levels was $\$ 271,500$. The costs of the MARS MRIs on 12 patients were approximately $\$ 24,000$. Therefore, the total cost of screening for this study was $\$ 612,250$ (Table 2). The cost therefore was $\$ 1,925$ per patient.

Table 2

\begin{tabular}{|l|l|l|l|}
\hline Exam/Test & $\begin{array}{l}\text { Number of } \\
\text { Exams (n) }\end{array}$ & $\begin{array}{l}\text { Cost per exam } \\
\text { (dollars) }\end{array}$ & $\begin{array}{l}\text { Total cost } \\
\text { (dollars) }\end{array}$ \\
\hline $\begin{array}{l}\text { Clinical } \\
\text { Exam/X-rays }\end{array}$ & 905 & 350 & 316,750 \\
\hline $\begin{array}{l}\text { Metal Ion } \\
\text { Levels }\end{array}$ & 905 & 300 & 271,500 \\
\hline MARS MRI & 12 & 2000 & 24,000 \\
\hline Total & & & 612,250 \\
\hline
\end{tabular}

\section{Cost per ALTR}

Eight patients in this study were revised secondary to an ALTR which was confirmed on the pre-operative MARS MRI and intraoperatively. Therefore, our current screening protocol has a cost of $\$ 76,531$ per ALTR identified.

\section{Costs of Planned Screening Protocol (every two years)}

Utilizing the planned screening protocol every two years, the cost of clinical exams and x-rays would be $\$ 456,750$. The cost of screening the entire cohort of patients with metal ion levels would be $\$ 391,200$. The costs of the MRI evaluations would also be $\$ 24,000$. The total costs of screening utilizing this protocol would be $\$ 871,950$, or $\$ 2,742$ per patient. Additionally, the cost of this theoretical screening protocol would be approximately $\$ 108,994$ per ALTR (Table 3).

Table 3

\begin{tabular}{|l|l|l|l|}
\hline Exam/Test & $\begin{array}{l}\text { Number of } \\
\text { Exams (n) }\end{array}$ & $\begin{array}{l}\text { Cost per exam } \\
\text { (dollars) }\end{array}$ & $\begin{array}{l}\text { Total cost } \\
\text { (dollars) }\end{array}$ \\
\hline $\begin{array}{l}\text { Clinical Exam/ } \\
\text { X-rays }\end{array}$ & 1304 & 350 & 456,750 \\
\hline $\begin{array}{l}\text { Metal Ion } \\
\text { Levels }\end{array}$ & 1304 & 300 & 391,200 \\
\hline MARS MRI & 12 & 2000 & 24,000 \\
\hline Total & & & 871,950 \\
\hline
\end{tabular}

\section{Costs of Theoretical Screening Protocol (annual)}

Utilizing an annual screening protocol, the cost of clinical exams and x-rays would be $\$ 912,800$. The cost of screening the entire cohort of patients with metal ion levels would be $\$ 782,400$. The costs of the MRI evaluations would also be $\$ 24,000$. The total costs of screening utilizing this protocol would be $\$ 1,719,200$, or $\$ 5,406$ per patient. Additionally, the cost of this theoretical screening protocol would be approximately $\$ 214,900$ per ALTR (Table 4).

Table 4
\begin{tabular}{|l|l|l|l|}
\hline Exam/Test & $\begin{array}{l}\text { Number of } \\
\text { Exams (n) }\end{array}$ & $\begin{array}{l}\text { Cost per exam } \\
\text { (dollars) }\end{array}$ & $\begin{array}{l}\text { Total cost } \\
\text { (dollars) }\end{array}$ \\
\hline $\begin{array}{l}\text { Clinical Exam/ } \\
\text { X-rays }\end{array}$ & 2608 & 350 & 912,800 \\
\hline $\begin{array}{l}\text { Metal Ion } \\
\text { Levels }\end{array}$ & 2608 & 300 & 782,400 \\
\hline MARS MRI & 12 & 2000 & 24,000 \\
\hline Total & & & $1,719,200$ \\
\hline
\end{tabular}

\section{Comparison of Theoretical Screening Protocol (four- years)}

Utilizing a protocol to screen every four-years, the cost of clinical exams and $x$-rays would be $\$ 228,200$. The cost of screening the entire cohort of patients with metal ion levels would be $\$ 195,600$. The costs of the MRI evaluations would also be $\$ 24,000$. The total costs of screening utilizing this protocol would be $\$ 447,800$, or $\$ 1,408$ per patient. Additionally, the cost of this theoretical screening 
protocol would be approximately $\$ 55,975$ per ALTR (Table 5). The following table compares the screening costs amongst the various durations of screening (Table 6).

Table 5

\begin{tabular}{|l|l|l|l|}
\hline Exam/Test & $\begin{array}{l}\text { Number of } \\
\text { Exams (n) }\end{array}$ & $\begin{array}{l}\text { Cost per exam } \\
(\text { dollars })\end{array}$ & $\begin{array}{l}\text { Total cost } \\
(\text { dollars })\end{array}$ \\
\hline $\begin{array}{l}\text { Clinical Exam/ } \\
\text { X-rays }\end{array}$ & 652 & 350 & 228,200 \\
\hline $\begin{array}{l}\text { Metal Ion } \\
\text { Levels }\end{array}$ & 652 & 300 & 195,600 \\
\hline MARS MRI & 12 & 2000 & 24,000 \\
\hline Total & & & 447,800 \\
\hline
\end{tabular}

Table 6

\begin{tabular}{|l|l|l|l|l|}
\hline Protocol & $\begin{array}{l}\text { Current } \\
\text { Screening }\end{array}$ & Annual & $\begin{array}{l}\text { Two- } \\
\text { years }\end{array}$ & $\begin{array}{l}\text { Four- } \\
\text { years }\end{array}$ \\
\hline $\begin{array}{l}\text { Total Costs } \\
\text { (dollars) }\end{array}$ & 612,250 & $1,719,200$ & 871,950 & 447,800 \\
\hline $\begin{array}{l}\text { Costs/Patient } \\
\text { (dollars) }\end{array}$ & 1,925 & 5,406 & 2,742 & 1,408 \\
\hline $\begin{array}{l}\text { Costs/100 Patients } \\
\text { (dollars) }\end{array}$ & 192,500 & 540,600 & 274,200 & 140,800 \\
\hline
\end{tabular}

\section{Discussion}

Current screening protocols for monitoring patients with metal on metal total hip arthroplasties are not uniform $[\underline{14}, \underline{16}-\underline{18}]$. In the United Kingdom, annual screenings with metal ion levels are required. However, in the United States, starting in 2010 the FDA mandated ion level screening every two years for asymptomatic MoM THA. This mandate is no longer required but is still generally followed. One recent study has demonstrated that metal ion levels appear to remain stable over time and annual metal ion levels are likely not necessary [14]. This led us to reevaluate our current screening process. There is a substantial cost for screening patients, and more frequent screens will continue to increase costs. However, to our knowledge, no study has evaluated the costs of screening protocols in asymptomatic patients with MoM THA. Therefore, the following study was designed to evaluate theoretical and actual costs of screening this patient population.

Utilizing a less stringent screening protocol than what the MHRA recommends in the UK (screening every year), we identified a total cost of screening for this study of $\$ 612,250$ over an 8.2 year time period. These screening costs are relatively high. However, these costs are substantially less than what may be observed with annual screening protocols. Our results demonstrate an approximately three-fold increase in the costs of screening utilizing annual protocols. As was previously discussed and demonstrated in our study, metal ion levels appear to remain fairly constant with repeat lab evaluation [14]. It should be noted that the true incidence of ALTR was not known in our study. We have made the assumption that all cases of ALTR were identified with the current screening protocol. While it is intuitive that more frequent screening would lead to increasing costs, it is not certain if more frequent screening will identify more patients with an ALTR. MARS MRI has been noted to identify fluid collections in well-functioning ceramic on polyethylene and metal on polyethylene THAs $[\underline{19}, \underline{20}]$. The two main screening tools for identifying an ALTR (metal ion levels and MARS MRI) do not necessarily confirm the diagnosis of ALTR. Therefore, there does not appear to be a nonsurgical method for defining the true incidence of ALTR.

As was demonstrated in this study, screening asymptomatic MoM THA patients is expensive. Further research is necessary to more accurately define at risk patients for an ALTR. In this study, all patients were implanted with the Pinnacle MoM acetabular component. This implant has been associated with statistically significantly lower metal ion levels than other MoM implant designs [21]. Smith et. al. noted the Median Co levels were 2.8 and $3.3 \mu \mathrm{g} / \mathrm{l}$ in the Durom and Birmingham groups, respectively, compared to only $0.52 \mu \mathrm{g} / \mathrm{l}$ in the Pinnacle group $(\mathrm{p}<0.001)$. They also noted that the median $\mathrm{Cr}$ levels were 2 and $2.2 \mu \mathrm{g} / \mathrm{l}$ in the Durom and Birmingham groups, respectively, compared to only $1.2 \mu \mathrm{g} / \mathrm{l}$ in the Pinnacle group $(\mathrm{p}<0.001)$. Only eight patients $(<3 \%)$ had confirmed cases of ALTR in our study. It is possible that implant specific screening may result in increased efficiency of identifying ALTR as well as decreasing the costs of screening. Matharu et. al. previously identified implant specific metal ion thresholds for detecting ALTR. This study evaluated the BHR and the Pinnacle modular two piece acetabular component [22]. These implant specific cutoff values were then applied to an external cohort of patients and were once again noted to improve the detection of an ALTR [ $\underline{23}]$. However, there remains debate as to whether or not there are truly implant specific differences in metal ion levels [23]. Therefore, future screening protocols may place an emphasis on the frequency of screening based on risk stratification [24]. Future screening protocols might include implant design, abduction angle, head size, and symptoms.

It should be noted that screening tests in the medical field are regularly utilized in order to identify conditions with a high morbidity and or mortality such as cancer. Screening tests are commonly highly sensitive and will be associated with few false negative results. However, these 
tests may not necessarily be specific and often times require a confirmatory test to rule in or out the disease process. An example of this would be the prostate specific antigen (PSA) which is obtained to screen for prostate cancer. An elevated PSA $(>4.0 \mathrm{ng} / \mathrm{mL})$ will require a biopsy to confirm the diagnosis. Ideal screening tests are highly sensitive and have a low cost, and in the case of prostate cancer, the frequency and threshold of screening has been improved over time. Although an ALTR is not cancer, the associated morbidity can be devastating. For this reason, we still advocate screening asymptomatic patients with MoM THA. However, it is important to consider the costs of screening and potentially optimize the screening protocols to maximize sensitivity and decrease costs.

While the data was prospectively collected, the study design was retrospectively performed (retrospectively analyzing metal ions in a prospective cohort of MoM THA patients) and therefore has limitations. First, the screening protocol utilized in this study was not standardized. Serial clinical examinations, radiographs, and metal ion levels are now obtained every two years. During the majority of the study, routine screening protocols were not utilized. There is recent data that shows that serial metal ion levels may not be necessary in this asymptomatic patient population. Second, there are several limitations in the calculation of annual screening costs. It is possible that metal ion levels fluctuate day to day, or with activity, and therefore more frequent screening may increase the number of elevated metal ion levels obtained and potentially more ALTR identified. This has been simplified only to demonstrate the substantial cost differences noted when more frequent screening protocols are utilized. Third, metal ion labs have continued to decrease in costs. In 2014, cobalt and chromium ion levels cost approximately $\$ 300$, however current costs have dropped to $\$ 124$. Clearly, the cost-effectiveness will improve with decreasing costs of the test. Finally, the true incidence of ALTR is not known for the patient population in this study. Eight patients were revised with confirmed intraoperative ALTR identified. Only 12 patients underwent a MARS MRI and therefore 306 patients were not imaged. It is possible that a subset of these patients may have an ALTR with normal metal ion levels and therefore we note this as a limitation.

\section{Conclusion}

ALTR is a potentially devastating complication associated with MoM THA. Unfortunately, screening protocols are not uniform and rates of ALTR are low. The costs of screening asymptomatic patients in this study were
$\$ 612,250$. Due to the low incidence of ALTR in this patient population $(n=8)$, the cost of screening per ALTR was $\$ 76,531$. While more frequent screening may potentially increase the identification of ALTR, annual screening was associated with approximately a three-fold increase in the costs. Screening asymptomatic patients with MoM THA is necessary, but an emphasis should be placed on increasing the sensitivity of screening while decreasing the costs.

\section{Bibliography}

1. Chalmers BP, Perry KI, Taunton MJ, Mabry TM, Abdel MP. Diagnosis of adverse local tissue reactions following metal-on-metal hip arthroplasty. Curr Rev Musculoskelet Med. 2016;9(1):67-74. doi:10.1007/s12178-016-9321-3.

2. Mokka J, Junnila M, Seppänen M, et al. Adverse reaction to metal debris after ReCap-M2A-Magnum large-diameter-head metal-on-metal total hip arthroplasty. Acta Orthop. 2013;84(6):549-554. doi:10.3109/17453674.2013.859419.

3. Bernthal NM, Celestre PC, Stavrakis AI, Ludington JC, Oakes DA. Disappointing short-term results with the DePuy ASR XL metal-on-metal total hip arthroplasty. J Arthroplasty. 2012;27(4):539-544. doi:10.1016/j.arth.2011.08.022.

4. Matharu GS, Pandit HG, Murray DW. Poor Survivorship and Frequent Complications at a Median of 10 Years After Metal-on-Metal Hip Resurfacing Revision. Clin Orthop Relat Res. 2016;475(2):304-314. doi:10.1007/s11999-016-4882-4.

5. Plummer DR, Berger RA, Paprosky WG, Sporer SM, Jacobs JJ, Della Valle CJ. Diagnosis and Management of Adverse Local Tissue Reactions Secondary to Corrosion at the Head-Neck Junction in Patients With Metal on Polyethylene Bearings. J Arthroplasty. 2016;31(1):264-268. doi:10.1016/j.arth.2015.07.039.

6. Griffin WL. Metal ion levels: how can they help us? J Arthroplasty. 2014;29(4):659660. doi:10.1016/j.arth.2014.02.005.

7. Mistry A, Cahir J, Donell ST, Nolan J, Toms AP. MRI of asymptomatic patients with metal-on-metal and polyethylene-on-metal total hip arthroplasties. Clin Radiol. 2011;66(6):540-545. doi:10.1016/j.crad.2011.02.002.

8. Sutphen SA, MacLaughlin LH, Madsen AA, Russell JH, McShane MA. Prevalence of Pseudotumor in Patients After Metal-On-Metal Hip Arthroplasty Evaluated with Metal Ion Analysis and MARS-MRI. J Arthroplasty. 2016;31(1):260-263. doi:10.1016/j.arth.2015.07.011.

9. Garbuz DS, Hargreaves BA, Duncan CP, Masri BA, Wilson DR, Forster BB. The John Charnley Award: Diagnostic accuracy of MRI versus ultrasound for detecting pseudotumors in asymptomatic metal-on-metal THA. Clin Orthop Relat Res. 2014;472(2):417-423. doi:10.1007/s11999-013-3181-6.

10. Griffin WL, Fehring TK, Kudrna JC, et al. Are Metal Ion Levels a Useful Trigger for Surgical Intervention? J Arthroplasty. 2012;27(8):32-36. doi:10.1016/j. arth.2012.03.020.

11. Hart A., Sabah S., Sampson B, et al. Surveillance of Patients with Metal-on-Metal Hip Resurfacing and Total Hip Prostheses. J Bone Jt Surgery-American Vol. 2014;96(13):1091-1099. doi:10.2106/JBJS.M.00957.

12. Paustenbach DJ, Galbraith DA, Finley BL. Interpreting cobalt blood concentrations in hip implant patients. Clin Toxicol (Phila). 2014;52(2):98-112. doi:10.310 9/15563650.2013.857024.

13. Medical and Healthcare products Regulatory Agency (MHRA). Medical Device Alert: all metal-on-metal (MoM) hip replacements. MDA/2012/036. http://www. mhra.gov.uk/. Published 2012.

14. Kiran M, Shivarathre D, Peter VK. Blood Metal Ion Levels Have Limited Utility in the Surveillance of Asymptomatic Large-Head Metal-on-Metal Total Hip Arthroplasties. J Arthroplasty. July 2017. doi:10.1016/j.arth.2017.07.015.

15. Sidaginamale RP, Joyce TJ, Lord JK, et al. Blood metal ion testing is an effectivescreening tool to identify poorly performing metal-on-metal bearingsurfaces. Bone Joint Res. 2013;2(5):84-95. doi:10.1302/2046-3758.25.2000148.

16. Hjorth MH, Stilling M, Soballe K, et al. No association between pseudotumors, high serum metal-ion levels and metal hypersensitivity in large-head metal-on-metal total hip arthroplasty at 5-7-year follow-up. Skeletal Radiol. 2016;45(1):115125. doi:10.1007/s00256-015-2264-8.

17. Reito A, Parkkinen J, Puolakka T, Pajamäki J, Eskelinen A. Diagnostic utility of joint fluid metal ion measurement for histopathological findings in metal-on-metal hip replacements. BMC Musculoskelet Disord. 2015;16(1):393. doi:10.1186/ s12891-015-0851-4.

18. Renner L, Schmidt-Braekling T, Faschingbauer M, Boettner F. Do cobalt and chromium levels predict osteolysis in metal-on-metal total hip arthroplasty? Arch Orthop Trauma Surg. 2016;136(12):1657-1662. doi:10.1007/s00402-016-2565-y.

19. Fehring TK, Fehring K, Odum SM. Metal Artifact Reduction Sequence MRI 
Abnormalities Occur in Metal-on-polyethylene Hips. Clin Orthop Relat Res. 2015;473(2):574-580. doi:10.1007/s11999-014-3873-6.

20. Jennings JM, Martin JR, Kim RH, Yang CC, Miner TM, Dennis DA. Metal Artifact Reduction Sequence MRI Abnormalities in Asymptomatic Patients with a Ceramic-on-Polyethylene Total Hip Replacement. J Bone Jt Surg. 2017;99(7):593598. doi:10.2106/JBJS.16.00910.

21. Smith J, Lee D, Bali K, et al. Does bearing size influence metal ion levels in largehead metal-on-metal total hip arthroplasty? A comparison of three total hip systems. J Orthop Surg Res. 2014;9:3. doi:10.1186/1749-799X-9-3.

22. Matharu GS, Berryman F, Brash L, Pynsent PB, Treacy RBC, Dunlop DJ. The Effectiveness of Blood Metal Ions in Identifying Patients with Unilateral Birmingham Hip Resurfacing and Corail-Pinnacle Metal-on-Metal Hip Implants at Risk of Adverse Reactions to Metal Debris. J Bone Jt Surg. 2016;98(8):617-626. doi:10.2106/JBJS.15.00340.

23. Matharu GS, Berryman F, Judge A, et al. Blood Metal Ion Thresholds to Identify Patients with Metal-on-Metal Hip Implants at Risk of Adverse Reactions to Metal Debris. J Bone Jt Surg. 2017;99(18):1532-1539. doi:10.2106/JBJS.16.01568.

24. Hothi HS, Eskelinen AP, Berber R, et al. Factors Associated With Trunnionosis in the Metal-on-Metal Pinnacle Hip. J Arthroplasty. 2017;32(1):286-290. doi:10.1016/j.arth.2016.06.038.
SUBMISSION HISTORY

Submitted: October 24, 2018

Reviewed: December 10, 2018

Revised: December 16, 2018

Accepted: March 8, 2019

Published: March 31, 2019

\section{AUTHOR AFFILIATIONS}

1 J. Ryan Martin, MD; Bryan Springer, MD ; William Griffin, MD OrthoCarolina, Hip and Knee Center, 2001 Vail Avenue Suite 200A, Charlotte, NC 28207

2 Jesse Otero, MD, PhD University of lowa Carver College of Medicine, 200 Hawkins Drive, lowa City, IA 52242-1009

(Direct inquires to Ryan Martin, johrmart@gmail.com)

\section{AUTHOR DISCLOSURES}

The authors declare that there are no disclosures regarding the publication of this paper.

\section{COPYRIGHT \& OPEN ACCESS}

(C) 2019 Martin, Otero, Springer, Griffin. All rights reserved. Authors retain copyright and grant the journal right of first publication with the work. Reconstructive Review is an open access publication and follows the Creative Commons Attribution-NonCommercial CC BY-NC. This license allows anyone to download works, build upon the material, and share them with others for non-commercial purposes as long as they credit the senior author, Reconstructive Review, and the Joint Implant Surgery \& Research Foundation (JISRF). An example credit would be: "Courtesy of (senior author's name), Reconstructive Review, JISRF, Chagrin Falls, Ohio". 


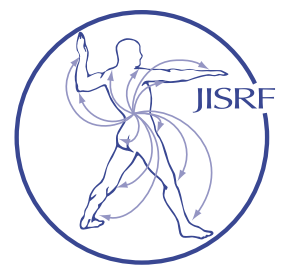

\section{Effects of Acetabular Cup Orientation and Implant Design on Psoas Impingement in Total Hip Arthroplasty}

Ries $M^{1}$, Faizan $A^{2}$, Zhang $Z^{2}$, Scholl $L^{2}$

\section{Abstract}

Background: Durable fixation has been demonstrated with use of large (jumbo) cementless cups in revision total hip arthroplasty (THA). However, anterior protrusion of the cup rim may impinge on the iliopsoas tendon and cause groin pain. The purpose of this study was to assess the effect of cup position and implant design on iliopsoas impingement.

Methods: THA was performed on six cadaver hips using oversized (jumbo) acetabular components, 60 to $66 \mathrm{~mm}$. A stainless steel cable was inserted into the psoas tendon sheath to identify the location of the psoas muscle. CT scans were performed on each cadaver and imported in an imaging software. The acetabular shells, cables, and pelvi were segmented to create separate solid models of each. The shortest distance between each shell and cable was measured. To determine the influence of cup inclination and anteversion, the inclination $\left(30^{\circ} / 40^{\circ} / 50^{\circ}\right)$ and anteversion $\left(10^{\circ} / 20^{\circ} / 30^{\circ}\right)$ angles were varied in the virtual model for both a hemispheric and offset head center shell design.

Results: The shell to wire distance increased linearly with greater cup anteversion (R2>0.99) while inclination had less effect. The distance was greater for the offset head center cup in comparison to the hemispheric cup. Our results indicate that psoas impingement is related to both cup position and implant geometry.

Conclusions: For an oversized jumbo cup, psoas im- pingement is reduced by greater anteversion while cup inclination has little effect. An offset head center cup with an anterior recess was helpful in reducing psoas impingement in comparison to a conventional hemispherical geometry.

\section{Background}

Total hip arthroplasty (THA) is a successful procedure with high survivorship and patient satisfaction. However, groin pain after THA has been reported in a subset of patients. The etiology is considered to be related to impingement between the iliopsoas tendon and anterior acetabular component [1-7]. As a result, illiopsoas tendonitis can be a considerable cause of pain and dissatisfaction in THA patients.

Psoas tendonitis after THA can be treated non-operatively with NSAID's, cortisone injections, and physical therapy $[\underline{5}, \underline{6}]$. However for patients with persistent symptoms surgery consisting of psoas tenotomy or revision THA is indicated $[\underline{3}, \underline{4}, \underline{6}, \underline{7}]$.

Cup orientation and size can influence the risk of psoas impingement. Lewinnek defined the safe zone of acetabular cup placement with an inclination range of $30^{\circ}-50^{\circ}$ and anteversion range of $5^{\circ}-25^{\circ}[\underline{8}]$. Recently, the utility

Keywords: Iliopsoas; impingement; total hip arthroplasty; revision; acetabular; anterior

Level of Evidence: N/A (in vitro study) 
of safe zone has been questioned, yet it continues to serve as a guide for cup placement in THA [9]. The ranges for both inclination and anteversion after THA are wide and can also be affected by spinal deformity [10]. Large acetabular cups which are typically used in revision THA have a greater surface area have more potential to cause psoas impingement. Odri et al reported that patients with cups greater than $6 \mathrm{~mm}$ larger than the native acetabulum had a significant increase in groin pain after THA [2]. More anatomic implant designs have been developed including an anterior recess or bevel in the acetabular shell and anatomically contoured dual mobility femoral head to mitigate the risk of psoas impingement $[\underline{7}, \underline{11}, \underline{12}, \underline{13}]$.

Clinically, groin pain has been used as a surrogate for potential psoas impingement. However, direct assessment of psoas impingement in patients is not straightforward and it may require advanced imaging techniques such as MRI or fluoroscopy imaging under dynamic loading conditions. The purpose of this study was to assess the effect of cup orientation and implant design on risk of psoas impingement in human cadavers using $\mathrm{CT}$ imaging to construct 3D models of the pelvis and soft tissue.

\section{Materials}

Three fresh frozen human cadavers were obtained to perform bilateral THA for this study, Table 1. Cadavers with an intact lumbar spine were used to preserve the anatomic origin of the iliopsoas muscle. The hip was exposed through a conventional posterior approach. The acetabulum was reamed using hemispherical reamers in $2 \mathrm{~mm}$ increments with the goal of reaming the acetabulum to a diameter $10 \mathrm{~mm}$ larger than the native acetabulum and maintaining the inferior edge of the reamer at the anatomic inferior acetabulum. Offset head center acetabular shells (Restoration Anatomic Shell, Stryker, Mahwah, NJ) were implanted in all cases (Figure 1). At least one fixation screw was used with each shell. The shell sizes used in this study were $60 \mathrm{~mm}, 62 \mathrm{~mm}$ and $66 \mathrm{~mm}$ as in shown

Table 1: Demographics and implant sizes used in each cadaver

\begin{tabular}{|l|c|c|c|}
\hline Specimen \# & $\begin{array}{c}\text { Age, Gender, } \\
\text { BMI }\end{array}$ & Operated side & $\begin{array}{c}\text { Acetabular cup } \\
\text { size, mm }\end{array}$ \\
\hline Specimen 1 & 62 yrs., F, 17.5 & Left & 64 \\
\hline & & Right & 62 \\
\hline Specimen 2 & 73 yrs., F, 26 & Left & 64 \\
\hline & & Right & 64 \\
\hline Specimen 3 & 84 yrs., F, 18 & Left & 60 \\
\hline & & Right & 60 \\
\hline
\end{tabular}

in table 1 . The relatively large shell sizes were chosen to simulate THA revision cases. On the femoral side, tapered wedge primary stems (Accolade II, Stryker, Mahwah, NJ) were used in all cases. A $2 \mathrm{~mm}$ diameter flexible stainless steel cable (Dall-Miles cable system, Stryker, Mahwah, $\mathrm{NJ})$ was inserted into the psoas tendon sheath between the muscle and the surrounding membrane to identify the location of the psoas muscle radiographically (Figure 2). Additional sutures were used to secure the cable to

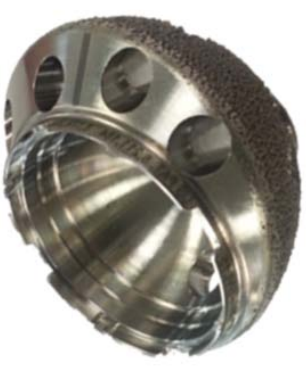

Figure 1: Offset head center acetabular shell which includes an anterior bevel in the rim of the implant (Restoration Anatomic Shell, Stryker, Mahwah, NJ).

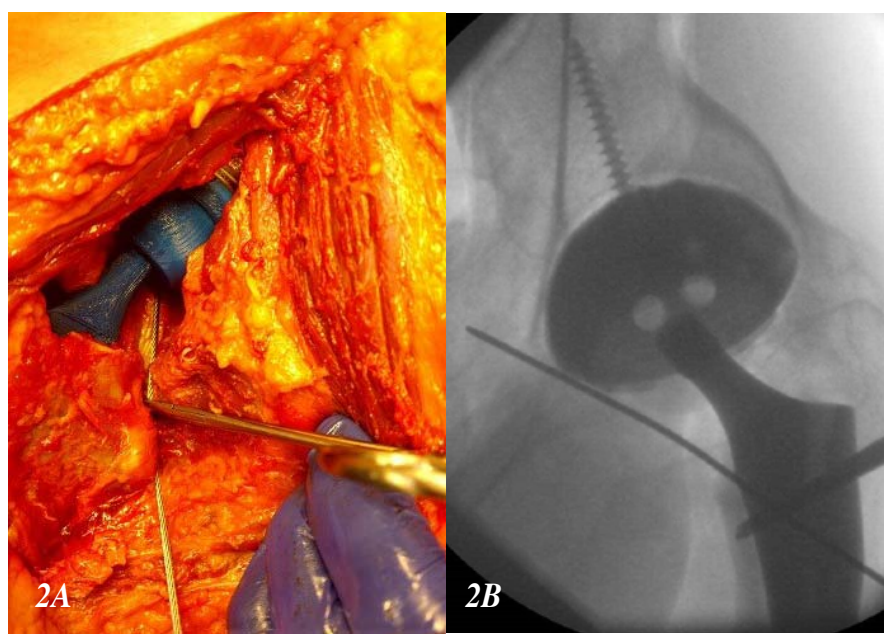

Figure 2. (A) Photo illustrates a cable inserted into the psoas tendon sheath at the level of the lesser trochanteror through a conventional posterior approach. (B) Flouroscopic image demonstrates the position of the cable in the psoas tendon sheath in proximity to the inferior margin of the acetabular shell.

the distal psoas tendon to ensure that the cable remained attached to the psoas during the procedure and imaging.

Following the procedures, cadavers were sent for computed tomography (CT) imaging (CT parameters: $1 \mathrm{~mm}$ axial slices; $120-140 \mathrm{kV} ; 200-250 \mathrm{~mA}$ ). The CT images were imported into the imaging software Mimics (Materialize, Belgium) for further analysis. The acetabular shells, cables, and pelvi were segmented to create distinct solid models of each. This was done to study the spatial relationship between the shell and cable, which was assumed to represent the position of the psoas tendon. Computer aided design (CAD) models of each shell were superimposed on the acetabular shells obtained from CT images. This allowed us to create clean models of the shells implanted in the solid models created from the CT scans. To compare the offset head center shell to a conventional hemispher- 

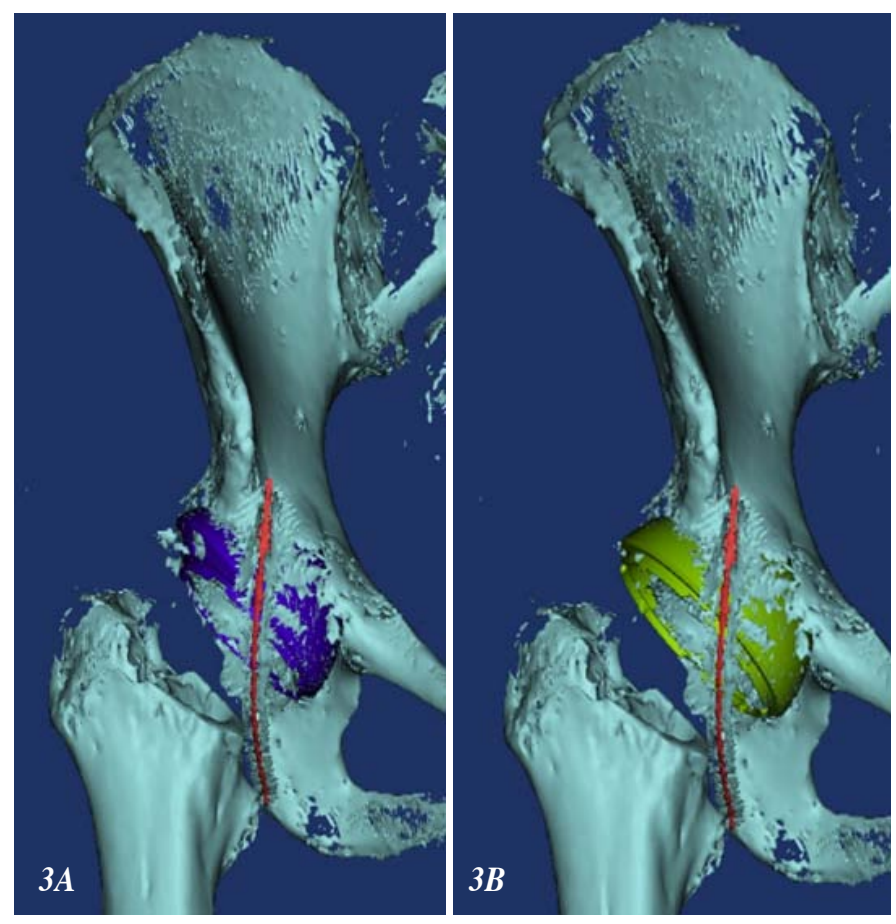

Figure 3. (A) Solid model of the pelvis created using a typical CT scan. The offset head center shell (blue) and cable (red) are shown. (B) Solid model of the same pelvi where the offset head center has been replaced by a conventional hemispherical shell (Green).

ical shell in the same orientation, the offset head center shell was virtually replaced with an equivalent diameter hemispherical shell by overlaying the outer shell surfaces of both designs and keeping the faces of shells parallel, (Figure 3). This allowed analysis of the conventional hemispherical shells in the orientation identical to that of the offset head center shells. The shortest distance between each shell and cable was measured. To determine the influence of cup inclination and anteversion on psoas impingement, multiple inclination and anteversion angles were simulated. For both shell designs, three different inclination angles $\left(30^{\circ} / 40^{\circ} / 50^{\circ}\right)$ and three different anteversion $\left(10^{\circ} / 20^{\circ} / 30^{\circ}\right)$ angles were studied by virtually placing each shell in these orientations respectively. A positive distance value indicated clearance between the shell and the wire while a negative value indicated impingement. A linear regressions analysis was conducted to determine the correlation coefficient factor between the changes in cup anteversion/inclination angles and the level of impingement.
Table 2: Original orientation of shells implanted in each cadaver

\begin{tabular}{|l|c|c|}
\hline Specimen \# & Operated side & $\begin{array}{c}\text { Original shell inclination/ } \\
\text { anteversion }\end{array}$ \\
\hline Specimen 1 & Left & $44.65^{\circ} / 23.34^{\circ}$ \\
\hline & Right & $41.71^{\circ} / 33.83^{\circ}$ \\
\hline Specimen 2 & Left & $40^{\circ} / 17^{\circ}$ \\
\hline & Right & $31.68^{\circ} / 23.54^{\circ}$ \\
\hline Specimen 3 & Left & $32.97^{\circ} / 28.98^{\circ}$ \\
\hline & Right & $46.69^{\circ} / 6.31^{\circ}$ \\
\hline
\end{tabular}

\section{Results}

The original orientations of the offset head center shells are presented in Table 2. The effect of change in anteversion on both shell designs is depicted in figure 4 . With the virtual implantation of both shell designs at orientations $40^{\circ} / 10^{\circ}, 40^{\circ} / 20^{\circ}, 40^{\circ} / 30^{\circ}$ (inclination/anteversion) we found that greater anteversion decreased psoas impingement in both shell designs. For example, $40^{\circ} / 30^{\circ}$ orientation resulted in no impingement in either shell design. The correlation factor was also very high $(\mathrm{R} 2>0.99)$ indicating a strong linear relationship between wire distance and shell anteversion angle.

Figure 5 illustrates the influence of inclination angle on shell to wire distances. When the influence of inclination angle on psoas impingement was analyzed by comparing wire distances for three orientations $\left(30^{\circ} / 20^{\circ}, 40^{\circ} / 20^{\circ}\right.$, $50^{\circ} / 20^{\circ}$ ), the effect was less pronounced than anteversion. There was a trend for lower inclination angles to result in

\section{Wire Clearance vs Cup Anteversion}

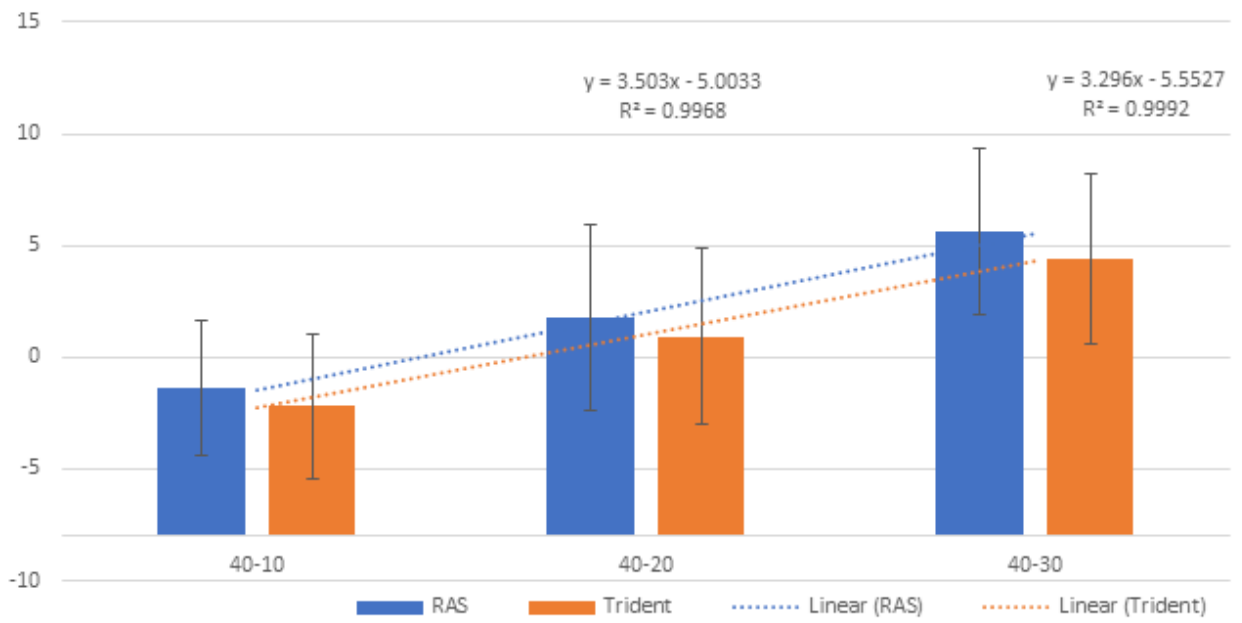

Figure 4. Effect of increasing anteversion from 10 to 30 degrees on shell to wire distance for a fixed inclination value of 40 degrees. The vertical axis represents the closest distance ( $\mathrm{mm})$ between the cable in the psoas tendon and acetabular component for the offset cup (RAS) and hemispherical shell (Trident). A negative value indicates psoas impingement and positive value indicates clearance between the psoas and acetabular component. 
less impingement, yet the correlation coefficient values were lower (R2 $=0.77$ for offset head center and $\mathrm{R} 2=0.94$ for conventional design).

The delta between the wire distances for offset center and hemispherical shells were calculated for each specimen. For the offset center shells, the shell to wire distance in all cases was positive (range 0.07 $3.44 \mathrm{~mm}$ ) indicating that there was clearance between the shells and psoas. When the offset head center was replaced with the conventional hemispherical shell, the distance was negative (range: -1.32-1.41) indicating psoas impingement in 3 out of 6 cases.

\section{Discussion}

Most acetabular defects encountered in revision THA have a distorted but expanded rim (Paprosky type 2) and can be treated with a large cementless cup and screw fixation [14]. Results of large (jumbo) cementless cups in revision THA have demonstrated durable long term fixation and implant survivorship $[\underline{15}, \underline{16}]$. A "jumbo" cup has been considered to be approximately $10 \mathrm{~mm}$ larger than the native acetabulum $[\underline{16}, 17]$. However, cup sizes $6 \mathrm{~mm}$ or larger than the native acetabulum have been associated with an increase in groin pain which has been attributed to psoas tendonitis [2]. Since psoas tendonitis appears to be related to the amount of anterior overhang of the cup rim beyond the physiologic or anatomic bony rim, both cup size and implant position can affect the risk of psoas tendonitis.

Our findings indicate that cup anteversion has a direct effect on risk of psoas impingement while cup inclination has a less significant relationship. For the oversized hemispheric cups used in this study anteversion of 20 degrees or more was required to avoid cup impingement. However the cadavers used in this study were in the supine position and in vivo studies have demonstrated considerable change in the relative inclination and anteversion from supine to sitting to standing positions [18]. Patients with spinal disease or limited spine motion also have an increased risk of impingement and dislocation which suggests that this patient population would also have an increased risk of psoas impingement and tendonitis [19]. Other studies have questioned whether there is a "safe range" of cup position to avoid dislocation after THA []ㅛ. These findings suggest
Wire Clearance vs Cup Inclination

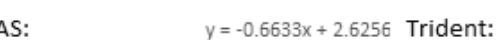

$-0.6633 x+2.6256$ Trident: $\quad y=-0.8167 x+2.0167$
$R^{2}=0.767$

$R^{2}=0.9423$ $R^{2}=0.767$
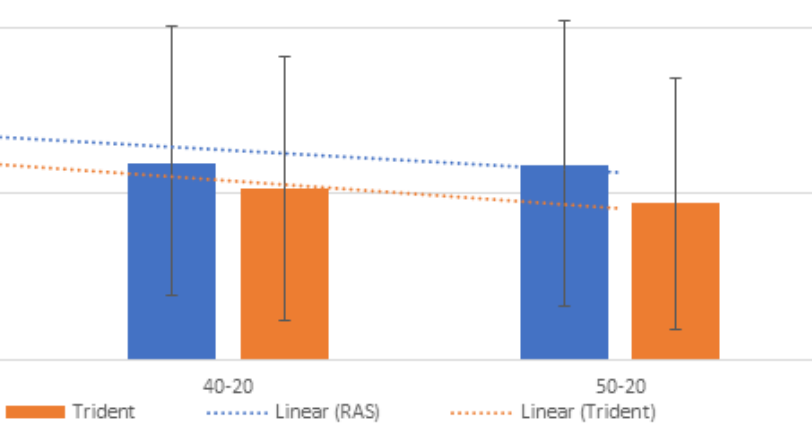

sing inclination from 30 to 50 degrees on shell to wire distance for a fixed anteversion value of 20 degrees. The vertical axis represents the closest distance ( $\mathrm{mm})$
between the cable in the psoas tendon and acetabular component for the offset cup (RAS) and hemispherical shell (Trident). A negative value indicates psoas impingement and positive value indicates clearance between the psoas and acetabular component.

that while adequate anteversion may have a protective effect on mitigating the risk of psoas tendonitis there may not be a "safe range" of cup position to avoid psoas tendinitis, particularly with use of oversized "jumbo" cups.

The anatomic acetabular rim has an asymmetric contour which includes an anterior recess that the psoas tendon crosses, while acetabular components have traditionally been symmetric hemispheric or low-profile (slightly less than a hemisphere) shaped. The hemispheric acetabular component provides greater coverage of the femoral head while the low-profile cup geometry provides greater range of motion to impingement. More asymmetric implant designs have been developed to mitigate the risk of psoas impingement. Bousquet described use of an anatomic dual mobility cup in which the implant rim matches the anatomic contour of the native acetabulum with a cut out for the psoas tendon $[\underline{20}, \underline{21}]$. The Restoration Anatomic Shell, which was used in this study is intended to restore the anatomic head center and mitigate risk of psoas impingement with an anterior bevel in the rim of the component as an alternative to a hemispheric cup $[\underline{12}, \underline{13}]$. A similar result could be achieved with use of an augment above a cup which then avoids the anterior overhang of a larger hemispheric cup without an augment [22]. However this technique which requires two independently fixed implants can be technically challenging. Modification of the conventional hemispheric femoral head to an anatomic contoured dual mobility head may also reduce the risk of psoas impingement [11]. The advantage of implant designs such as those described above is that risk of psoas 
impingement would appear to be improved independent of cup position. Our results indicate that use of a large diameter offset head center cup reduced risk of psoas impingement by an amount essentially equivalent to an increase in anteversion of a hemispheric cup of 10 degrees. However clinical studies will be necessary to determine if this implant design has the predicted clinical benefit of reducing symptomatic psoas tendonitis in vivo.

\section{References}

1. Ueno T, Kabata T, Kajino Y, Inoue D, Ohmori T,Tsuchiya H. Risk Factors and Cup Protrusion Thresholds for Symptomatic Iliopsoas Impingement After Total Hip Arthroplasty: A Retrospective Case-Control Study. J Arthroplasty 2018; 33: 3288-3296.

2. Odri GA, Padiolleau GB, Gouin FT. Oversized Cups as a Major Risk Factor of Postoperative Pain After Total Hip Arthroplasty. J Arthroplasty 2014; 29: 753-756.

3. Henderson RA, Lachiewicz PF. Groin pain after replacement of the hip: aetiology, evaluation and treatment. J Bone Joint Surg 2012; 94B:145 -151.

4. Lachiewicz PF, Kauk JR. Anterior iliopsoas impingement and tendinitis after total hip arthroplasty. J Am Acad Orthop Surg 2009;17:337-344.

5. Nunley RM, Wilson JM, Gilula L, Clohisy JC, Barrack RL, Maloney WJ. Iliopsoas bursa injections can be beneficial for pain after total hip arthroplasty. Clin Orthop Relat Res 2010;468:519-526.

6. Chalmers BP, Sculco PK, Sierra RJ, Trousdale RT, Berry DJ. Iliopsoas Impingement After Primary Total Hip Arthroplasty: Operative and Nonoperative Treatment Outcomes. J Bone Joint Surg, 99-A, 557-564, 2017.

7. O'Connor MI. Use of an anatomical acetabular component for treatment of iliopsoas impingement. J Arthroplasty 2011; 26: 1570 e13-1570e15.

8. Lewinnek GE, Lewis JL, Tarr R, Compere CL, Zimmerman JR.Dislocations after total hip-replacement arthroplasties. J Bone Joint Surg 1978; 60-A: 217-220.

9. Abdel MP, von Roth P, Jennings MT, Hanssen AD, Pagnano MW. What Safe Zone? The Vast Majority of Dislocated THAs Are Within the Lewinnek Safe Zone for Acetabular Component Position. Clin Orthop Relat Res. 2016; 474:386-391.

10. DelSole EM, Vigdorchik JM, Schwarzkopf R, MD, Errico TJ, Buckland AJ. Total Hip Arthroplasty in the Spinal Deformity Population: Does Degree of Sagittal Deformity Affect Rates of Safe Zone Placement, Instability, or Revision? J Arthroplasty 2017; 32: 1910 -1917.

11. Zumbrunn T, Patel R, Duffy MP, Rubash HE, Malchau H, Freiberg AA. Muratoglu OK, Varadarajan KM. Cadaver-Specific Models for Finite-Element Analysis of Iliopsoas Impingement in Dual-Mobility Hip Implants. J Arthroplasty 2018; 11: 3574-3580.

12. Khlopas A, Chughtai M, Elmallah RK, Hip-Flores D, Malkani AL, Harwin SF, Mont MA, Ries MD. Novel Acetabular Cup for Revision THA Improves Hip Center of Rotation: A Radiographic Evaluation. Clin Orthop Relat Res 2018; 476: 315-322.

13. Faizan A, Black BJ, Fay BD, Heffernan CD, Ries MD. Comparison of Head Center Position and Screw Fixation Options Between a Jumbo Cup and an Offset Center of Rotation Cup in Revision Total Hip Arthroplasty: A Computer Simulation Study. J Arthroplasty 2016; 31:307-311.

14. Sheth NP, Nelson CL, Springer BD, Fehring TK, Paprosky WG.Acetabular bone loss in revision total hip arthroplasty: evaluation and management. J Am Acad Orthop Surg 2013; 21: 128-139.
15. von Roth P, Abdel MP, Harmsen WS, Berry DJ. Uncemented jumbo cups for revision total hip arthroplasty: a concise follow-up, at a mean of twenty years, of a previous report. 15. J Bone Joint Surg 2015; 97-A: 284-287.

16. Lachiewicz PF, Soileau ES. Fixation, survival, and dislocation of jumbo acetabular components in revision hip arthroplasty. J Bone Joint Surg 2013; 95-A: 543548.

17. Whaley AL, Berry DJ, Harmsen WS Extra-Large Uncemented Hemispherical Acetabular Components for Revision Total Hip Arthroplasty. J Bone Joint Surg 2001; 83-A: 1352-1357.

18. Langston J, Pierrepont J, Gu Y, Shimmin A. Risk factors for increased sagittal pelvic motion causing unfavourable orientation of the acetabular component in patients undergoing total hip arthroplasty. Bone Joint J 2018; 100-B: 845-852.

19. Esposito CI, Carroll KM, Sculco PK, Padgett DE, Jerabek SA, Mayman DJ. Total Hip Arthroplasty Patients With Fixed Spinopelvic Alignment Are at Higher Risk of Hip Dislocation. J Arthroplasty 2018; 33: 1449-1454.

20. Neri T, Philippot R, Farizon F, Boyer B. Results of primary total hip replacement with first generation Bousquet dual mobility socket with more than twenty five years follow up. About a series of two hundred and twelve hips. Int Orthop 2017; 41:557-561.

21. Boyer B, Philippot R, Geringer J, Farizon F.Primary total hip arthroplasty with dual mobility socket to prevent dislocation: a 22-year follow-up of 240 hips. Int Orthop 2012; 36: 511-518.

22. Whitehouse MR, Masri BA, Duncan CP, Garbuz DS. Continued good results with modular trabecular metal augments for acetabular defects in hip arthroplasty at 7 to 11 years. Clin Orthop Relat Res 2015; 473:521-527.

\author{
SUBMISSION HISTORY \\ Submitted: March 5, 2019 \\ Reviewed: June 6, 2019 \\ Accepted: July 1, 2019 \\ Published: November 12, 2019 \\ AUTHOR AFFILIATIONS \\ 1 Michael Ries, MD \\ Reno Orthopaedic Clinic, Reno, NV - USA \\ 2 Ahmad Faizan; Jingwei Zhang; Laura Scholl \\ Stryker Orthopaedics, Mahwah, NJ - USA \\ (Direct inquires to Michael Ries, mries@renoortho.com)
}

AUTHOR DISCLOSURES

Cadaveric and implant materials, and laboratory testing facilities used for this study were provided by Stryker Orthopaedics.

COPYRIGHT \& OPEN ACCESS

(C) 2019 Ries, Faizan, Zhang, Scholl. All rights reserved.

Authors retain copyright and grant the journal right of first publication with the work. Reconstructive Review is an open access publication and follows the Creative Commons Attribution-NonCommercial CC BY-NC. This license allows anyone to download works, build upon the material, and share them with others for non-commercial purposes as long as they credit the senior author, Reconstructive Review, and the Joint Implant Surgery \& Research Foundation (JISRF). An example credit would be: "Courtesy of (senior author's name), Reconstructive Review, JISRF, Chagrin Falls, Ohio". 
Wide Rake Retractors with Ergonomic Handle Designed for general use soft tissue retraction, the ergonomic handle allows for a better grip and less fatigue Non-glare finish featured on the metal retractor parts.
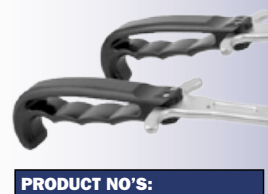

6051 [Deep, Sharp] 6052 [Deep, Blunt] 6053 [Shallow, Sharp] 딸 6054 [Shallow, Blunt] USA MADE

Rake Retractors with Ergonomic Handle

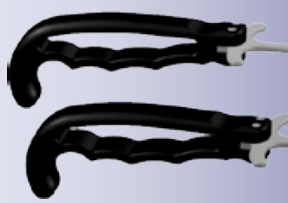

Designed for general use soft tissue retraction, the ergonomic handle allows for a better grip and less fatigue

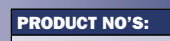
4839 [3-Prong] 4840 [4-Prong] Non-glare finish featured on the metal retractor parts.

\section{Modified Rongeur} with Pistol Grip Handle

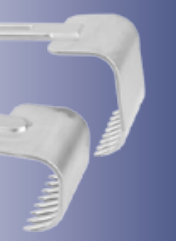

Design modification by Morteza Meftan, MD an
of an original design by James T. Mazzara, MD.

Tapered, narrow jaw and a pistol grip that lessens hand fatigue and slippage, and allows for better visualization
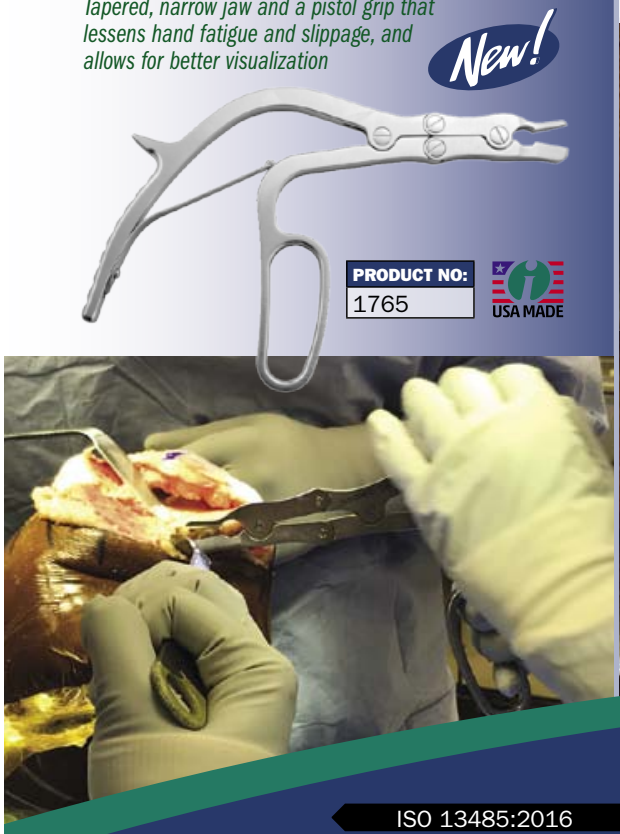

FREE TRIAL ON MOST INSTRUMENTS

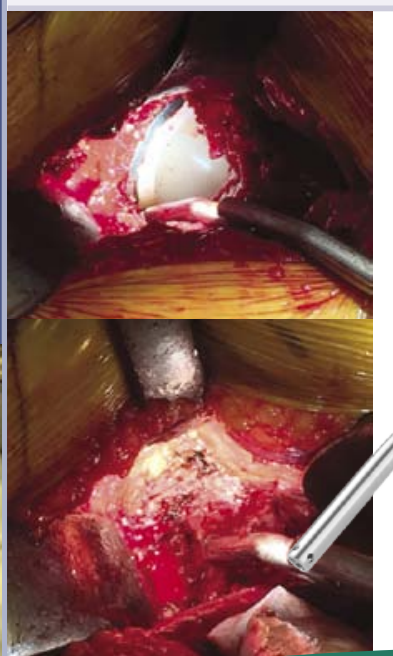

\section{Lighted Yankaur Suction Device}

Designed to help provide effective suction with the addition of a light source

for enhanced visualization

Designed by Adolph V. Lombardi Jr., MD

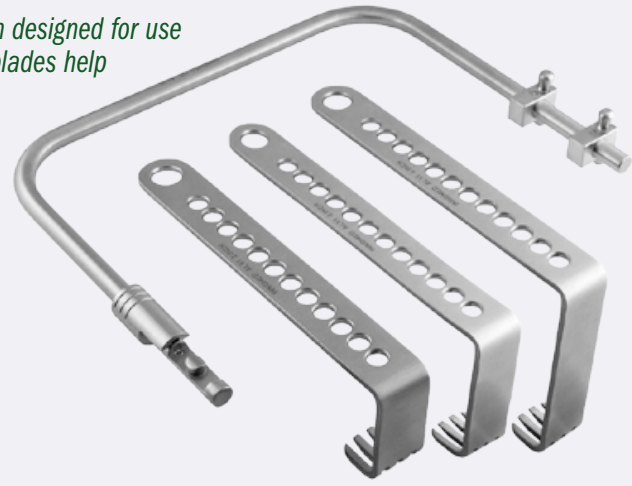

vice comes with one (1) Disposable LED Light Source (\#8010-01). Can also be attached to a fiber optic light cable with ACMI (female) connector

\section{PRODUCT NO'S:}

8016-L-01 [Kit] Device with Disposable LED Light Source Also available individually:

8016-L [Suction Device Only]

$\underline{E}(\boldsymbol{I})$ 8010-01 [Disposable LED Light Source] Pkg of 1

USA MADE $8010-10$ [Disposable LED Light Source] Pkg of 10 

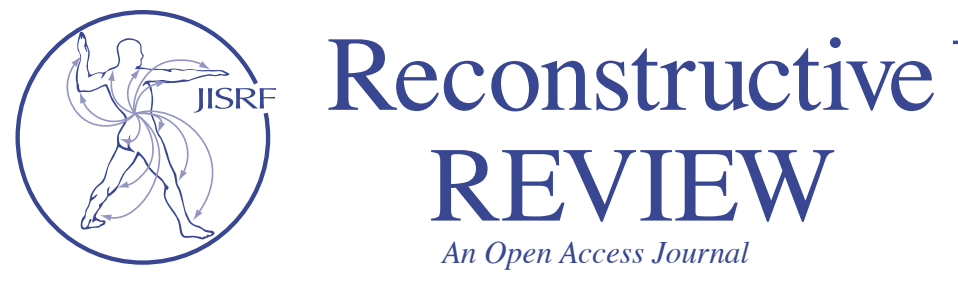

\section{Long-Term Screening is Necessary in Patients with Metal on Metal Total Hip Arthroplasty}

Martin $J R^{1}$, Odum $S^{1}$, Griffin $W L^{1}$

\section{Abstract}

Background: Adverse reactions to metal debris with catastrophic failures have been seen with a number of metal on metal (MoM) total hip designs. Understanding survivorship and factors associated with failure will allow for more targeted surveillance of those patients at highest risk for failure. The purpose of this study was to assess the mid to long term survivorship and specific factors associated with failure for a large cohort of a single modular MoM design.

Methods: Consecutive patients treated with a modular metal on metal bearing with a five to fourteen year followup were included. Clinical outcome scores and radiographic data were prospectively collected. Failure was defined as revision of either component for any reason during the study period. Multiple implant, surgical, and patient factors were analyzed for associations with elevated ion levels or revision due to adverse reactions to metal debris.

Results: The average age at the time of surgery for the 253 patients included in the study was 55 . There were 28 revisions $(7.5 \%)$, eight due to metallosis $(2 \%)$. Survivorship was $89 \%$ at 12.6 years with revision for any reason as the end point. Survivorship was $93 \%$ when limited to revision for ALTR as the end point. Time in situ was the only variable that was statistically associated with an increased risk of failure due to ALTR $(\mathrm{p}<0.0001)$

Conclusion: In this large series of a single design modular metal-metal total hip we found relatively low rates of revision due to adverse reactions to metal debris. The only variable associated with a statistically significant risk of ALTR was time in situ. Therefore, long-term surveillance is necessary in patients with a MoM THA.

\section{Background}

Metal on Metal (MoM) total hip arthroplasty (THA) was widely used throughout the 2000's as an alternative bearing to metal on polyethylene. Potential benefits included decreased wear rates and the ability to utilize a larger femoral head size for improved stability $[1,2]$. However, following the initial enthusiasm with MoM THA, numerous studies began showing increased failure rates with MoM bearing implants. Specifically, increased implant failure due to adverse local tissue reactions (ALTR) likely related to the release of metal ions from the bearing surface [근 $]$. For this reason, several MoM THA designs were pulled from the market and or recalled $[\underline{3}, 6]$.

Currently, screening protocols to help with the early identification of ALTR rely on metal ion levels (Cobalt and Chromium), imaging studies, or some combination of the two. The definition of an "elevated ion level" remains controversial. In the UK, $7 \mathrm{ppb}$ is used as a trigger for further

Keywords: metal on metal; total hip replacement; screening protocols

Level of Evidence: IV 
evaluation, whereas Hart et al noted that ion levels above $4 \mathrm{ppb}$ were associated with abnormal bearing wear. Several studies have determined that ion levels alone should not be used as a trigger for surgery, but should be used in conjunction with patient symptoms, physical exam, radiographic evaluation, and the track record of the implant involved [ $[-11]$. Patients that are deemed to be at higher risk for ALTR should then proceed with cross sectional imaging using a MARS-MRI technique or Ultrasound evaluation to look for adverse reactions.

Multiple studies and registries have demonstrated a wide range of outcomes for the different MoM designs. The Australian registry has identified a $40 \%$ failure rate with the ASR THA at 10 years compared to $9.5 \%$ failure for the Pinnacle modular MoM. Multiple other studies have identified improved results with this same particular modular MoM THA design [11-13].

The FDA has recommended continued surveillance every two years for all patients with MoM THAs, regardless of design. It is likely that the majority of patients with a MoM bearing and low risk factors are being screened unnecessarily. Therefore, the following study was designed with two main goals: 1 . To report the long-term outcomes, including revision and reoperation rates, as well as metal ion levels of the Pinnacle modular two-piece MoM THA design, and 2. To determine if we can improve surveillance by targeting high risk patient populations of MoM THAs utilizing this data.

\section{Materials and Methods}

A query of our institutional total joint patient registry was performed to identify patients who have had a primary total hip replacement with a cementless, modular Pinnacle MoM implant, by a single surgeon, at a minimum of two years, postoperatively. 318 primary THA patients (457 hips) met the inclusion criteria. After obtaining IRB approval, data collection began by reviewing electronic health records. Patients who had not been seen in the clinic within the year prior to the start of the study were contacted to return for clinical exams. In addition to the routine clinical exam, metal ion levels were tested and standard radiographs were evaluated. Patients who were unable to return to the clinic were asked to complete a telephone interview that included a Hip Disability and Osteoarthritis Outcome Score (HOOS JR.) as well as questions regarding any component revision surgery. Patient retention methods included email, a letter, and three phone calls. If we were unable to reach the patient, they were defined as lost to follow up. The following data were collected: patient demo- graphic data (age, sex,), cobalt and chromium ion levels, femoral and acetabular component size, cup abduction angle, reason for revision surgery, and time in situ. The primary outcome variable was the need for revision total hip surgery. We also defined metallosis related failure as revision for ALTR or ion levels of $4.0 \mathrm{ppb}$ or greater.

Statistical Analysis: Standard descriptive statistics and analysis were carried out in SAS 9.4 (Cary, North Carolina). The distribution of the continuous variables was tested and found to be skewed. Therefore, a Wilcoxon two sample test was used to assess the bivariate association of continuous variables with failure. A Chi-square test was used with categorical variables with more than two response levels and a Fishers exact test was used to assess the bivariate association of binary variables with failure. Separate univariate logistic regression models were first fit to assess their association with failure related to metallosis (ALTR or elevated ion levels) with the intention of including significantly associated variables in a multivariate model for further assessment. A significance level of .05 was used to determine statistical significance for all statistical tests.

Study Sample Characteristics: Of the 318 patients with 457 hips identified, 253 patients (80\%) with 374 hips $(82 \%)$ were included. Twenty-six patients with 34 hips were deceased and 39 patients with 49 hips were lost to follow up. Of the 253 patients included, 149 were male (59\%) and the average age at the time of surgery was 55 years (20-78 years). The average time in situ for the 374 hips was 8.3 yrs.

The use of metal ion levels as a screening tool for MoM THAs was not routinely available until 2010.

With this in mind, many of our patients did not have ion levels measured during the first several years following their MoM THA.

\section{Results}

\section{Revision Rate and Survival}

Twenty eight of the 374 hips were revised for an overall revision rate of $7.5 \%$ and the revision rate for adverse local

Table 1: Reason for revision

\begin{tabular}{|l|c|c|}
\hline & Frequency & Percent \\
\hline Infection & 11 & 3 \\
\hline ALTR & 8 & 2 \\
\hline Instability & 4 & 1 \\
\hline Other & 3 & $<1$ \\
\hline Aseptic Loosening & 2 & $<1$ \\
\hline Total & 28 & 7.5 \\
\hline
\end{tabular}


tissue reactions (ALTR) was 2\% (8 of 374 hips). The most common reason for revision was infection $(\mathrm{n}=11,3 \%)$. Table 1 lists all of revision diagnoses.

\section{Survivorship Curves}

Survivorship was $89 \%$ at 12.6 years with revision for any reason as the end point. However, survivorship was $93 \%$ when limited to revision for ALTR as the end point. Survivorship decreased to $75 \%$ when failure included revision for ALTR and/or the patient had elevated metal ion levels Figure 1.

\section{Factors Associated with Metallosis Related Failure}

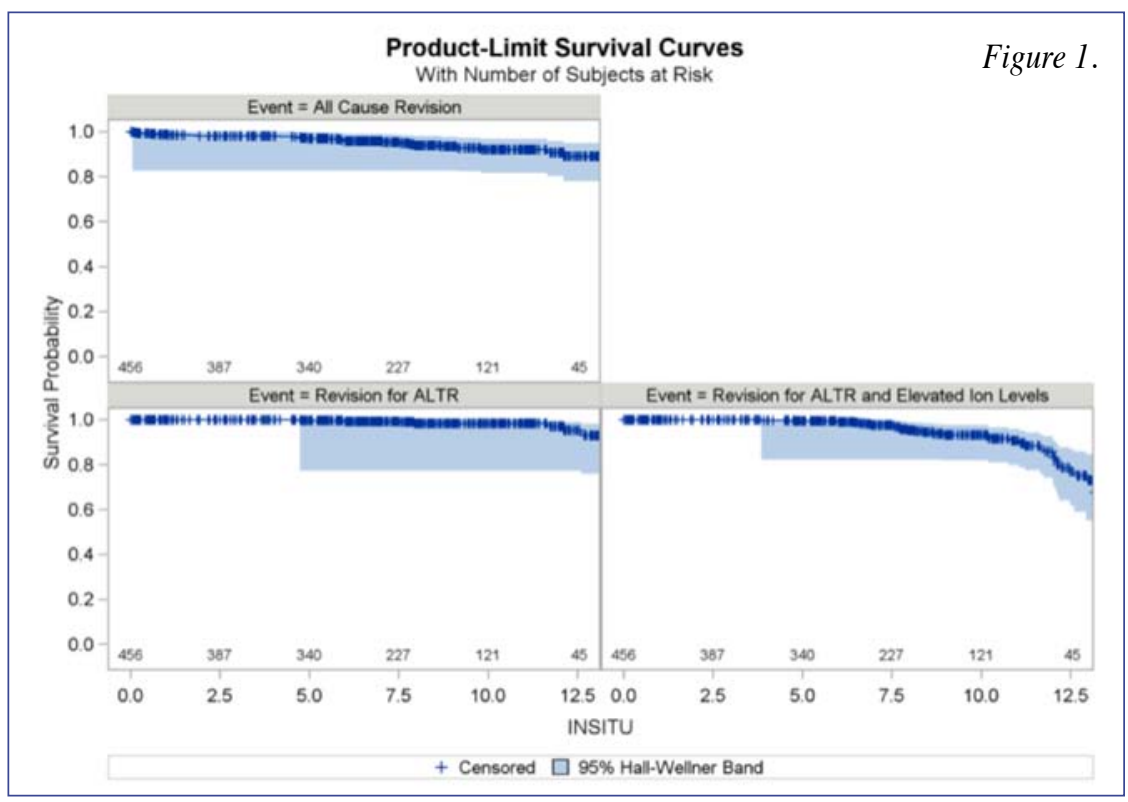

We evaluated patient and implant-related factors to determine if any were significantly associated with metallosis related failure defined as revision for ALTR or ion levels $>4.0$ (Table 2). There were no signifi-

Table 2: Univariate Analysis:

\begin{tabular}{|l|l|l|}
\hline & OR (95\% C.I.) & P-value \\
\hline Abduction Angle & $1.012(0.960,1.067)$ & 0.6539 \\
\hline Head Size & $0.939(0.833,1.059)$ & 0.3063 \\
\hline Cup Size & $1.056(0.969,1.151)$ & 0.2127 \\
\hline Age & $1.016(0.984,1.048)$ & 0.3347 \\
\hline Sex (ref. group Male) & $0.964(0.493,1.883)$ & 0.9143 \\
\hline Time in situ & $1.322(1.184,1.477)$ & $<0.0001^{* * *}$ \\
\hline
\end{tabular}

OR: odds ratio, C.I.: confidence interval, ref.: reference

*** Significant at the 0.001 probability level

cant associations between patient age or sex and the rate of metallosis related failure. Additionally, there were no significant differences in head size or cup abduction between those that had a metallosis related failure and those that did not. Time in situ was the only risk factor significantly associated $(\mathrm{p}<0.0001)$. Because only one variable, time in situ, was found to be significantly associated with failure at the bivariate level a multivariable regression model was not pursued.

Scatterplots were then constructed to evaluate how metal ions correlate with time in situ. The scatterplots in Figures 2 and 3 illustrate minimal positive correlations between cup abduction and time in situ and metal ion levels for unilateral patients only. As the time in situ increased the

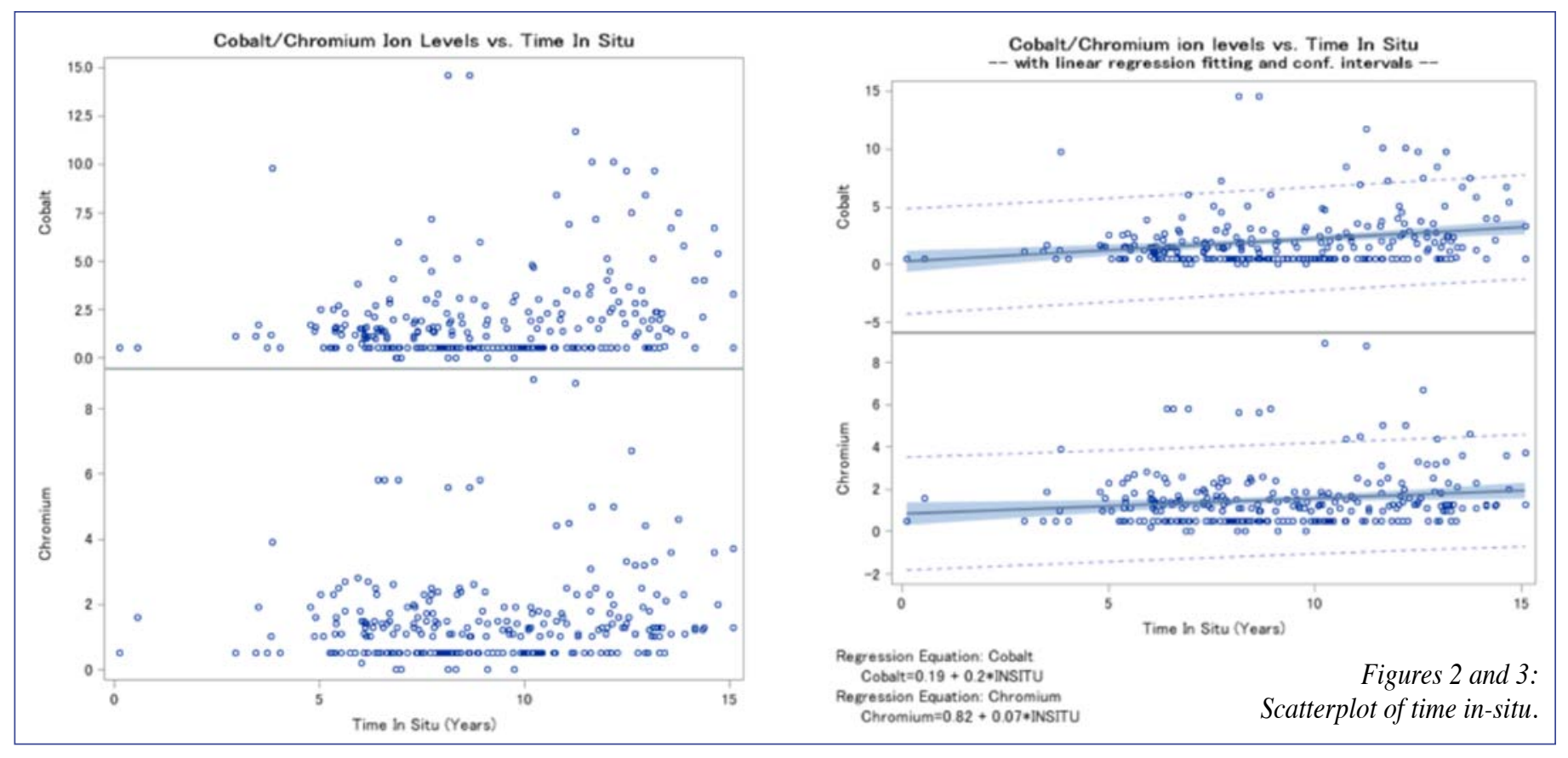


odds of failure significantly $(\mathrm{p}=.0008)$ increased (OR 1.39, 95\% CI 1.15-1.68). Best fit lines were included to graphically demonstrate an increase with time.

\section{Demographics of Patients with elevated metal ion levels}

35 patients were identified with elevated metal ion levels. There were 13 females and 22 males. The average cup abduction angle was 40 degrees and femoral head size and cup size were $36 \mathrm{~mm}$ and $56 \mathrm{~mm}$, respectively. 13 patients had both Chromium and Cobalt levels $\geq 4.0$, (range: Cobalt 4.7 - 14.6, Chromium 4.4 - 8.9). 2 patients had (only) Chromium levels $\geq 4.0$, (range: Chromium 5.8 - 5.8). 20 patients had (only) Cobalt levels $\geq 4.0$, (range: Cobalt 4.0 - 9.8).

\section{Demographics of patients revised for ALTR}

8 of 374 patients were revised for ALTR during this study. This group was comprised of 6 males and 2 females with an average age of 52. The average cup abduction angle was 41 degrees. The average femoral head size was 36 $\mathrm{mm}$ and cup size was $56 \mathrm{~mm}$. The average Co level was 7.67 and $\mathrm{Cr}$ level was 4.57.

Utilizing the grading system of Griffin et al, all intraoperative ALTRs received a score based on the extent of soft tissue necrosis [14]. (Grade $0=$ no metallosis; Grade $1=$ metallic staining, intracapsular fluid; Grade $2=$ extracapsular fluid; Grade 3 = extracapsular tissue necrosis). Of the 8 patients revised for ALTR, one patient had $1+$, four patients had $2+$, and three patients had $3+$ involvement.

\section{Discussion}

MoM THA has been largely abandoned in the United States due to concerns about adverse local tissue reactions related to metal ion release. Revision rates have been reported to be as high as $40 \%$ with the ASR cup at an average follow-up of 5 years [ $\underline{3}$ ]. Larger femoral head size has demonstrated significant elevations in metal ion levels [15]. However, not all MoM implants, have demonstrated these poor results. Specifically, the Pinnacle modular MoM design has demonstrated implant survivorship that is substantially better with a 7-year revision free survivorship of $97.8 \%$ [11]. The results of our study are also substantially better than other MoM designs with an 89\% survivorship at 12.6 years.

Screening protocols for patients with MoM THA are surgeon dependent, but commonly involve a combination of cobalt and chromium ion levels and cross-sectional imaging with MRI or US. However, there are numerous issues with these screening techniques. First, metal ion lev- els do not necessarily correlate with adverse local tissue reactions $[7,16]$. Second, the definition of "elevated" metal ion levels is not standardized. Cutoffs of $4.0 \mathrm{ppb}$ are commonly utilized, but ALTR can occur with levels under this. Finally, if a patient is identified with an "elevated" metal ion level, an MRI scan is commonly obtained. Fluid collections and or pseudotumors appear to be a common finding even in MoP and and CoP THA $[\underline{17}, \underline{18}]$. Furthermore, many of these lesions identified in MoM THAs have been demonstrated to decrease with time [19].

Currently, some advocate screening patients with a MoM THA every year with cobalt and chromium metal ion levels. Screening labs at our institution cost approximately 300 dollars per patient. 8 patients were identified and revised for ALTR during a 12.6 year time interval. For this study alone, the screening costs would be approximately 175,313 dollars to identify one patient with an ALTR, not including the costs of "elevated" levels where an MRI was obtained to confirm the diagnosis.

The results from this study indicate that the time in-situ was the only variable associated with an increased rate of failure. It is unclear what caused the late release of metal ions demonstrated in this study. The modular liner, bearing surface, or taper all represent potential sites of metal ion release, but without a formal analysis of the implants, we are unable to comment on the predominant source. Cup abduction angle, head size, sex, and patient age did not correlate with ion levels. Therefore, long-term follow-up is likely necessary for continuing surveillance in this patient population.

There were several limitations to this study. First, not all patients underwent a uniform screening protocol. Patients were implanted prior to our current understanding of the risks associated with MoM THAs. Therefore, screening protocols have changed with time and are not standardized amongst all surgeons. Secondly, serial ion levels were not included in this study. It is possible that metal ion levels that are initially low will remain low, whereas elevated levels may portend a worse prognosis and continue to trend upward. Finally, we have included only one implant, the Pinnacle two-piece MoM implant. This particular implant appears to have substantially improved results compared to other MoM implant designs and therefore this data is not necessarily applicable to all MoM THAs.

\section{Conclusion}

ALTR remains a challenging problem after MoM THA. However, we identified only 8 patients $(2 \%)$ who underwent revision secondary to ALTR at 12.6 years with the 
Pinnacle two-piece MoM design. Therefore, the vast majority of patients with this implant are being serially screened with a low probability of identifying an ALTR. Time in-situ was the only risk factor we identified that was associated with revision for ALTR. Therefore, improved screening protocols for MoM THA surveillance are necessary to improve detection and decrease cost.

\section{References}

1. Silverman EJ, Ashley B, Sheth NP. Metal-on-metal total hip arthroplasty: is there still a role in 2016? Curr Rev Musculoskelet Med [Internet]. 2016 Mar [cited 2017 Apr 24];9(1):93-6. Available from: http://www.ncbi.nlm.nih.gov/ pubmed/26791173

2. Williams D, Royle M, Norton M. Metal-on-Metal Hip Resurfacing. J Arthroplasty [Internet]. 2009 Jan [cited 2017 Apr 24];24(1):144-51. Available from: http:// www.ncbi.nlm.nih.gov/pubmed/18823742

3. Bernthal NM, Celestre PC, Stavrakis AI, Ludington JC, Oakes DA. Disappointing short-term results with the DePuy ASR XL metal-on-metal total hip arthroplasty. J Arthroplasty [Internet]. 2012 Apr [cited 2016 Jul 17];27(4):539-44. Available from: http://www.ncbi.nlm.nih.gov/pubmed/22000575

4. Clayton RAE, Beggs I, Salter DM, Grant MH, Patton JT, Porter DE. Inflammatory Pseudotumor Associated with Femoral Nerve Palsy Following Metal-on-Metal Resurfacing of the Hip: A Case Report. JBJS Case Connect [Internet]. 2008 Sep 1 [cited 2015 Jul 1];os-90(9):1988-93. Available from: http://www.ncbi.nlm.nih. gov/pubmed/18762660

5. Fricka KB, Ho H, Peace WJ, Engh CA. Metal-on-metal local tissue reaction is associated with corrosion of the head taper junction. J Arthroplasty [Internet]. 2012 Sep [cited 2016 Jul 17];27(8 Suppl):26-31.e1. Available from: http://www.ncbi. nlm.nih.gov/pubmed/22554728

6. Madanat R, Hussey DK, Donahue GS, Potter HG, Wallace R, Bragdon C, et al. Early Lessons From a Worldwide, Multicenter, Followup Study of the Recalled Articular Surface Replacement Hip System. Clin Orthop Relat Res [Internet]. 2016 Jan [cited 2016 Jul 17];474(1):166-74. Available from: http://www.ncbi. nlm.nih.gov/pubmed/26310677

7. Griffin WL. Metal ion levels: how can they help us? J Arthroplasty [Internet]. 2014 Apr [cited 2015 Aug 15];29(4):659-60. Available from: http://www.ncbi. nlm.nih.gov/pubmed/24655610

8. Smolders JMH, Hol A, van Susante JLC. Metal ion trend may be more predictive for malfunctioning metal-on-metal implants than a single measurement. Hip Int [Internet]. 2013 [cited 2017 Jun 28];23(5):434-40. Available from: http://www. ncbi.nlm.nih.gov/pubmed/23934907

9. Kiran M, Shivarathre D, Peter VK. Blood Metal Ion Levels Have Limited Utility in the Surveillance of Asymptomatic Large-Head Metal-on-Metal Total Hip Arthroplasties. J Arthroplasty [Internet]. 2017 Jul 20 [cited 2017 Sep 6]; Available from: http://www.ncbi.nlm.nih.gov/pubmed/28781016

10. Barrett WP, Kindsfater KA, Lesko JP. Large-diameter modular metal-on-metal total hip arthroplasty: incidence of revision for adverse reaction to metallic debris. J Arthroplasty [Internet]. 2012 Jun [cited 2017 Mar 20];27(6):976-83.e1. Available from: http://linkinghub.elsevier.com/retrieve/pii/S0883540312000630

11. Kindsfater KA, Sychterz Terefenko CJ, Gruen TA, Sherman CM. Minimum 5-year results of modular metal-on-metal total hip arthroplasty. J Arthroplasty [Internet]. 2012 Apr [cited 2017 Mar 20];27(4):545-50. Available from: http://linkinghub.elsevier.com/retrieve/pii/S0883540311003342

12. Hothi HS, Eskelinen AP, Berber R, Lainiala OS, Moilanen TPS, Skinner JA, et al. Factors Associated With Trunnionosis in the Metal-on-Metal Pinnacle Hip. J Arthroplasty [Internet]. 2017 Jan [cited 2017 Apr 24];32(1):286-90. Available from: http://www.ncbi.nlm.nih.gov/pubmed/27471212
13. Atrey A, Hart A, Hussain N, Waite J, Shepherd AJ, Young S. 601 metal-on-metal total hip replacements with $36 \mathrm{~mm}$ heads a 5 minimum year follow up: Levels of ARMD remain low despite a comprehensive screening program. J Orthop [Internet]. 2017 Mar [cited 2017 Apr 24];14(1):108-14. Available from: http://www. ncbi.nlm.nih.gov/pubmed/27829734

14. Griffin WL, Fehring TK, Kudrna JC, Schmidt RH, Christie MJ, Odum SM, et al. Are Metal Ion Levels a Useful Trigger for Surgical Intervention? J Arthroplasty [Internet]. 2012 Sep [cited 2018 Feb 9];27(8):32-6. Available from: http://www. ncbi.nlm.nih.gov/pubmed/22608683

15. Clarke MT, Lee PTH, Arora A, Villar RN. Levels of metal ions after small- and large-diameter metal-on-metal hip arthroplasty. J Bone Joint Surg Br [Internet]. 2003 Aug 1 [cited 2019 Jul 3];85-B(6):913-7. Available from: http://online.boneandjoint.org.uk/doi/10.1302/0301-620X.85B6.14166

16. Campbell PA, Kung MS, Hsu AR, Jacobs JJ. Do Retrieval Analysis and Blood Metal Measurements Contribute to Our Understanding of Adverse Local Tissue Reactions? Clin Orthop Relat Res [Internet]. 2014 Dec 27 [cited 2017 Apr 26];472(12):3718-27. Available from: http://www.ncbi.nlm.nih.gov/ pubmed/25160942

17. Fehring TK, Fehring K, Odum SM. Metal Artifact Reduction Sequence MRI Abnormalities Occur in Metal-on-polyethylene Hips. Clin Orthop Relat Res [Internet]. 2015 Feb 21 [cited 2017 Apr 26];473(2):574-80. Available from: http://www. ncbi.nlm.nih.gov/pubmed/25141843

18. Jennings JM, Martin JR, Kim RH, Yang CC, Miner TM, Dennis DA. Metal Artifact Reduction Sequence MRI Abnormalities in Asymptomatic Patients with a Ceramic-on-Polyethylene Total Hip Replacement. J Bone Jt Surg [Internet]. 2017 Apr 5 [cited 2017 Apr 26];99(7):593-8. Available from: http://www.ncbi.nlm.nih. gov/pubmed/28375892

19. Goldstein JM, Fehring TK, Fehring KA. Cystic Adverse Local Tissue Reactions in Asymptomatic Modular Metal-on-Metal Total Hips May Decrease Over Time. J Arthroplasty [Internet]. 2016 Jul [cited 2017 Apr 26];31(7):1589-94. Available from: http://www.ncbi.nlm.nih.gov/pubmed/26900148

\section{SUBMISSION HISTORY}

Submitted: May 2, 2019

Reviewed: June 9, 2019

Revised: July 10, 2019

Accepted: June 2, 2019

Published: November 12, 2019

AUTHOR AFFILIATIONS

1 J. Ryan Martin, MD; William Griffin, MD OrthoCarolina, Hip and Knee Center, Charlotte, NC - USA

2 Susan M. Odum, PhD OrthoCarolina Research Institute, Charlotte, NC - USA

(Direct inquires to Ryan Martin, johrmart@gmail.com)

\section{AUTHOR DISCLOSURES}

The authors declare that there are no disclosures regarding the publication of this paper.

\section{COPYRIGHT \& OPEN ACCESS}

(C) 2019 Martin, Odum, Griffin. All rights reserved. Authors retain copyright and grant the journal right of first publication with the work Reconstructive Review is an open access publication and follows the Creative Commons Attribution-NonCommercial CC BY-NC. This license allows anyone to download works, build upon the material, and share them with others for non-commercial purposes as long as they credit the senior author, Reconstructive Review, and the Joint Implant Surgery \& Research Foundation (JISRF). An example credit would be: "Courtesy of (senior author's name), Reconstructive Review, JISRF, Chagrin Falls, Ohio". 
Signature Orthopaedics France L'Arobase - 2 Rue Georges Charpak 81100 CASTRES
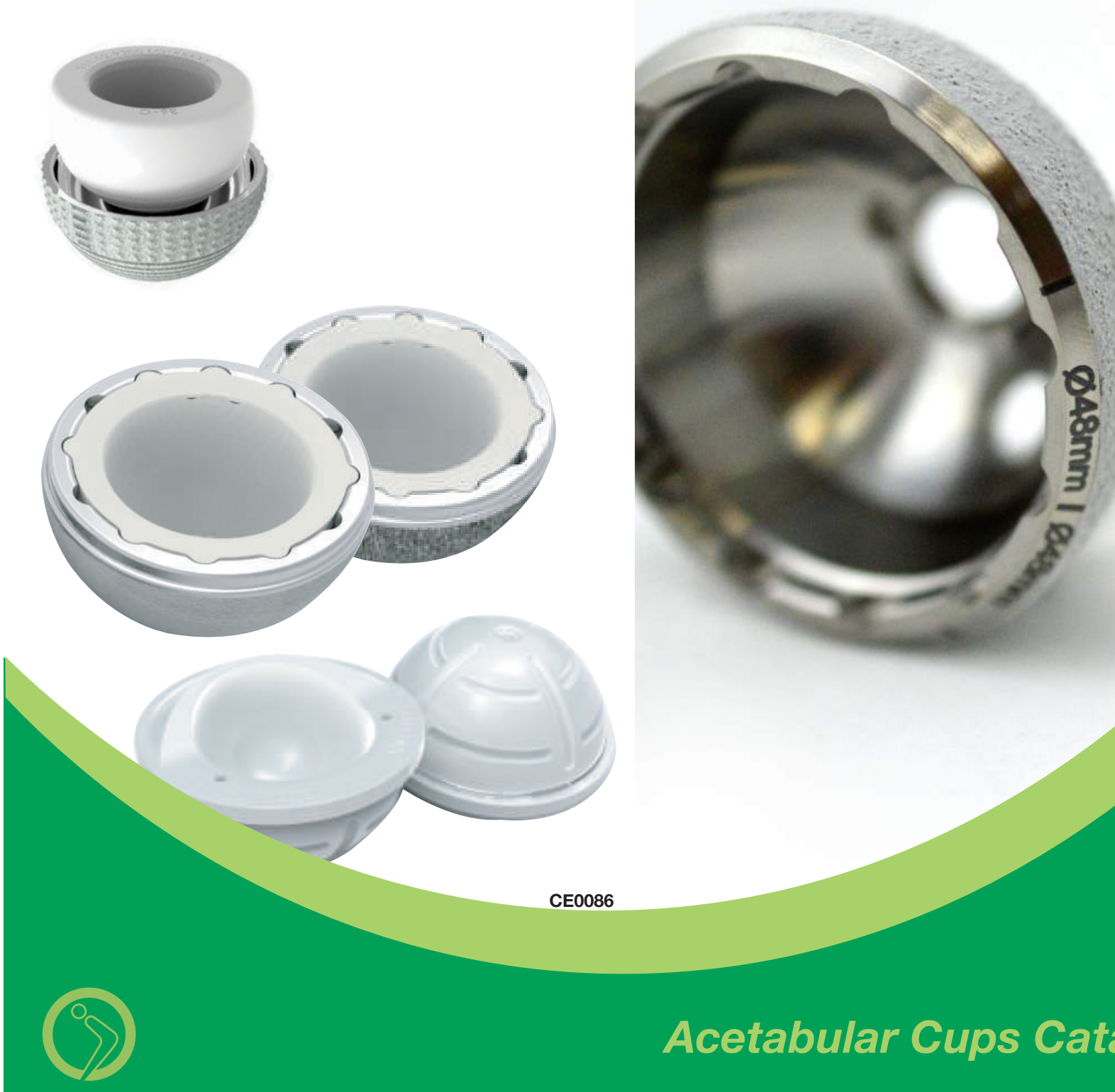

\section{Acetabular Cups Catalogue}

000-000-000

Signature Orthopaedics Europe 88 Harcourt St Dublin Ireland T+353 $16915293 \mathrm{~F}+35316915010$
Signature Orthopaedics Australia

7 Sirius Rd Lane Cove West NSW Australia

T+61 294285181 F+61 284566065

info@signatureortho.com.au

www.signatureortho.com.au 

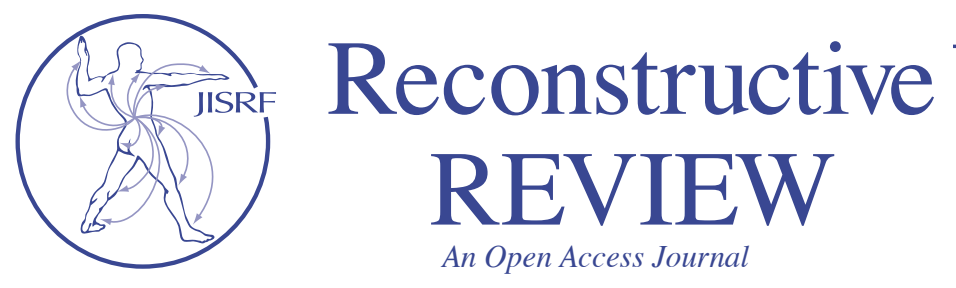

Check for updates

\section{Risk Factors for Blood Transfusion After Primary Total Hip Arthroplasty}

Kesler K ${ }^{1}$, Brown $T^{1}$, Martin $J^{2}{ }^{2}$, Springer $B D^{2}$, Otero $J E^{1}$

\begin{abstract}
Background: In the setting of rising healthcare costs, more cost efficiency in total hip arthroplasty (THA) is required. Following THA, most patients are monitored with serial hemoglobin/hematocrit $(\mathrm{H} / \mathrm{H})$ testing despite few needing blood transfusions. This testing adds cost and may not be necessary in most patients. This study aims to identify factors associated with transfusion, therefore guiding $\mathrm{H} / \mathrm{H}$ monitoring following THA.
\end{abstract}

Patients and Methods: Patients who underwent primary THA in 2015 were identified using the National Surgical Quality Improvement Project (NSQIP) database. Patients discharged on the day of surgery were excluded. Patients were classified into those receiving transfusion versus no transfusion. Demographics and comorbidities were compared between groups followed by univariate and multivariate analysis, allowing identification of patient characteristics and comorbidities associated with transfusion.

Results: Overall, 28664 patients who underwent THA patients were identified. Within this group, 6.1\% $(n=1737)$ had a post-operative transfusion. Patients receiving a blood transfusion were older, had lower body mass index, and had higher rates of chronic obstructive pulmonary disease (COPD), heart failure, dialysis, prior transfusion, and were more frequently ASA class 3-4 ( $<<0.001)$. Univariate analysis demonstrated that patients requiring transfusion had higher complication rates (4.3\% vs. $12.8 \%, \mathrm{p}<0.0001)$. Multivariate analysis identified age $>70$, diabetes, smoking, COPD, prior transfusion, and operative time $>2$ hours as independent risk factors for transfusion.
Conclusion: Among THA patients, characteristics and comorbidities exist that are associated with increased likelihood of transfusion. Presence of these factors should guide $\mathrm{H} / \mathrm{H}$ monitoring post-operatively. Selective $\mathrm{H} / \mathrm{H}$ monitoring can potentially decrease the cost of THA.

\section{Background}

As the procedure improves and the population ages, the demand for and frequency of primary total hip arthroplasty (THA) continues to increase within the United States. The demand for primary THA is projected to grow by $174 \%$ to 572,000 cases annually in 2030 in the United States. [1] In the current climate of increasing healthcare costs, this raises the importance of efficiency and cost-effectiveness in THA. Laboratory testing is the single highest volume medical activity and a significant factor in inpatient cost. [2] Reflex daily phlebotomy has been shown to be a significant contributor to cost and multiple strategies are being implemented to reduce its frequency throughout inpatient stays. [준 $\underline{\text { ] }}$ Daily postoperative hemoglobin/hematocrit $(\mathrm{H} / \mathrm{H})$ monitoring in THA is commonplace. However, if appropriately screened preoperatively, only a minority of patients actually progress to thresholds that require an allogenic blood transfusion. [5-7] Costs vary by institution with a recent study quoting $\$ 2800$ as the cost for postop-

Keywords: joint replacement; hip arthroplasty; blood transfusion; hemoglobin testing; hematocrit testing; phlebotomy

Level of Evidence: III (Case control study) 
erative day one $\mathrm{H} / \mathrm{H}$ testing per 100 joint replacement patients compared to $\$ 4000$ at the authors institution. [] Extrapolated across the entire United States joint replacement practice, there is significant opportunity to improve the cost of THA.

In effort to contain cost in THA while maintaining patient safety, thoughtful utilization of postoperative laboratory monitoring is an important modifiable variable. To date, multiple studies have investigated and proposed strategies for minimizing blood transfusion following THA. $[\underline{6}, \underline{8}, \underline{9}]$ It has been mentioned in the literature that hemoglobin testing is likely over utilized, however, data regarding when postoperative hemoglobin testing is necessary is lacking. [ $[$ ] The hypothesis of this retrospective case-control study is that objective factors associated with transfusion exist and could be used to guide more selective and cost effective postoperative $\mathrm{H} / \mathrm{H}$ monitoring in THA.

\section{Patients and Methods}

\section{Data Collection and Patient Selection}

With institutional review board approval, a large database retrospective analysis was performed. The American College of Surgeons National Surgical Quality Improvement Program (NSQIP) database was used to identify patients who underwent THA in 2015 using the primary current procedural terminology code for THA (27130). In an effort to isolate data regarding allogenic (donor) blood transfusions, those patients who discharged on the day of surgery were excluded from analysis as any day of surgery discharge transfusions would primarily represent autogenic transfusions collected, for example, in a Cell Saver System during surgery (Haemonetics Corp., Braintree, MA). This resulted in a final cohort of 28664 patient records available for analysis.

\section{Variables}

Patient demographic factors such as age, gender, race, body mass index, and functional status were easily assessable within the database. [For complete list, refer to Table I] In addition, data on patient comorbidities, pre-operative, and operative variables were collected from the database. These variables were characterized with respect to whether a patient did or did not receive a blood transfusion postoperatively and analyzed accordingly. [Table II]

\section{Outcomes}

The primary outcome examined between groups was whether patients received a blood transfusion post-operatively during the patient's hospital stay. As a means to build a multivariate model, the occurrence of post-operative complications in both the transfused and non-transfused groups was also addressed.

\section{Statistics}

Each patient's demographic factors, health factors, or comorbidities were compared using a univariate analysis with a p-value of less than 0.05 representing significance. Continuous variables were compared using a two-tailed student t-test whereas categorical variables were compared using a chi-squared test. In addition, this large dataset provided the ability to create a logistic regression model to analyze the data in a multivariate manner. The multivariate analysis was created using independent variables from the univariate comparison with p-values less than 0.1 . This allowed calculation of odds ratios based on the factors included and was expressed as a ratio with a $95 \%$ confidence interval. [Table III]

\section{Results}

In total from the database, 28,664 patients were identified who met study criteria. Within this group, $6.1 \%$ $(n=1737)$ received an allogenic blood transfusion postoperatively. In the transfusion group, patients were significantly older (64.5 vs. 67.3 years, $\mathrm{p}<0.001)$, more likely to be female $(53.8 \%$ vs. $68.7 \%, \mathrm{p}<0.001)$, had a lower body mass index $(24.4 \mathrm{vs} .21 .1 \mathrm{~kg} / \mathrm{m} 2, \mathrm{p}<0.001)$ and were more frequently ASA class $3-4$ (41.9\% vs. $58.5 \%$, p<0.001). Of note, the groups were not significantly different with regard to race or recent weight loss. [Table I]

Furthermore, univariate analysis of the groups demonstrated that patients in the transfusion group were significantly more likely to have COPD, congestive heart failure (CHF), dialysis, prior steroid use, history of bleeding disorder, and history of previous blood transfusion. With respect to pre-operative laboratory values, hematocrit, creatinine, serum albumin, and INR were all statistically worse in the transfusion group. The transfusion group was more likely to have a longer operation. [Table I]

There were statistically significant differences between the groups regarding post-operative complications with patients who received transfusions having higher rates of overall complications (12.78\% versus $4.28 \%$ respectively, $\mathrm{p}<0.001)$. Despite the overall high rate of complications, there were not statistically higher rates of wound dehiscence, deep vein thrombosis, pulmonary embolism, or stroke. All other measured complications where higher in the transfusion group. [Table II]

Multivariate logistic regression analysis revealed inde- 
Table I. Demographics, Comorbidities, Pre-operative, and Operative Variables

\begin{tabular}{|c|c|c|c|}
\hline & No Transfusion $(\mathrm{n}=\mathbf{2 6 9 2 7})$ & Transfusion $(n=1737)$ & p-value \\
\hline \multicolumn{4}{|l|}{ Demographics } \\
\hline Age, mean (SD) & $64.54(11.52)$ & $67.25(13.87)$ & $<0.0001$ \\
\hline Female gender $(\%)$ & 53.76 & 68.74 & $<0.0001$ \\
\hline Race/ethnicity (\%) & & & 0.0006 \\
\hline White & 88.62 & 85.60 & \\
\hline Black & 9.08 & 10.94 & \\
\hline Other & 2.30 & 3.45 & \\
\hline BMI (kg/m2), mean (SD) & $24.38(9.19)$ & $21.70(9.14)$ & $<0.0001$ \\
\hline Recent weight loss $(\%)$ & 0.17 & 0.40 & 0.0252 \\
\hline ASA class $(\%)$ & & & $<0.0001$ \\
\hline 1 - No Disturbance & 4.04 & 1.50 & \\
\hline 2 - Mild Disturbance & 54.06 & 40.01 & \\
\hline 3 - Severe Disturbance & 40.32 & 54.17 & \\
\hline 4- Life Threatening Disturbance/5-Moribund & 1.58 & 4.32 & \\
\hline Functional Status (\%) & & & $<0.0001$ \\
\hline Independent & 98.22 & 94.22 & \\
\hline Dependent & 1.78 & 5.78 & \\
\hline \multicolumn{4}{|l|}{ Pre-operative health and comorbidities } \\
\hline Diabetes mellitus $(\%)$ & 11.53 & 13.82 & 0.0040 \\
\hline Smoking $(\%)$ & 13.90 & 11.28 & 0.0021 \\
\hline Chronic obstructive pulmonary disease $(\%)$ & 3.88 & 6.10 & $<0.0001$ \\
\hline Congestive heart failure $(\mathrm{CHF})(\%)$ & 0.27 & 0.81 & $<0.0001$ \\
\hline Dialysis $(\%)$ & 0.21 & 0.86 & $<0.0001$ \\
\hline Steroids (\%) & 3.65 & 5.76 & $<0.0001$ \\
\hline Bleeding disorder $(\%)$ & 1.88 & 5.53 & $<0.0001$ \\
\hline Pre-op blood transfusion $(\%)$ & 0.05 & 0.86 & $<0.0001$ \\
\hline Open wound or wound infection (\%) & 0.30 & 0.86 & $<0.0001$ \\
\hline Pre-op Sepsis $(\%)$ & 0.17 & 0.40 & 0.0290 \\
\hline \multicolumn{4}{|l|}{ Pre-operative laboratory values } \\
\hline WBC, Mean (SD) & $7.11(2.74)$ & $7.01(2.69)$ & 0.1478 \\
\hline Hematocrit, Mean (SD) & $41.45(3.97)$ & $37.43(4.87)$ & $<0.0001$ \\
\hline Platelets, Mean (SD) & $248.7(65.55)$ & $251.7(84.50)$ & 0.1560 \\
\hline Creatinine, Mean (SD) & $0.91(0.42)$ & $1.00(0.81)$ & $<0.0001$ \\
\hline Serum Albumin, Mean (SD) & $4.14(0.39)$ & $4.00(0.49)$ & $<0.0001$ \\
\hline INR, Mean (SD) & $1.02(0.22)$ & $1.06(0.34)$ & $<0.0001$ \\
\hline \multicolumn{4}{|l|}{ Operative Variables } \\
\hline Wound class & & & $<0.0001$ \\
\hline Clean & 99.53 & 97.41 & \\
\hline Clean-contaminated & 0.31 & 1.44 & \\
\hline Contaminated & 0.10 & 0.52 & \\
\hline Dirty or infected & 0.07 & 0.63 & \\
\hline \multicolumn{4}{|l|}{ Length of operation, min (SD) } \\
\hline Mean (SD) & $91.62(38.85)$ & $122.0(59.15)$ & $<0.0001$ \\
\hline
\end{tabular}


Table II. Complications

\begin{tabular}{|l|c|c|c|}
\hline Complications (\%) & $\begin{array}{c}\text { No Transfusion } \\
(\mathbf{n = 2 6 9 2 7})\end{array}$ & $\begin{array}{c}\text { Transfusion } \\
(\mathbf{n = 1 7 3 7})\end{array}$ & p-value \\
\hline Any Complication & 4.28 & 12.78 & $<0.0001$ \\
\hline \multicolumn{5}{|l|}{} \\
\hline Superficial Wound Infection & 0.59 & 0.92 & 0.0821 \\
\hline Deep Wound Infection & 0.34 & 0.81 & 0.0020 \\
\hline Organ Space Infection & 0.25 & 0.63 & 0.0029 \\
\hline Wound Dehiscence & 0.16 & 0.23 & 0.5309 \\
\hline Pneumonia & 0.27 & 1.78 & $<0.0001$ \\
\hline Urinary Tract Infection & 0.76 & 2.19 & $<0.0001$ \\
\hline Sepsis & 0.25 & 0.58 & 0.0107 \\
\hline Septic Shock & 0.04 & 0.29 & $<0.0001$ \\
\hline Deep Vein Thrombosis & 0.35 & 0.63 & 0.0531 \\
\hline Pulmonary Embolism & 0.26 & 0.40 & 0.249 \\
\hline Renal Insufficiency & 0.09 & 0.35 & 0.0014 \\
\hline Acute Renal Failure & 0.04 & 0.17 & 0.0402 \\
\hline Stroke & 0.06 & 0.17 & 0.1175 \\
\hline Cardiac Arrest & 0.06 & 0.23 & 0.0299 \\
\hline Myocardial Infarction & 0.17 & 1.15 & $<0.0001$ \\
\hline Unplanned Intubation & 0.13 & 0.40 & 0.0039 \\
\hline Unplanned Re-admission & 3.17 & 7.94 & $<0.0001$ \\
\hline Re-operation & $59(2.12)$ & $4.07(3.88)$ & $<0.0001$ \\
\hline Mortality & & & $<0.0001$ \\
\hline Length of hospital stay (days) & \multicolumn{3}{|l|}{} \\
\hline
\end{tabular}

pendent factors associated with increased transfusion rates including age greater than 70 years, non-independent functional status, ASA class 3 or greater, diabetes, smoking, COPD, pre-operative steroid use, previous transfusion, and operative time greater than 2 hours. Despite significance in univariate analysis, congestive heart failure, dialysis, and a history of a bleeding disorder did not prove to be independently associated with post-operative blood transfusion. [Table III]

\section{Discussion}

Healthcare spending continues to increase and with this increase surgeons, patients, and payers are more interested in controlling cost across hospitals. The cost of laboratory testing has already been recognized as an important area for improvement relating to economical spending. [2-4] Multiple studies, including this study, have demonstrated that allogenic blood transfusions occur at nontrivial rates following THA.[ㅍ-9] These studies addressed frequency
Table III. Multivariable logistic regression for the probability of blood transfusion

\begin{tabular}{|l|c|c|}
\hline & $\begin{array}{c}\text { Odds } \\
\text { Radio }\end{array}$ & $\begin{array}{c}\mathbf{9 5 \%} \text { Confidence } \\
\text { Interval }\end{array}$ \\
\hline Age 50-60 versus <50 & 0.96 & $0.74-1.25$ \\
\hline Age 60-70 versus <50 & $\mathbf{0 . 9 5}$ & $\mathbf{0 . 7 4}-\mathbf{1 . 2 3}$ \\
\hline Age 70-80 versus <50 & $\mathbf{1 . 3 6}$ & $\mathbf{1 . 0 5}-\mathbf{1 . 7 7}$ \\
\hline Age >80 versus <50 & 1.48 & $1.11-1.98$ \\
\hline Female Gender & 1.11 & $0.98-1.26$ \\
\hline Race & 0.93 & $0.61-1.40$ \\
\hline $\begin{array}{l}\text { Non-independent } \\
\text { functional status }\end{array}$ & $\mathbf{1 . 5 1}$ & $\mathbf{1 . 1 0}-\mathbf{2 . 0 6}$ \\
\hline ASA class (\%) & 1.25 & $0.76-2.05$ \\
\hline 2 - Mild Disturbance & $\mathbf{2 . 1}$ & $\mathbf{1 . 2 8}-\mathbf{3 . 4 6}$ \\
\hline 3 - Severe Disturbance & $\mathbf{3 . 6}$ & $\mathbf{1 . 9 9}-\mathbf{6 . 3 8}$ \\
\hline $\begin{array}{l}\text { 4- Life Threatening } \\
\text { Disturbance/5-Moribund }\end{array}$ & $\mathbf{1 . 2}$ & $\mathbf{1 . 0 1}-\mathbf{1 . 4 3}$ \\
\hline Diabetes mellitus & $\mathbf{1 . 2 1}$ & $\mathbf{1 . 0 1}-\mathbf{1 . 4 5}$ \\
\hline Smoking (\%) & $\mathbf{1 . 3 3}$ & $\mathbf{1 . 0 4}-\mathbf{1 . 7 0}$ \\
\hline $\begin{array}{l}\text { Chronic obstructive } \\
\text { pulmonary disease }(\%)\end{array}$ & 1.31 & $0.65-2.68$ \\
\hline $\begin{array}{l}\text { Congestive heart failure } \\
\text { (CHF)(\%) }\end{array}$ & 1.03 & $0.43-2.43$ \\
\hline Dialysis (\%) & $\mathbf{1 . 4 8}$ & $\mathbf{1 . 1 4}-\mathbf{1 . 9 1}$ \\
\hline Steroids (\%) & 1.06 & $0.76-1.48$ \\
\hline Bleeding disorder (\%) & $\mathbf{3 . 4 6}$ & $\mathbf{1 . 3 3}-\mathbf{9 . 0 2}$ \\
\hline $\begin{array}{l}\text { Pre-op blood transfusion } \\
\text { (\%) }\end{array}$ & $\mathbf{1 . 2 4}$ & $\mathbf{1 . 0 7}-\mathbf{1 . 4 3}$ \\
\hline Operative Time >2 hours & & \\
\hline
\end{tabular}

of transfusion as well as strategies for minimizing rates of transfusion; however, the avoidance of reflex $\mathrm{H} / \mathrm{H}$ testing was not addressed in prior studies. In this cohort, the $6.1 \%$ $(n=1737)$ of patients who received allogenic blood transfusions represent a minority of the over 28,000 patient analyzed, many of whom underwent serial $\mathrm{H} / \mathrm{H}$ testing.

It was our belief that associated factors exist that would be able to guide more appropriate $\mathrm{H} / \mathrm{H}$ testing in patients following THA. This study sought to isolate patients who under went THA and evaluate if such statistically significant factors exist. Our results indicate that those patients at the highest risk requiring a transfusion tended to be older and had lower body mass indices in addition to having higher ASA classes. Pre-operative laboratory values including hematocrit, creatinine, serum albumin, and INR were all statistically worse in the transfusion group, however, the differences between the two groups regarding laboratory values were thought to be below clinical sig- 
nificance and not included in multivariate analysis. [Table I] Comorbidities including diabetes, COPD, and smoking proved to be a significant in the multivariate analysis and demonstrate that these represent independent risk factors.

Further study will likely be needed prior to the development of specific guidelines for $\mathrm{H} / \mathrm{H}$ testing after THA, however, it is our recommendation from the findings in this study that surgeons critically evaluate whether is $\mathrm{H} / \mathrm{H}$ testing is necessary for all patients. Specifically, non-smoking patients under 70 years old without a history of steroid use or previous transfusion who are independent at baseline and do not carry a diagnosis of COPD or diabetes deserve extra consideration regarding the necessity of daily reflex $\mathrm{H} / \mathrm{H}$ testing.

This study is not without imitations. As in all database studies, the findings in this study rely on accurate coding and documentation including that of comorbidities and transfusion events in the electronic medical record. Tranexamic acid (TXA) administration likely plays a role in rates of transfusion following THA. TXA use, dosing, and timing varies widely between practices and was not evaluated as part of this study. As TXA use increases and potentially standardizes it may serve as another factor influencing decisions regarding $\mathrm{H} / \mathrm{H}$ testing. In addition, there is some ambiguity relating to the transfusion $\mathrm{H} / \mathrm{H}$ threshold used by various surgeons. It is a necessary assumption that most surgeons would be following generally accepted transfusion guidelines and we do not believe this assumption affects the generalizability or validity of this study.

In a large cohort of patients who underwent THA, independent demographic characteristics, operative factors, and comorbidities exist that are statistically associated with an increased likelihood of transfusion. Given these findings, it is recommended that surgeons critically evaluate the necessity and utility of reflex daily $\mathrm{H} / \mathrm{H}$ in those patients that are the least likely to meet transfusions thresholds. Further studies regarding specific guidelines for $\mathrm{H} / \mathrm{H}$ testing should be conducted and ultimately may result in more efficient healthcare resource utilization.

\section{References}

1. Kurtz, S., et al., Projections of primary and revision hip and knee arthroplasty in the United States from 2005 to 2030. JBJS, 2007. 89(4): p. 780-785.

2. Zhi, M., et al., The landscape of inappropriate laboratory testing: a 15 -year metaanalysis. PloS one, 2013. 8(11): p. e78962.

3. Stuebing, E.A. and T.J. Miner, Surgical vampires and rising health care expenditure: reducing the cost of daily phlebotomy. Archives of Surgery, 2011. 146(5): p. 524-527.

4. May, T.A., et al., Reducing unnecessary inpatient laboratory testing in a teaching hospital. American journal of clinical pathology, 2006. 126(2): p. 200-206.

5. Hart, A., et al., Blood transfusion in primary total hip and knee arthroplasty. Incidence, risk factors, and thirty-day complication rates. JBJS, 2014. 96(23): p. 1945-1951.

6. Holt, J.B., et al., Minimizing blood transfusion in total hip and knee arthroplasty through a multimodal approach. The Journal of arthroplasty, 2016. 31(2): p. 378382.

7. Bedard, N.A., et al., Recent trends in blood utilization after primary hip and knee arthroplasty. The Journal of arthroplasty, 2017. 32(3): p. 724-727.

8. Martin, J.R., et al., Noninvasive Hemoglobin Monitoring: A Rapid, Reliable, and Cost-Effective Method Following Total Joint Replacement. JBJS, 2016. 98(5): p. 349-355.

9. Frew, N., et al., Impact of a blood management protocol on transfusion rates and outcomes following total hip and knee arthroplasty. The Annals of The Royal College of Surgeons of England, 2016. 98(6): p. 380-386.

\section{SUBMISSION HISTORY}

Submitted: May 2, 2019

Reviewed: June 9, 2019

Revised: July 10, 2019

Accepted: June 2, 2019

Published: November 22, 2019

\section{AUTHOR AFFILIATIONS}

1 Kyle K. Kesler, MD; Timothy S. Brown, MD; Jesse Otero, MD, PhD University of lowa Hospital and Clinics, lowa City, IA - USA

2 J. Ryan Martin, MD; Bryan D. Springer, MD OrthoCarolina, Hip and Knee Center, Charlotte, NC - USA

(Direct inquires to Kyle Kesler, kyle-kesler@uiowa.edu)

AUTHOR DISCLOSURES

This research received no specific grant from any funding agency in the public, commercial, or not-for-profit sectors. The Author(s) declare(s) that there is no conflict of interest.

\section{COPYRIGHT \& OPEN ACCESS}

(C) 2019 Kesler, Brown, Martin, Springer, Otero. All rights reserved. Authors retain copyright and grant the journal right of first publication with the work. Reconstructive Review is an open access publication and follows the Creative Commons Attribution-NonCommercial CC BY-NC. This license allows anyone to download works, build upon the material, senior author Reconstructive Review, and the Joint Implant Surgery \& Research Foundation (JISRF). An example credit would be: "Courtesy of (senior author's name), Reconstructive Review, JISRF, Chagrin Falls, Ohio". 


\section{Eliminate Cable-Generated Metal Debris}

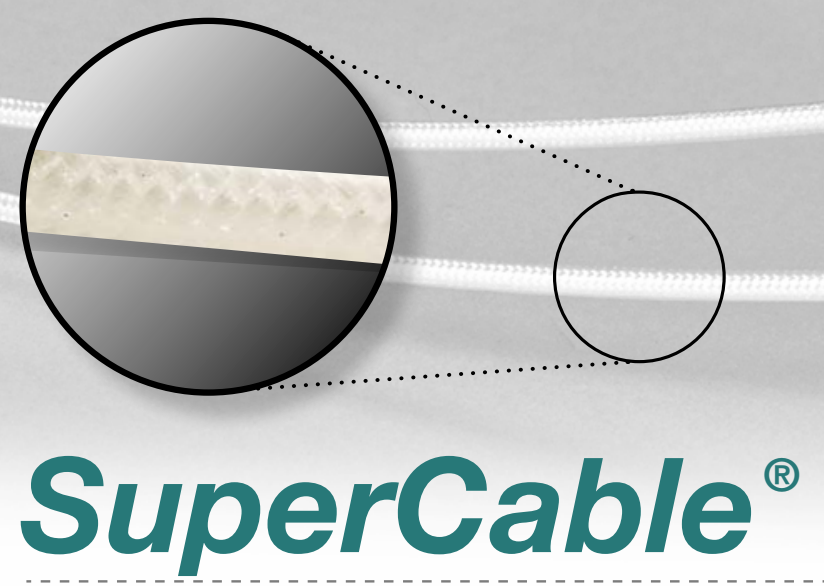

\section{Polymer Cerclage System}

This unique polymer cable eliminates one possible source of metal debris and metal ions in your patient's fracture or reconstructive procedure. Metal cables have been shown to suffer from significant rates of fatigue failure and to contribute to the generation of local and systemic metallic debris burden. ${ }^{1,2}$

Laboratory testing demonstrates that the remarkably tough SuperCable withstands over one million load cycles while fully tensioned and abraded by a simulated bone plate, with negligible damage to the cable and metal plate. ${ }^{3}$

SuperCable has no sharp ends to irritate patient tissue, cut gloves, or create a "sharps injury" risk.

With over 50,000 cables used in cases worldwide since 2004, SuperCable has demonstrated its clinical effectiveness ${ }^{4,5,6}$ and offers significant benefit versus old technology metal cable and wire.

\footnotetext{
1. Callaghan et al (1997) Contribution of cable debris generation to accelerated polyethylene wear. Clin Orthop 344:20.

2. Jacobs et al (2004). Accumulation in liver and spleen of metal particles generated at nonbearing surfaces in hip arthroplasty. J Arthroplasty 19:94.

3. Sarin, Mattchen, Hack (2005) Novel iso-elastic cerclage cable for treatment of fractures. ORS. Washington, DC. 739 .

4. Della Valle et al (2010) Early experience with a novel nonmetallic cable. Clinical Orthop 468:2382. 5. Edwards et al (2011) Utility of polymer cerclage cables in revision shoulder arthroplasty. Orthopedics 34:264

6. Berend, Lombardi et al (2014) Polymer Cable/Grip-Plate System with Locking Screws for Stable Fixation to Promote Healing of Trochanteric Osteotomies or Fractures in Revision Total Hip Arthroplasty. Surg Tech Intl. 25:227.
}

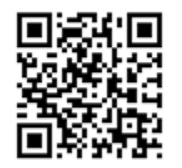

For additional information or to schedule a product evaluation, please give us a call at 800-827-5775. To view a video demonstration, visit us on the Web at: www.kinamed.com

\section{Proven Performance}

- In clinical use since 2004

- Over 50,000 implantations

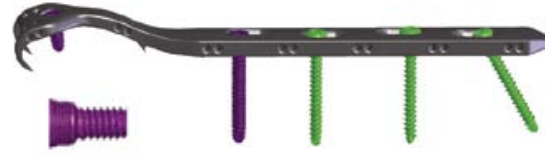

Locking or compression screw can be placed in any screw position
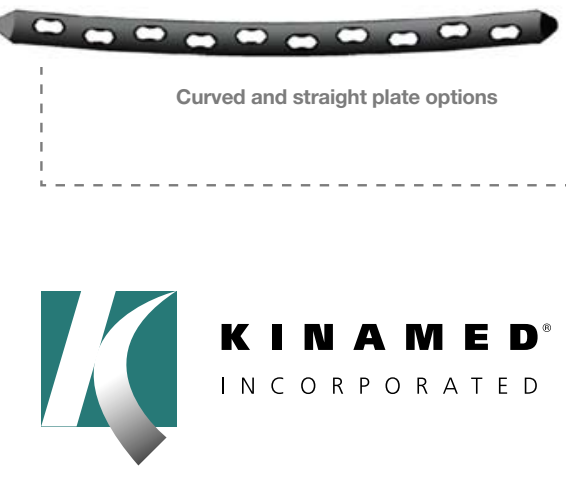

K】 A A M E D

I NCORPORATED

Expect Innovation. 


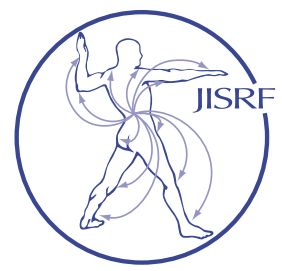

Check for updates

\section{What is Considered a Conflict of Interest or What to Disclose in Lectures and Publications?}

McTighe $T^{1}$

$\mathrm{R}$ ecently our Journal was criticized for allowing a co-author to submit and publish a technical paper when said surgeon is involved in a litigation matter. "I am very surprised indeed that you do not consider being a defendant in legal action concerning the very practice being defended in an article amounts to a conflict of interest."

This made me think it might be an appropriate time to revisit this issue. I think it is important to understand some of the history regarding disclosure and conflict of interest.

What should a conflict of interest policy include when it comes to Continuing Medical Education (CME)? One might think this is an easy question but I have been involved with this question since the 1990s and find that it is one of the more difficult areas of debate. [1]

A policy on conflict of interest (COI) should require those with a conflict (or who think they may have a conflict) to disclose the conflict or potential conflict.

CME in the United States clearly dates back to the formation of the American Medical Association (AMA) in 1873 with publication of its first publication in 1883 Journal of the American Medical Association (JAMA).

This issue of COI has been much discussed and debated over the years and the topic of FDA investigation back in 1991and 1992 resulting in a 1995 publication The Statutory Basis for FDA Regulation of Scientific and Educational Information. []]

The Accreditation Council for Continuing Medical Education (ACCME) intervened in 1992 and was successful in pointing out to the FDA that a governing body was al- ready in place concerning $\mathrm{CME}$ activities. However, the FDA did instruct the ACCME that if they changed their guidelines concerning commercial support of CME activities to standards they would basically back off from official involvement. As a result ACCME in 1992 adopted new standards for all ACCME accredited sponsors.

These 1992 standards have been the foundation for many organizations in establishing their own guidelines and standards for educational activities into publications. The ACCME has updated their Standards in 2004, 2005 and more recently in 2014. []]

\section{ACCME Standards}

1. General Responsibilities of Accredited Sponsors The accredited sponsors are responsible for the content, quality, and scientific integrity of all CME activities certified for credit. Identification of continuing medical education needs, determination of educational objectives, and selection of content, faculty, educational methods and materials is the responsibility of the accredited sponsor. Similarly, evaluation must be designed and performed by the accredited sponsor.

2. Enduring Materials - The accredited sponsors are responsible for the quality, content, and use of enduring materials for purposes of CME credit.

3. Identifying Products, Reporting on Research and

Keywords: conflict of interest; disclosures; lectures; publications 
Discussing Un-Labeled Use of Products - Presentations must give a balanced view of options. Faculty use of generic names will contribute to the impartiality. If trade names are used, those of several companies should be used rather than only that of a single supporting company. Reporting scientific research offered by a commercial entity to provide a presentation reporting the results of scientific research shall be accompanied by a detailed outline in the presentation, which shall be used by the accredited sponsor to confirm the scientific objectivity of the presentation. Concerning unlabeled uses of products or an investigational use not yet approved for any purpose is discussed during the educational activity, the accredited sponsor shall require the speaker to disclose that the product is not labeled for the use under discussion or that the product is still investigational.

4. Exhibits and Other Commercial Activities - When commercial exhibits are part of the overall program, arrangements for these should not influence planning or interfere with presentation of CME activities. Exhibit placement should not be a condition of support for CME activity. No commercial, promotional material shall be displayed or distributed in the same room immediately before, during, or immediately after an educational activity certified for credit. Representatives of commercial supporters may attend an educational activity but not engage in sales activities while in the room where the activity takes place.

5. Management of Funds from Commercial Sources The ultimate decision regarding funding arrangements for CME activities must be the responsibility of the accredited sponsor. Funds from a commercial source should be in the form of an educational grant made payable to the accredited sponsor for the support of programming. The terms, conditions, and purposes of such grants must be documented by a single agreement between the commercial supporter and the accredited sponsor. No other funds from a chimerical source shall be paid to the director of the selectivity. Payment of reasonable honoraria and reimbursement of out of pocket expenses for faculty is customary and proper. Commercial support must be acknowledged in printed announcements and brochures. However, reference must not be made to specific products.

6. Commercially Supported Social Event - Should not compete with nor take precedence over the educational events.

7. Policy On Disclosure of Faculty and Sponsor Relationships - An accredited sponsor shall have a policy disclosure of the existence of any significant financial interest or other relationship a faculty member or a sponsor has with the manufacturer of any commercial products discussed in an educational presentation.
8. Financial Support for Participants in Educational Activities - In connection with an educational activity offered by an accredited sponsor, the sponsor may not use funds originating from a commercial source to pay travel, lodging, registration fees, honoraria, or personal expenses for non-faculty attendees. Scholarships or other special funding to permit medical Students, residents, or fellows to attend selected educational conferences may be provided as long as the selection of students, residents or fellows who will receive the funds is made either by the academic or training institution or by the accredited sponsor with the full concurrence of the academic or training institution.

Conclusion: There is no question that commercial support can contribute significantly to the quality of CME activities. However, there have been abuses in the past and the ACCME new standards will help to assure scientific integrity of all $\mathrm{CME}$ activities that receive certification for credit.

The standards have evolved and I would suggest anyone that publishes and or lectures at CME activities should know the Standards because most lectures that I have observed do not comply with the requirements.

In my opinion, although medical journals have lagged behind ACCME standards with regards to conflict of interest, they have established their own policies on the matter. Almost all medical journals now require authors to disclose COI, however the same standards have not been employed for editors and reviewers. [4]

Haque et al, looked at 703 editors and COI policies at 60 medical journals. $57 \%$ of the journals had policies in place governing COI for editors, but only $21 \%$ publicly reported the disclosures. [4]

Journals and CME activities have focused on financial conflict of interest (FCOI) but is that sufficient? Certainly there can be other factors that can influence the behavior and actions of persons in a position of authority. A 2004 study, argued that "...the automatic nature of self-interest gives it a primal power to influence judgment and makes it difficult for people to understand its influence on their judgment, let alone eradicate its influence." [ $\underline{5}]$

There have been published examples of overtly biased actions by editors. "For example, an orthopedic surgeon, during his tenure as an editor published many studies in his journal favoring products from a company, which paid him millions of dollars in patent royalties." [ㅁ]

What about the potential issues of editors and or reviewers trying to gain favor by approving manuscripts submitted by key surgeons who influence appointments to key memberships in professional societies and committees. I suggest that we have to understand better what motivates behavior and what is the level of trust in a given profes- 
sional standard of behavior.

In 2007 The American Academy of Orthopaedic Surgeons (AAOS) adopted Standards of Professionalism on Orthopaedic-Industry Conflicts of Interest that require orthopaedic surgeon members to identify and disclose potential conflicts of interest to their patients. [7]

JISRF created a web page that deals with Patient-Physician Guide, Patient Disclosure Letter, Patient Disclosure Poster, and AAOS Patient-Physician Communications. This page is not intended to be and end all result on the subject but a convenient resource page. We recommend that you also check with your individual professional societies for their policies on disclosure. []]

\section{All Policy and Procedures can be Viewed on Reconstructive Review Website. [9]}

The following highlights some of our policies that pertain to COI.

The process of peer review assures the quality of the content in the articles, with the goal being new knowledge and skills that are of practical benefit to the readers of Reconstructive Review. The Editor-in-Chief and Managing Editor initially review all submissions. At this point articles may be rejected without peer review if it is felt that they are not of high enough quality or not relevant to Reconstructive Review. Once submissions pass initial review they are sent out for peer review.

To provide open-access, peer reviewed articles Reconstructive Review relies on individuals who are willing to take on the responsibility, and privilege, to review articles written by their peers. Please take a moment to look at the general guidelines we provide to reviewers that outline their purpose, good practices, and responsibilities.

\section{Double-blind Review Process and Timeframe}

Reconstructive Review operates a double-blind peerreview system; that is, reviewers and authors are not informed of each other's identities during the review process. If the reviewer, Managing Editor, and/or Editor-in-Chief feel more revisions are deemed necessary a submission may undergo several reviews.

- Reviewers must take care not to identify themselves, their patients, or their institutions within the body of their comments.

- Reviews are read by the assigned Managing Editor, who makes the preliminary decision to accept or decline, or to ask the author to revise the article. The Managing Editor may also request that the reviewer comment on an extensively revised article that he or she had reviewed previously in an earlier version.

- Reviews are to be returned in a timely manner, within
2 weeks of invitation, as determined by the Editorial Board of Directors. Because the Managing Editor's decision must wait until all reviews are complete, a delay by a single reviewer slows the editorial process. Reviewers agree to review an article only if they have the proper expertise and are confident that they can meet the deadline.

Based on the feedback from these reviewers and the judgment of the editorial team, a decision is given on the article. Possible decisions are to Accept Submission, Revisions Required, Resubmit for Review, and Decline Submission.

Once an article has been published in Reconstructive Review any ongoing, or post-publication review and/or commentaries are handled by submitting Letters to the Editor.

\section{Appeals}

If you believe the editorial team has incorrectly rejected your article, authors may send an appeal to the editorial office. To submit an appeal please send an email to the editorial office giving as much detail as possible about why you believe that your article has been incorrectly rejected. Please do not re-submit your article.

\section{Open Access Policy}

This journal provides immediate open access to its content on the principle that making research freely available to the public supports a greater global exchange of knowledge.

\section{Archiving}

This journal utilizes the PKP Private LOCKSS network and Portico to create a distributed archiving system among participating libraries and permits those libraries to create permanent archives of the journal for purposes of preservation and restoration. For more information please visit PKP Private LOCKSS network and Portico.

All content published on Reconstructive Review is digitally archived off site as well. When issues are created copies of full text articles are deposited on CrossRef. In addition, full backups are regularly performed by the site's hosting company and by Journal Editorial Services.

\section{Self-archiving}

Under the terms of the license, authors are entitled to deposit the final published version of their article in institutional and/or centrally organized repositories immediately upon publication, provided that Reconstructive Review is attributed as the original place of publication and that correct citation details are given. Authors are also strongly en- 
couraged to deposit the URL of their published article, in addition to the PDF version.

\section{Publication Ethics}

Authors should observe high standards with respect to publication ethics as set out by the Commission on Publication Ethics (COPE) and International Committee of Medical Journal Editors (ICMJE). Falsification or fabrication of data, plagiarism, including duplicate publication of the authors' own work without proper citation, and misappropriation of the work are all unacceptable practices. Any cases of ethical misconduct are treated very seriously and will be dealt with in accordance with the COPE guidelines. Reconstructive Review is currently registered with CrossRef and will be using their CrossCheck services to screen for plagiarism.

\section{Authorship}

All authors listed on the article should have contributed significantly to the experimental design, its implementation, or analysis and interpretation of the data. All authors should have been involved in the writing of the article at draft and any revision stages and should have read and approved the final version. Anyone who made major contributions to the writing of the article should be listed as an author (e.g. "ghost writing" is prohibited by Reconstructive Review). Any other individuals who made less substantive contributions to the experiment or the writing of the article should be listed in the acknowledgement section. Any change in authorship (including author order) after the initial article submission must be approved in writing by all authors.

\section{Originality}

By submitting your article to Reconstructive Review it is understood that this it is an original article and is unpublished work and is not under consideration elsewhere. Plagiarism, including duplicate publication of the author's own work, in whole or in part without proper citation is not tolerated by Reconstructive Review. Articles submitted to Reconstructive Review will be checked for originality using CrossCheck.

\section{Informed Consent}

Patients have a right to privacy that should not be infringed without informed consent. Articles should include a statement that the patient's written consent was obtained and any information, including illustrations, should be as anonymized as far as possible. Authors should indicate that local ethical committees have approved the design of the work or that it conforms to standards currently applied in the country of origin. The name of the authorizing body should be stated in the paper.

Patients' identities must be removed in all figures (i.e., $\mathrm{x}$-rays, MRIs, charts, photographs, etc.). Written informed consent is required from any potentially identifiable patient or legal representative, and should be presented in either the Methods section or the Acknowledgements.

\section{Material Disclaimer}

The opinions expressed in Reconstructive Review are those of the authors and contributors, and do not necessarily reflect those of the editors, the editorial board, JISRF, or the organization to which the authors are affiliated.

\section{Conflict-of-Interest, Disclosures}

As part of the online submission process, corresponding authors are required to confirm whether they or their co-authors have any conflicts of interest to declare, and to provide details of these. If the Corresponding author is unable to confirm this information on behalf of all co-authors, the authors in question will then be required to submit a completed form to the Editorial Office. It is the Corresponding author's responsibility to ensure that all authors adhere to this policy.

\section{Charges}

All content published in Reconstructive Review is made freely available online to all under an Open Access model. Currently there are no charges associated with submitting an article to Reconstructive Review for peer-review and publication. There are no subscription fees and all content is available as full text in either PDF and/or HTML.

\section{Complaints}

This procedure applies to complaints about content of Reconstructive Review as well as the policies, procedures, or actions of Reconstructive Review's editorial staff. We welcome complaints as they provide an opportunity and a spur for improvement, and we aim to respond quickly, courteously, and constructively.

Our definition of a complaint is as follows:

- The complainant defines his or her expression of unhappiness as a complaint.

- We infer that the complainant is not simply disagreeing with a decision we have made or something we have published but think that there has been a failure of process - for example, a long delay or a rude response - or a severe misjudgment.

- The complaint must be about something that is within the responsibility of Reconstructive Review's content or process. 
Reconstructive Review is aware of the complaints stated below:

1. Authorship complaints

2. Plagiarism complaints

3. Multiple, duplicate, concurrent publication/Simultaneous submission

4. Research results misappropriation

5. Allegations of research errors and fraud

6. Research standards violations

7. Undisclosed conflicts of interest

8. Reviewer bias or competitive harmful acts by reviewers

\section{Policy for Handling Complaints}

If the Journal receives a complaint that any contribution to the Journal infringes intellectual property rights or contains material inaccuracies, libelous materials or otherwise unlawful materials, the Journal will investigate the complaint. Investigation may include a request that the parties involved substantiate their claims. The Journal will make a good faith determination whether to remove the allegedly wrongful material. A decision not to remove material should represent the Journal's belief that the complaint is without sufficient foundation, or if well-founded, that a legal defense or exemption may apply, such as truthfulness of a statement in the case of libel. Journal should document its investigation and decision. We strive to ensure that Reconstructive Review is of the highest quality and is free from errors. However, we accept that occasionally mistakes might happen.

\section{Editorial Complaints Policy}

The Managing Editor and staff of Reconstructive Review will make every endeavor to put matters right as soon as possible in the most appropriate way, offering right of reply where necessary. As far as possible, we will investigate complaints in a blame-free manner, looking to see how systems can be improved to prevent mistakes occurring.

\section{Guiding Principles}

Our general approach to complaints is that they are a rare but inevitable part of a process that involves putting together complex material at great speed. We accept that we make mistakes and try to treat all complaints with urgency, however small. We believe that timely solutions can prevent problems escalating. All substantial errors and complaints are referred to senior executives within the editorial staff as a matter of course.

The procedure outlined below aims to be fair to those making complaints and those complained about. All com- plaints will be acknowledged (within three working days if by email). If possible a definitive response will be made within two weeks. If this is not possible an interim response will be given within two weeks. Interim responses will be provided until the complaint is finally resolved. If the complainant remains unhappy, complaints should be escalated to the editor, whose decision is final.

\section{How to Make a Complaint}

Complaints about editorial content should be made as soon as possible after publication, preferably in writing by email to: editors@ReconstructiveReview.org.Please write your complaint with journal title, vol. no., issue no., paper title, and page no.

\section{Corrections, Retractions, and Expressions of Concern}

JISRF, Reconstructive Review and its editors take all reasonable steps to identify and prevent the publication of papers where research misconduct has occurred, including plagiarism (all submissions screened using Ithenticate $\AA$ ), citation manipulation, and data falsification/fabrication, among others. In no case does Reconstructive Review or its editors encourage such misconduct, or knowingly allow such misconduct to take place. In the event that Reconstructive Review's publisher or editors are made aware of any allegation of research misconduct relating to a published article in the journal, JISRF and the senior editorial staff shall follow COPE's guidelines in dealing with allegations. In addition, Reconstructive Review utilizes a service provided by Crossref called Crossmark. This service gives readers quick and easy access to the current status of a piece of content. With one click, you can see if content has been updated, corrected or retracted.

The issue of conflict of interest and what and how to disclose will be an ongoing area of concern and debate for years to come.

The following quote from Phyllis Pettit Nassi clearly states the challenge. "When you talk about trust you have to know the way a group thinks, how they interact, how they communicate, how they educate. You have to know what their roles and relationships are. What are their values? Their practices? What are the expected behaviors?"

Members of JISRF and Reconstructive Review will stay diligent with regard to $\mathrm{COI}$ and disclosure issues and from time to time will update our policies and procedures. We welcome comments on this subject and look forward to addressing concerns within a common sense approach. 


\section{References}

1. McTighe T, Vise G.T., Bechtol C.O., CME Conflict of Interest, AAOS Scientific Exhibit 1993 San Francisco, CA.

2. Boulding M, The Statutory Basis for FDA Regulation of Scientific and Educational Information. Journal of Pharmacy and Law, Vol. 4, No. 2, pages 123-142 (1995)

3. Standards for Commercial Support: Standards to Ensure the Independence of CME

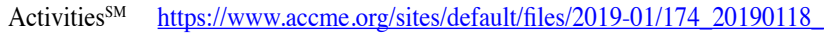
ACCME Standards for Commercial Support.pdf

4. Haque W, Minhajuddin A, Gupta A, Agrawal D, Conflicts of interest of editors of medical journals. Published: May 18, 2018. doi: 10.1371/journal.pone.0197141

5. Moore DA L. Self-Interest, Automaticity, and the Psychology of Conflict of Interest. Social Justice Research. 2004;17:189.

6. Journal-Sentinel M. Journal editor gets royalties as articles favor devices Dec 2009 [07/28/16]. Available from: http://www.jsonline.com/watchdog/watchdogreports/80036277.html.

7. Patient Discussion Guide AAOS. http://www.jisrf.org/pdfs/patient-discussionguide.pdf

8. http://www.jisrf.org/professional-disclosure-jisrf.html

9. https://reconstructivereview.org/ojs/index.php/rr/about/ editorialPolicies\#custom-7

\begin{abstract}
SUBMISSION HISTORY
Submitted: March 6, 2019

Reviewed: March 10, 2019

Accepted: March 11, 2019

Published: March 31, 2019

AUTHOR AFFILIATIONS

1 Timothy McTighe, Dr HS (hc); Joint Implant Surgery \& Research Foundation, 46 Chagrin Shopping Plaza, \#117, Chagrin Falls, OH 44022 US

(Direct reprint requests to Timothy McTighe, tmct@jisrf.org)

\section{AUTHOR DISCLOSURES}

The authors declare that there are no disclosures regarding the publication of this paper.

\section{COPYRIGHT \& OPEN ACCESS}

(C) 2019 McTighe. All rights reserved.

Authors retain copyright and grant the journal right of first publication with the work. Reconstructive Review is an open access publication and follows the Creative Commons Attribution-NonCommercial CC BY-NC. This

license allows anyone to download works, build upon the material, 政 senior author, Reconstructive Review, and the Joint Implant Surgery \& Research Foundation (JISRF). An example credit would be: "Courtesy of (senior author's name), Reconstructive Review, JISRF, Chagrin Falls, Ohio".
\end{abstract}

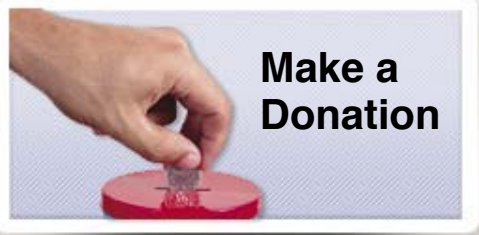

\section{Play a Role in Our Ground Breaking Research}

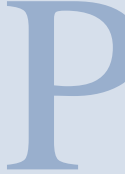

erhaps you were a patient and you were able to regain an important part of your life. Or, perhaps you are simply someone interested in medical research and seeking a new way to participate. Whatever the case, your

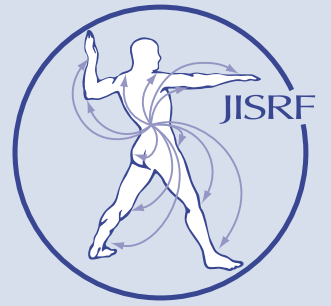
generosity in helping to fund research is critical to our success - and much appreciated.

The Joint Implant Surgery \& Research Foundation is a not-for-profit 501(c)(3) corporation. Your contributions enable scientific discoveries that will help future patients. Contributions over the years from people like you have helped to shape orthopaedics today.

\section{Contributions}

Donations of any amount will immediately be put to use to fund ongoing and future orthopaedic research projects.

\section{How to Give}

- Your gift of cash, securities or other negotiable assets is immediately put to use in our research.

- Your contributions are fully tax deductible as specified under Section 501(c)(3) regulations.

For more information please visit our website at www.jisrf.org or contact us at:

\section{Joint Implant Surgery} \& Research Foundation 46 Chagrin Shopping Plaza, \#117 Chagrin Falls, OH 44022 440.785 .9154 


\section{JISRF Mission Statement}

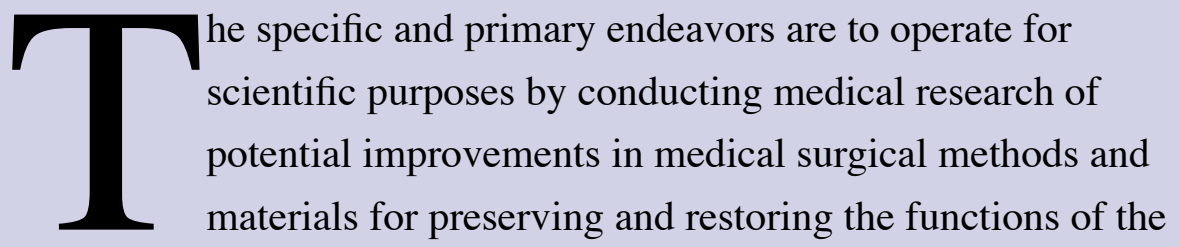

human body joints and associated structures which are threatened or

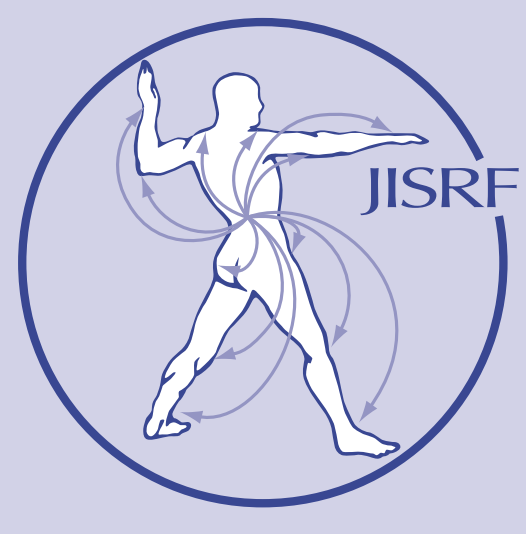
impaired by defects, lesions or diseases.

This Journal as all activities conducted by JISRF are available to all interested surgeons, scientists and educators. Our focus is on new cutting edge technologies, science - all with the intent to raise the level of discussion and discovery. Please become a part of this endeavor, we look forward to your interest and participation.

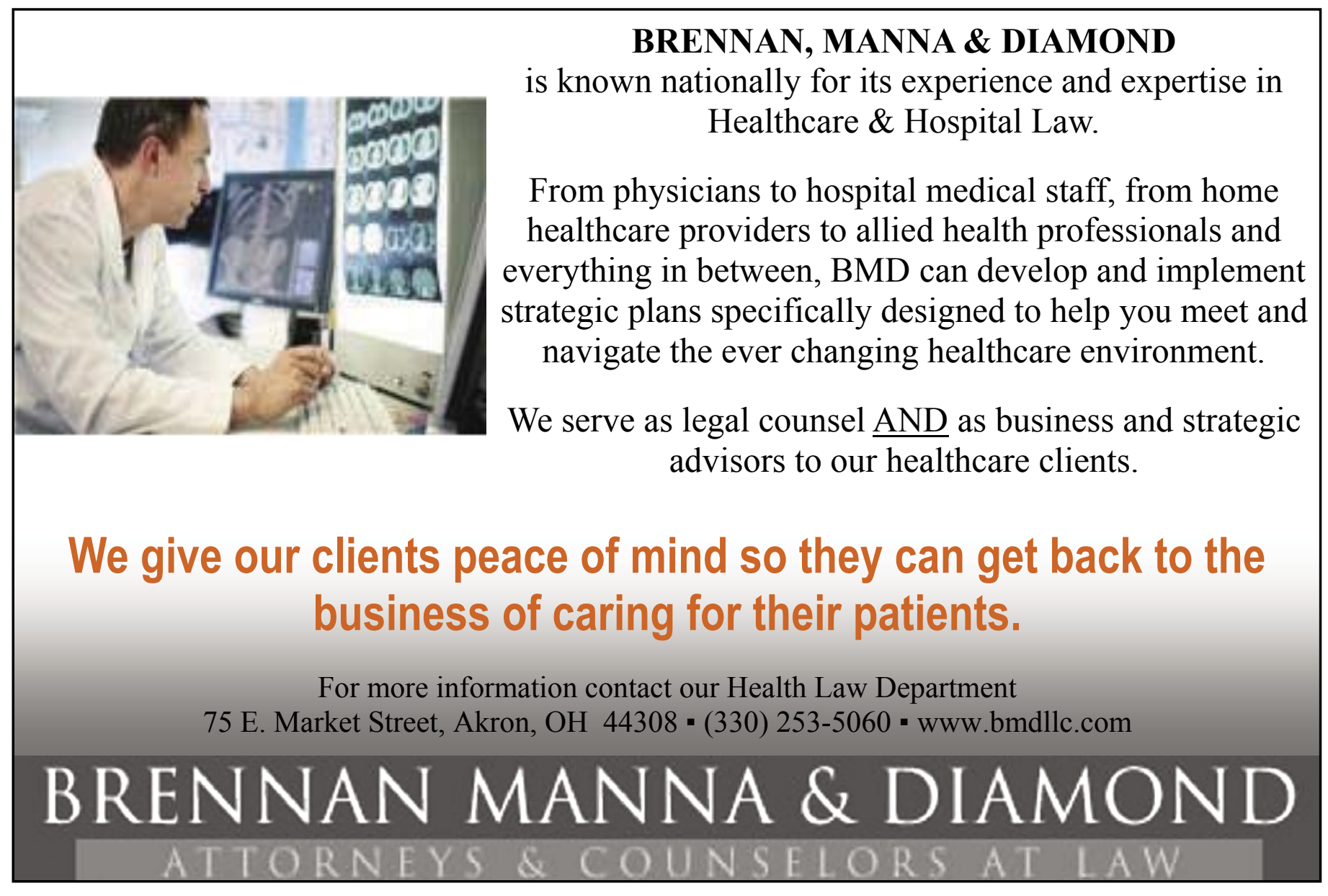




\section{Levels of Evidence}

Reconstructive Review has adopted the American Academy of Orthopaedic Surgeons (AAOS) Levels of Evidence for Primary Research Question. These guidelines will now be part of the review process for manuscript submission.

\begin{tabular}{|c|c|c|c|c|}
\hline & \multicolumn{4}{|c|}{ Types of Studies } \\
\hline & $\begin{array}{l}\text { Therapeutic Studies - } \\
\text { Investigating the results of } \\
\text { treatment }\end{array}$ & $\begin{array}{l}\text { Prognostic Studies - } \\
\text { Investigating the effect of a } \\
\text { patient characteristic on the } \\
\text { outcome of disease }\end{array}$ & $\begin{array}{l}\text { Diagnostic Studies - } \\
\text { Investigating a diagnostic } \\
\text { test }\end{array}$ & $\begin{array}{l}\text { Economic and Decision } \\
\text { Analyses - Developing an } \\
\text { economic or decision model }\end{array}$ \\
\hline Level I & $\begin{array}{l}\text { - High quality randomized } \\
\text { trial with statistically } \\
\text { significant difference or } \\
\text { no statistically significant } \\
\text { difference but narrow } \\
\text { confidence intervals } \\
\text { - Systematic Review2 of } \\
\text { Level I RCTs (and study } \\
\text { results were homogenous3) }\end{array}$ & $\begin{array}{l}\text { - High quality prospective } \\
\text { study4 (all patients were } \\
\text { enrolled at the same point } \\
\text { in their disease with } \geq 80 \% \\
\text { follow-up of enrolled patients) } \\
\text { - Systematic review2 of Level } \\
\text { I studies }\end{array}$ & $\begin{array}{l}\text { - Testing of previously } \\
\text { developed diagnostic criteria } \\
\text { on consecutive patients (with } \\
\text { universally applied reference } \\
\text { "gold" standard) • Systematic } \\
\text { review2 of Level I studies }\end{array}$ & $\begin{array}{l}\text { - Sensible costs and } \\
\text { alternatives; values obtained } \\
\text { from many studies; with } \\
\text { multiway sensitivity analyses } \\
\text { - Systematic review2 of Level } \\
\text { I studies }\end{array}$ \\
\hline Level III & $\begin{array}{l}\text { - Case control study7 } \bullet \\
\text { Retrospective6 comparative } \\
\text { study } 5 \bullet \text { Systematic review2 } \\
\text { of Level III studies }\end{array}$ & - Case control study7 & $\begin{array}{l}\text { - Study of non-consecutive } \\
\text { patients; without consistently } \\
\text { applied reference "gold" } \\
\text { standard • Systematic review2 } \\
\text { of Level III studies }\end{array}$ & $\begin{array}{l}\text { - Analyses based on limited } \\
\text { alternatives and costs; and } \\
\text { poor estimates } \bullet \text { Systematic } \\
\text { review2 of Level III studies }\end{array}$ \\
\hline
\end{tabular}

1. A complete assessment of quality of individual studies requires critical appraisal of all aspects of the study design.

2. A combination of results from two or more prior studies.

3. Studies provided consistent results.

4. Study was started before the first patient enrolled.

5. Patients treated one way (e.g. cemented hip arthroplasty) compared with a group of patients treated in another way (e.g. uncemented hip arthroplasty) at the same institution.

6. The study was started after the first patient enrolled.

7. Patients identified for the study based on their outcome, called "cases"; e.g. failed total arthroplasty, are compared to those who did not have outcome, called "controls"; e.g. successful total hip arthroplasty.

8. Patients treated one way with no comparison group of patients treated in another way. 


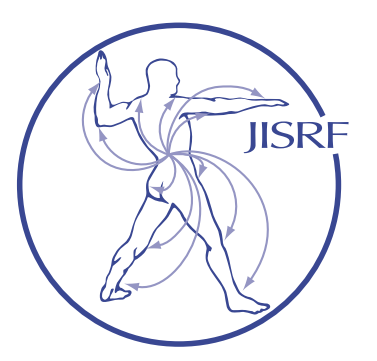

\section{Reconstructive Review Disclosure Statement}

The following information will be published on each paper.

Please check one or more if pertinent of the following:

1. No benefits or funds were received in direct or indirect support of this article.

2. Benefits or funds were received in support of this article either directly or indirectly.

$\square$. Either family, institution I am associated with, or I have received benefits or funds either directly or indirectly regarding this article.

$\square$ 4. Describe:

Author's Signature:

(Typed signature is valid for online submission.)

Joint Implant Surgery \& Research Foundation

www.jisrf.org

\section{Conflict of Interest Statement JISRF Orthopaedic Industry Affiliations (Past \& Present)}

Many Authors, Co-Authors, JISRF, or its Members have had affiliations past or present with one or more of these organizations.

\section{AAHKS}

AAOS

American Society of Biomechanics

Apex Surgical

Australian Orthopaedic Association

Bactrin International, INC.

Concept Design \& Development,

DePuy

Dow Coring Wright

Encore Medical

E.M. Warburg, Pincus \& Co., LLC

Global Orthopaedic Technology

Harrington Arthritis Research Center

Howmedica

ISTA

Johnson \& Johnson

Joint Medical Products Corp.

Kirschner

Kenesis Medical, Inc

Montreal General Hospital Orthopaedic Lab

NASA

ORS

OrthoDevelopment

OTI

Richards Manufacturing

Signature Orthopaedics

Smith \& Nephew, Inc.

Society for Biomaterials

Zimmer

\section{Disclosure Statement}

JISRF and the Reconstructive Review take disclosure very serious and often readers don't appreciate the indirect benefit writers receive in publications. Many of our contributors are officially associated with JISRF by the membership on study groups, editorial committee and or clinical / surgical advisors. JISRF is dependent on donations and commercial funding. The overall success of this funding benefits indirectly all that are associated with activities produced by JISRF.

\section{Disclosure for Authors}

Article 1, page 11.

Buch [1]; Schroeder [1]; Buch [1]; Eberle [1]

Article 2, page 17.

Durbhakula [3]; Durbhakula [1]; Durbhakula [1]

Article 3, page 23 .

Venet [3]; Tesson [1]; Le Cour Grandmaison [1]; Fraquet [1]; Brazil [3]; McTighe [3]

Article 4, page 31 .

Martin [1]; Otero [1]; Springer [1]; Griffin [1]

Article 5, page 37.

Ries [1]; Faizan [1]; Zhang [1]; Scholl [1]

Article 6, page 43 .

Martin [1]; Odum [1]; Griffin [1]

Article 7, page 49.

Kesler [1]; Brown [1]; Martin [1]; Springer [1]; Otero [1]

Article 8, page 55 .

McTighe [1] 


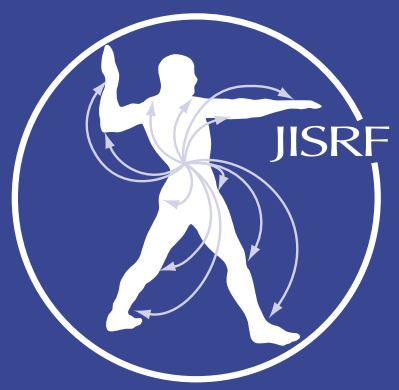

Joint Implant Surgery and Research Foundation 46 Chagrin Shopping Plaza, \#117

Chagrin Falls, Ohio 44022

www.jisrf.org $\bullet$ www.reconstructivereview.org 